NIST Technical Note 1749

\title{
Robustness of Steel Gravity Frame Systems with Single-Plate Shear Connections
}

Joseph A. Main

Fahim Sadek

http://dx.doi.org/10.6028/NIST.TN.1749

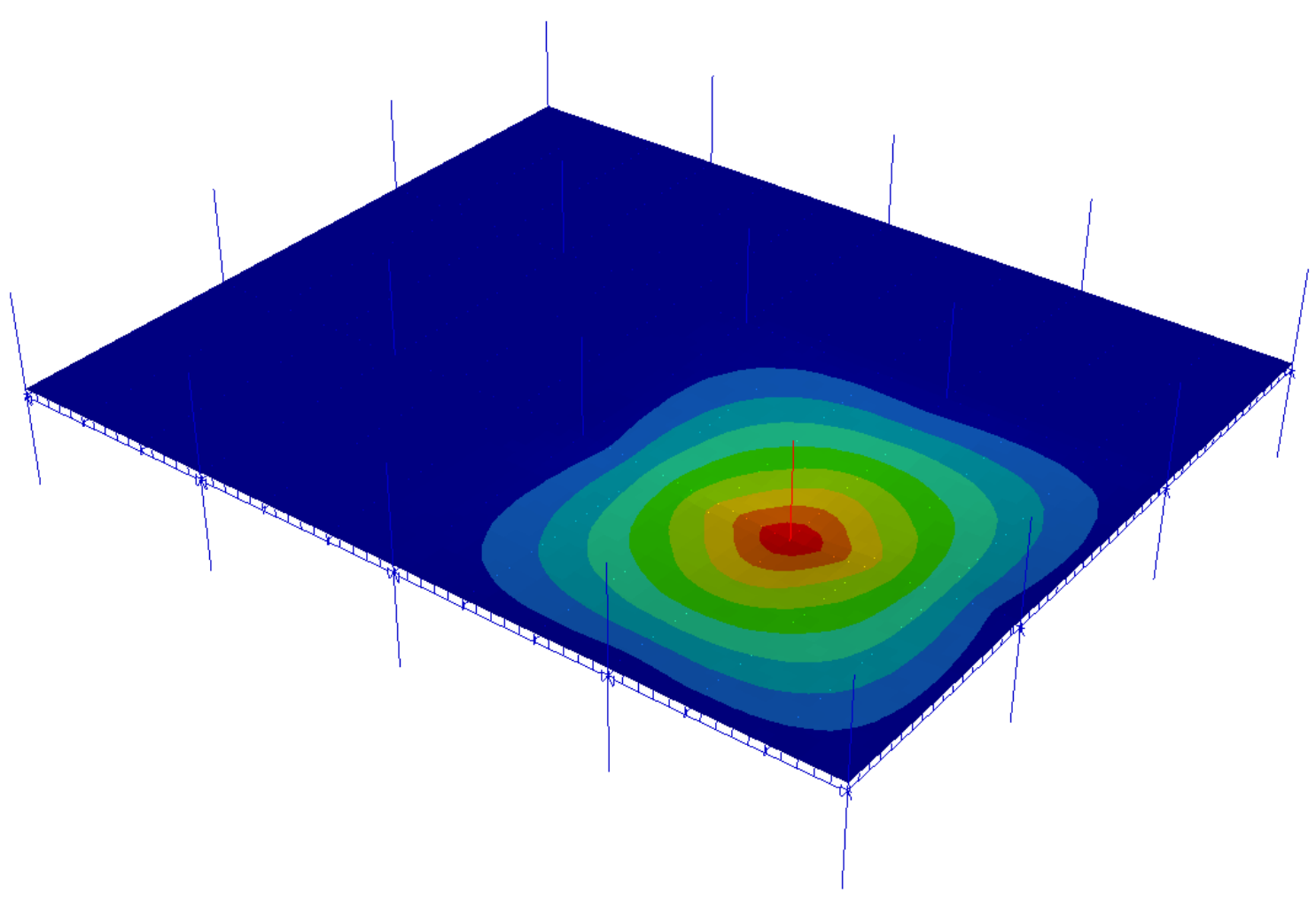



NIST Technical Note 1749

\title{
Robustness of Steel Gravity Frame Systems with Single-Plate Shear Connections
}

\author{
Joseph A. Main \\ Fahim Sadek \\ Engineering Laboratory \\ National Institute of Standards and Technology
}

http://dx.doi.org/10.6028/NIST.TN.1749

July 2012

(includes corrections dated February 2013)

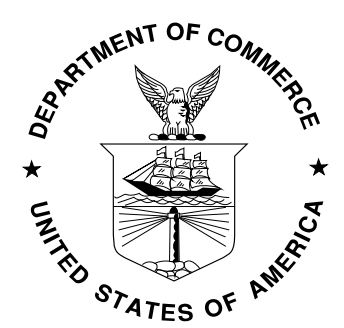

U.S. Department of Commerce Rebecca Blank, Acting Secretary

National Institute of Standards and Technology Patrick D. Gallagher, Under Secretary of Commerce for Standards and Technology and Director 
Certain commercial entities, equipment, or materials may be identified in this document in order to describe an experimental procedure or concept adequately. Such identification is not intended to imply recommendation or endorsement by the National Institute of Standards and Technology, nor is it intended to imply that the entities, materials, or equipment are necessarily the best available for the purpose.

The policy of the National Institute of Standards and Technology is to include statements of uncertainty with all NIST measurements. In this document, however, measurements of authors outside of NIST are presented, for which uncertainties were not reported and are unknown.

National Institute of Standards and Technology Technical Note 1749 Natl. Inst. Stand. Technol. Tech. Note 1749, 111 pages (February 2013)

http://dx.doi.org/10.6028/NIST.TN.1749

CODEN: NTNOEF 


\section{ABSTRACT}

This report presents a computational assessment of the performance of steel gravity framing systems with single-plate shear ("shear tab") connections and composite floor slabs under column loss scenarios. The computational assessment uses a reduced modeling approach, while comparisons with detailed model results and available experimental data are presented to establish confidence in the reduced models. The reduced modeling approach enables large multi-bay systems to be analyzed much more efficiently than the detailed modeling approaches used in previous studies. Both quasi-static and sudden column loss scenarios are considered, and an energy-based approximate procedure for analysis of sudden column loss is adopted, after verification through comparisons with direct dynamic analyses, further enhancing the efficiency of the reduced modeling approach. Reduced models are used to investigate the influence of factors such as bay spacing, slab continuity, and the mode of connection failure on the collapse resistance of gravity frame systems. Simple equations for the rotational capacities of the connections are derived as a function of a few parameters including the span length and the connection depth. These equations yield good agreement with computed rotational capacities of connections both in bare steel assemblies (i.e., no slab) and in composite floor systems, where composite action leads to reduced rotational capacities. The reduced models are used to assess the adequacy of current structural integrity requirements, and based on the computational results, a new relationship is proposed between the uniform load intensity and the tie forces required for collapse prevention.

Keywords: Buildings; Connections; Disproportionate collapse; Floors; Finite element method; Nonlinear analysis; Progressive collapse; Steel structures. 


\section{ACKNOWLEDGMENTS}

This study considers prototype buildings designed by S. K. Ghosh and Associates, with guidance and review by the following panel of experts: David R. Bonneville (Degenkolb Engineers, San Francisco, CA), Donald O. Dusenberry (Simpson, Gumpertz \& Heger, Waltham, MA), Ramon Gisanz (Gilsanz, Murray, Steficek, LLP, New York, NY), Thomas A. Sabol (Englekirk \& Sabol, Los Angeles, CA), Andrew W. Taylor (KPFF Consulting Engineers, Seattle, WA). Christopher H. Raebel and Scott L. Thompson of the Milwaukee School of Engineering provided experimental data from their tests of twospan beam assemblies with single plate shear connections. Valuable comments and input on this work were provided by H.S. Lew (NIST), Judy Liu (Purdue University), Yihai Bao (NIST), and Sam-Young Noh (Hanyang University). Helpful exchanges with Bruce R. Ellingwood (Georgia Tech) and David J. Stevens (Protection Engineering Consultants, San Antonio, TX) during the course of this work are also gratefully acknowledged. 


\section{TABLE OF CONTENTS}

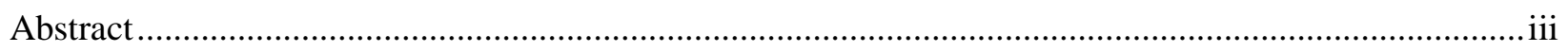

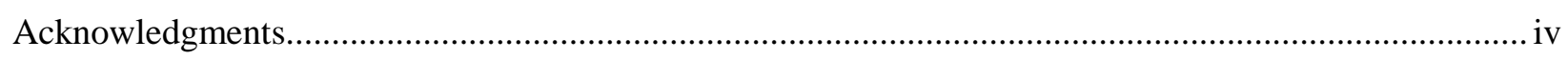



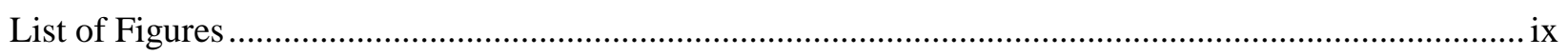

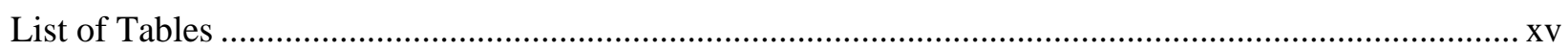

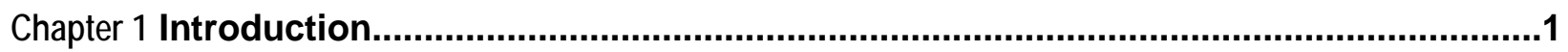

Chapter 2 Prototype Gravity Framing Systems …..........................................................



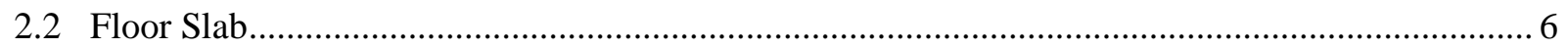



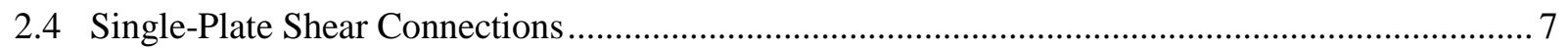

Chapter 3 Modeling and Analysis of Single-Plate Shear Connections ..................................9

3.1 Detailed Modeling Approach...................................................................................................... 10



3.1.2 Comparison with double shear test data .......................................................................... 13

3.1.3 Comparison with bolt bearing test data ........................................................................ 15

3.1.4 Comparison with single shear test data .......................................................................... 15



3.2.1 Load-deformation relationships for nonlinear springs .................................................... 17

3.2.2 Comparison with detailed modeling of axial extension .................................................... 21

3.3 Modeling of Two-Span Beam Assembly Tests ............................................................................. 23

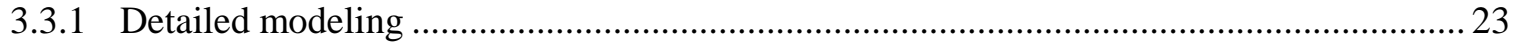

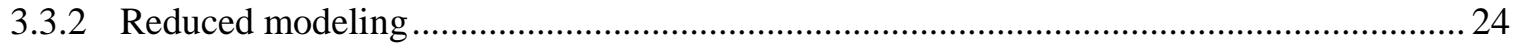

3.3.3 Comparison of experimental and computational results .................................................. 25

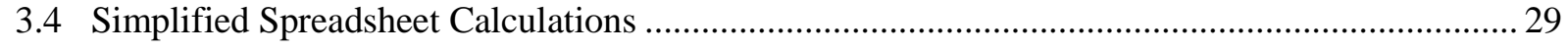

3.4.1 Two-span beam assembly with exterior pin supports ....................................................... 29

3.4.2 Two-span beam assembly with two shear connections per span......................................... 35

3.5 Behavior of Prototype Shear Connections …............................................................................. 39

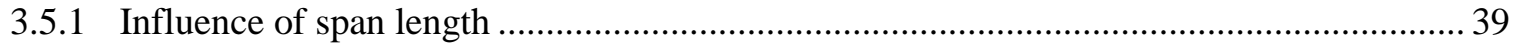






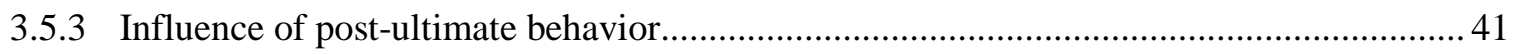

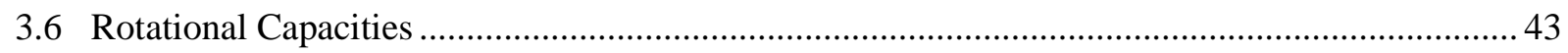

3.6.1 Two-span beam assembly with exterior pin supports ..................................................... 44

3.6.2 Two-span beam assembly with two shear connections per span....................................... 46

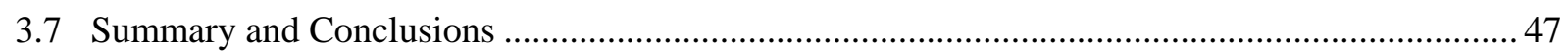

Chapter 4 Modeling and Analysis of Composite Floor Systems .....................................51



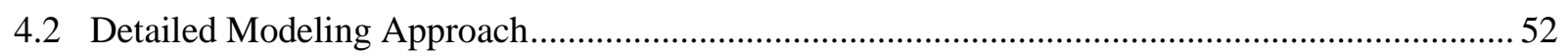

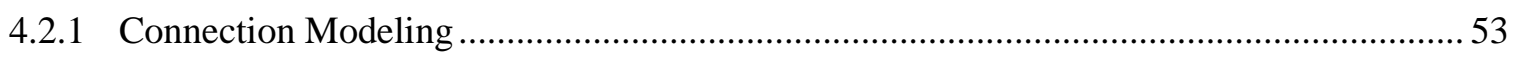

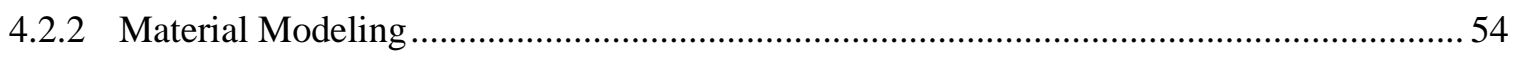

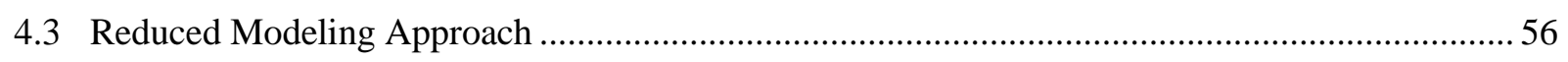

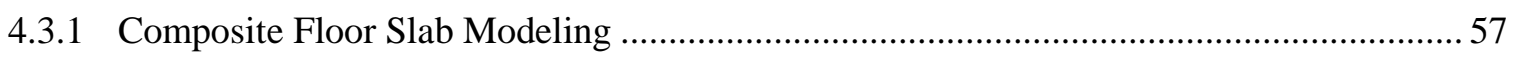

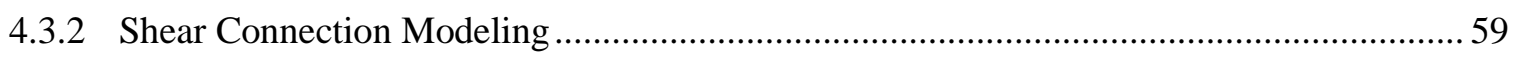





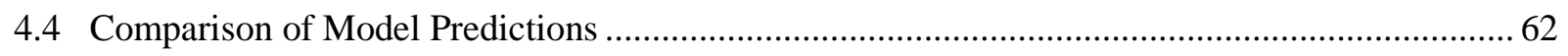

Chapter 5 Assessment of Collapse Resistance..............................................................63



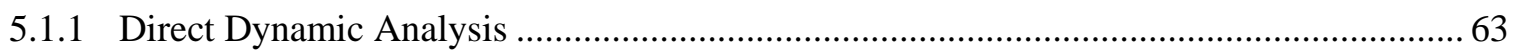

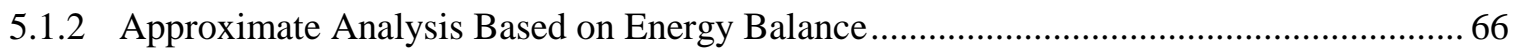

5.1.3 Comparison of Direct and Approximate Analysis Results.............................................67 67

5.1.4 Determination of Ultimate Capacity under Sudden Column Loss .................................... 67

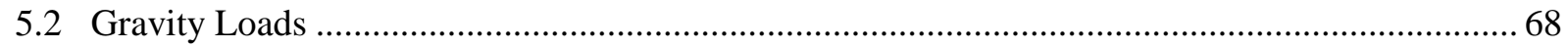

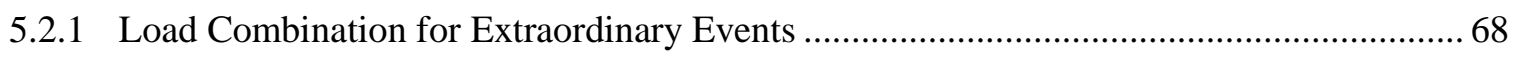

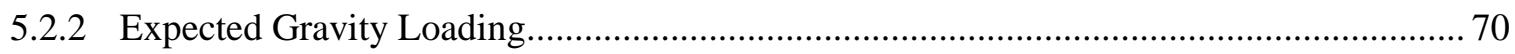

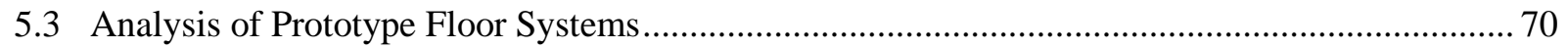

5.3.1 Prototype Building A: $6.10 \mathrm{~m}$ by $9.14 \mathrm{~m}$ (20 ft by $30 \mathrm{ft})$ Bay Spacing............................. 70

5.3.2 Prototype Building B: 10.16 m by 9.14 m (33 ft by $30 \mathrm{ft}$ ) Bay Spacing........................... 75

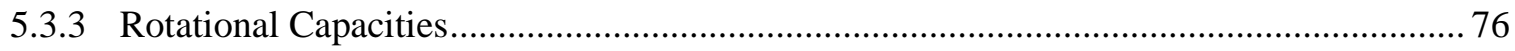

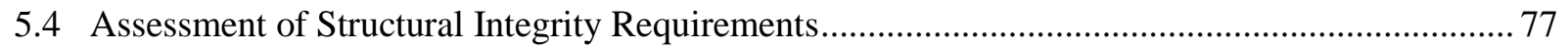

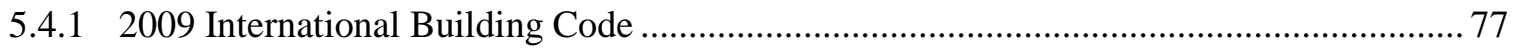

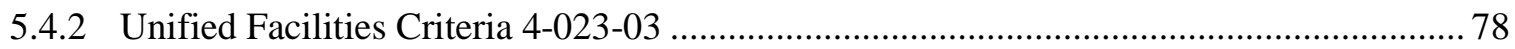




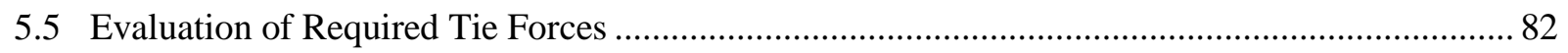



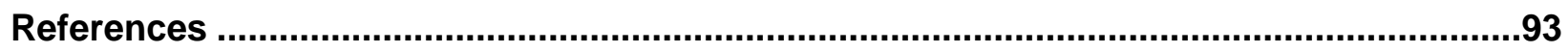


This page intentionally left blank. 


\section{LIST OF FIGURES}

Figure $2-1$. Plan layouts for (a) 5 bay $\times 5$ bay building (building A) and (b) 5 bay $\times 3$ bay building

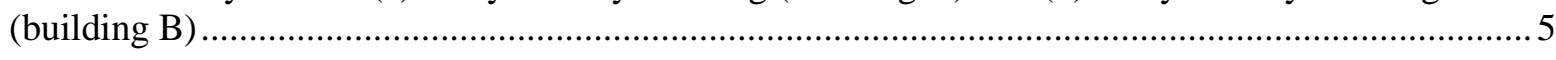



Figure 2-3. Details of single-plate shear connections: (a) three bolt rows; (b) four bolt rows..................... 8

Figure 3-1. Two-span beam assembly under pushdown loading with unsupported center column.............9

Figure 3-2. Detailed model of single-plate shear connection showing finite element mesh of (a) beam, (b)

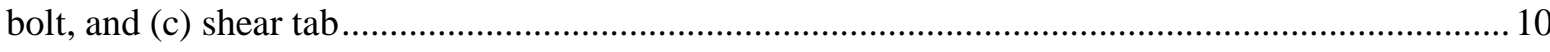

Figure 3-3. (a) True stress-strain and (b) engineering stress-strain curves for A325 and A490 highstrength bolt material: comparison of computed results with coupon tests from Kulak et al. (1986). 11

Figure 3-4. Finite element mesh of bolt tensile coupon: (a) prior to loading; (b) after fracture ................ 11

Figure 3-5. Stress-strain curves used to represent steel plates in computational models of bolted

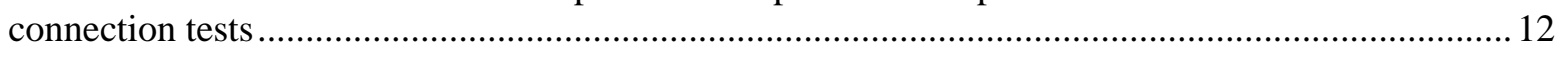

Figure 3-6. Finite element mesh of plate tensile coupon: (a) prior to loading; (b) after fracture............... 12

Figure 3-7. Stress-strain curves used to represent A36 and A992 steel in detailed models of shear tab connections from the prototype buildings................................................................................... 13

Figure 3-8. Detailed model of bolt double-shear test: (a) section view at ultimate load; (b) bolt mesh after

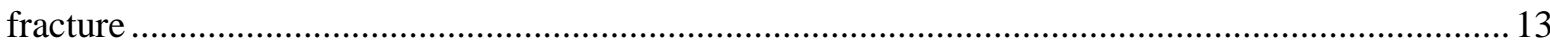

Figure 3-9. Bolt shear stress vs. deformation curves from double-shear specimens: comparison of computed results with experimental data from Wallaert and Fisher (1965) ..................................... 14

Figure 3-10. (a) Load-displacement curves for bolt tearout: comparison of computed results with experimental data from Rex and Easterling (2003); (b) contours of effective plastic strain from detailed model at ultimate load ............................................................................................ 15

Figure 3-11. (a) Load-deformation curves for single-shear specimen: comparison of detailed model predictions with experimental results from Richard et al. (1980); (b) section view through bolt centerline and (c) side view (with bolt hidden) of detailed model at ultimate load........................... 16

Figure 3-12. Reduced model of single-plate shear connection ............................................................. 17

Figure 3-13. Axial load-deformation relationships for bolt springs controlled by: (a) bearing failure; (b)

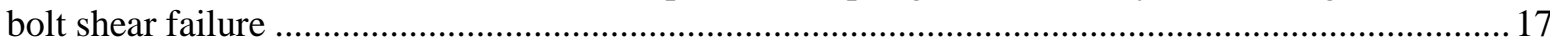

Figure 3-14. Deformation at ultimate load vs. depth of bolt group...................................................... 19

Figure 3-15. Vertical shear load-deformation relationship for bolt springs ...........................................2 21

Figure 3-16 Detailed models of prototype connections under axial tension showing deformations at ultimate tensile load (bolts hidden): (a) N-S connection in buildings A and B; (b) E-W connection in

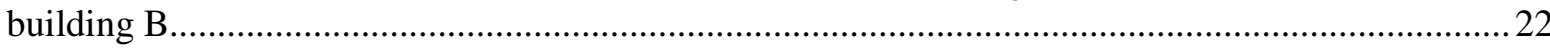

Figure 3-17 Comparison of reduced and detailed model results for tensile behavior of a single bolt row: (a) N-S beam connection in buildings A and B; (b) E-W beam connection in building B................22

Figure 3-18. Configuration of two-span beam assemblies tested by Thompson (2009) ...........................23 
Figure 3-19. Detailed model of two-span beam assembly tested by Thompson (2009): (a) overview; (b) region near exterior pin connection

Figure 3-20. (a) Reduced model of two-span beam assembly tested by Thompson (2009); (b) loaddisplacement curves used for bolt springs

Figure 3-21. Comparison of detailed and reduced model results with experimental measurements (Thompson 2009) for two-span beam assemblies: (a) vertical load and (b) axial force versus vertical column displacement (numerical labels on curves indicate the test number for a given connection size)

Figure 3-22. Deformations of 4-bolt assembly at ultimate load: (a) overview; (b) section view through bottom bolt.

Figure 3-23. Connection regions of detailed models at ultimate load: (a) 3 bolts; (b) 4 bolts; (c) 5 bolts (bolts hidden to show bearing-induced elongation of bolt holes in shear tabs)...

Figure 3-24. (a) Two-span beam assembly with exterior pin supports; (b) concentrated load; (c) uniform load.

Figure 3-25. Deformed geometry of beam span with exterior pin support: (a) overview; (b) near shear tab connection to center column

Figure 3-26. Free body diagram of beam .

Figure 3-27 (a) Applied vertical load, (b) shear force at pin support, (c) beam axial force at pin support, and (d) bending moment at shear tab vs. vertical column displacement for two-span beam assembly with pin supports.

Figure 3-28 Comparison of spreadsheet calculation with detailed and reduced model results for two-span beam assembly with exterior pin supports: (a) vertical load and (b) axial force versus vertical column displacement.

Figure 3-29. Detailed model of N-S beam span in building A with pin support at one end 34

Figure 3-30 (a) Two-span beam assembly with two shear connections per span; (b) deformed geometry of beam; (c) free body diagram of beam.

Figure 3-31 (a) Applied vertical load and (b) beam axial force vs. vertical column displacement for twospan beam assembly with two shear connections per span.

Figure 3-32 Comparison of detailed model, reduced model, and spreadsheet calculation results for a twospan beam assembly with two shear connections per span: (a) vertical load and (b) axial force versus vertical displacement of center column.

Figure 3-33. Detailed model of N-S beam span in building A with shear connections at both ends......... 37

Figure 3-34 Localization of deformation in post-ultimate softening response of detailed model: (a) $\Delta=500 \mathrm{~mm}$ (20 in), near ultimate load; (b) $\Delta=800 \mathrm{~mm}$ (31 in), post ultimate load.

Figure 3-35 Localization of deformation in post-ultimate softening response of reduced model: (a) $\Delta=500 \mathrm{~mm}$ (20 in), near ultimate load; (b) $\Delta=800 \mathrm{~mm}$ (31 in), post ultimate load. 39

Figure 3-36 (a) Vertical load and (b) beam axial force vs. vertical displacement of center column for different span lengths with three bolts per shear tab connection.

Figure 3-37 (a) Vertical load and (b) beam axial force versus vertical displacement of center column for $9.1 \mathrm{~m}$ (30 ft) beam spans with different numbers of bolts per shear tab connection.

Figure 3-38. Alternate post-ultimate behaviors of a single bolt row in a shear tab connection under axial tension 
Figure 3-39 (a) Vertical load and (b) beam axial force versus vertical displacement of center column for

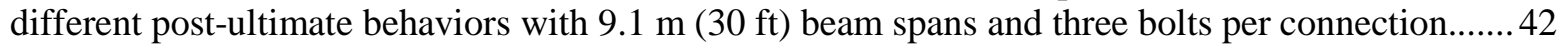

Figure 3-40 (a) Vertical load and (b) beam axial force versus vertical displacement of center column for

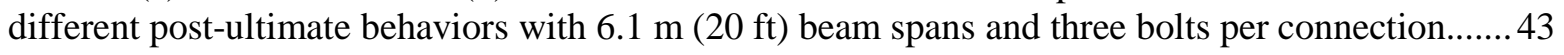

Figure 3-41 (a) Vertical load and (b) beam axial force versus vertical displacement of center column for

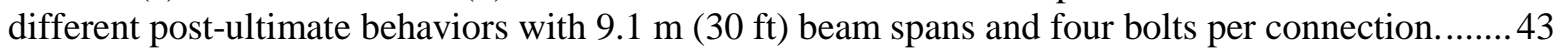

Figure 3-42. Deformed geometry of beam span with exterior pin support at beam mid-height ...............44

Figure 3-43. Comparison of experimental and analytical rotational capacity values for $L=1.89 \mathrm{~m}$

$(6.21 \mathrm{ft})$ with exterior pin supports (circles indicate mean values, while error bars indicate maximum

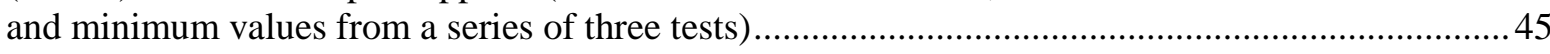

Figure 3-44. Comparison of analytical rotational capacities to values obtained from reduced models with two shear connections per span: (a) $6.1 \mathrm{~m}$ (20 ft) span; (b) $9.1 \mathrm{~m}$ (30 ft) span................................47

Figure $4-1.2$ bay $\times 2$ bay gravity framing system from prototype building A ...................................... 51

Figure 4-2 Comparison of applied load and total reaction computed from detailed model: (a) concentrated load; (b) uniform load. (2 bay $\times 2$ bay floor system from building A)......................... 52

Figure 4-3 Detailed model of composite floor system. ......................................................................... 53

Figure 4-4 Finite element mesh used in detailed model: (a) composite floor slab; (b) beam-to-column connections.

Figure 4-5 Engineering stress-strain curves used to represent wire reinforcement, shear studs, and steel deck.

Figure 4-6 Influence of hourglass control coefficient QM on load-displacement curves for detailed models with different concrete material types: (a) Material type 72R3; (b) material type 159. (2 bay $\times 2$ bay floor system from building A; concentrated load) ............................................................ 56

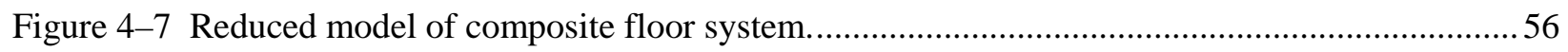

Figure 4-8 Finite element mesh used in reduced model: (a) composite floor system; (b) beam-to-column connection.

Figure 4-9 Reduced modeling of composite floor slab: (a) actual profile; (b) alternating strong and weak strips. 57

Figure 4-10 Shell element meshes of floor slab with element sizes of (a) $1016 \mathrm{~mm}$, (b) $610 \mathrm{~mm}$, and (c) $295 \mathrm{~mm}$.

Figure 4-11 Alternative arrangements for strips of shell elements in reduced models: (a) weak strips along girders; (b) strong strips along girders.

Figure 4-12 Influence of mesh refinement on load-displacement curves for reduced models: (a) weak strips along girders; (b) strong strips along girders. ( 2 bay $\times 2$ bay floor system from building $A$; concentrated load).

Figure 4-13. (a) Detailed model of 3-bolt shear tab connection subjected to (b) torsion and (c) transverse shear.

Figure 4-14. Comparison of detailed and reduced models for (a) torsional and (b) transverse shear behavior of shear tab connections.

Figure 4-15 Shear force versus slip relationship for shear studs used in reduced models. 61 
Figure 4-16 Comparison of load-displacement curves from detailed and reduced models: (a) concentrated load; (b) uniform load. (2 bay $\times 2$ bay floor system from building A).

Figure 5-1. (a) Vertical reaction at center column base and (b) vertical displacement of center column in 2 bay $\times 2$ bay floor system from building A under sudden column loss.

Figure 5-2. Deflections of 2 bay $\times 2$ bay floor system from building A: (a) at equilibrium prior to column loss; (b) at peak displacement after column loss

Figure 5-3. Direct analysis procedure for generating a load-displacement curve for sudden column loss 65

Figure 5-4. Approximate procedure for generating a load-displacement curve for sudden column loss... 66

Figure 5-5. Comparison of load-displacement results from direct and approximate analyses of sudden column loss ( 2 bay $\times 2$ bay floor system from building $A$ )

Figure 5-6. Load-displacement curves under central column loss for floor systems from building A with gradual softening in post-ultimate response of connections: (a) 2 bay $\times 2$ bay; (b) 4 bay $\times 4$ bay..... 71

Figure 5-7. 4 bay $\times 4$ bay gravity framing system from prototype building A …................................... 71

Figure 5-8. Load-displacement curves under central column loss for floor systems from building A with sudden fracture in post-ultimate response of connections: (a) 2 bay $\times 2$ bay; (b) 4 bay $\times 4$ bay........ 72

Figure 5-9. Axial forces at beam ends (arrows) and tensile force per length normal to slab edges (filled areas) for 2 bay $\times 2$ bay floor system from building A under central column displacements of (a) $206 \mathrm{~mm}$ (initial connection failure) and (b) $474 \mathrm{~mm}$ (ultimate static capacity).

Figure 5-10. Axial forces at beam ends (arrows) and tensile force per length normal to slab edges (filled areas) for 4 bay $\times 4$ bay floor system from building A under central column displacements of (a) $206 \mathrm{~mm}$ (initial connection failure) and (b) $497 \mathrm{~mm}$

Figure 5-11. Load-displacement curves for 4 bay $\times 4$ bay floor system from building A: (a) loss of nearpenultimate column (D4); (b) loss of penultimate column (D5)

Figure 5-12. Load-displacement curves for 3 bay $\times 4$ bay floor system from building B: (a) loss of nearpenultimate column (D3); (b) loss of penultimate column (E3) ..................................................... 75

Figure $5-13.3$ bay $\times 4$ bay gravity framing system from prototype building $B$.................................... 76

Figure 5-14. Layout of additional slab reinforcement to provide UFC 4-023-03 tie forces: (a) 4 bay $\times 4$ bay framing system from building A; (b) 3 bay $\times 4$ bay framing system from building $B$................ 80

Figure 5-15. Engineering stress-strain curves for steel reinforcing bars.

Figure 5-16. Load-displacement curves for 4 bay $\times 4$ bay floor system from building A with horizontal ties that satisfy UFC 4-023-03: (a) loss of near-penultimate column (D4); (b) loss of penultimate column (D5).....

Figure 5-17. Load-displacement curves for 3 bay $\times 4$ bay floor system from building $B$ with horizontal ties that satisfy UFC 4-023-03: (a) loss of near-penultimate column (D3); (b) loss of penultimate column (E3)

Figure 5-18. Load-displacement curves for 4 bay $\times 4$ bay floor system from building A with floor slab S16-2.5: (a) loss of near-penultimate column (D4); (b) loss of penultimate column (D5) ............... 83

Figure 5-19. Load-displacement curves for 3 bay $\times 4$ bay floor system from building B with floor slab S16-5: (a) loss of near-penultimate column (D3); (b) loss of penultimate column (E3) .................. 83

Figure 5-20. Load-displacement curves for 3 bay $\times 4$ bay floor system from building B with floor slab S16-14: (a) loss of near-penultimate column (D3); (b) loss of penultimate column (E3) .................8 84 
Figure 5-21. Load-displacement curves for 4 bay $\times 4$ bay floor system from building A with different levels of slab reinforcement: (a) sudden loss of near-penultimate column (D4); (b) sudden loss of penultimate column (D5)

Figure 5-22. Load-displacement curves for 3 bay $\times 4$ bay floor system from building B with different levels of slab reinforcement: (a) sudden loss of near-penultimate column (D4); (b) sudden loss of penultimate column (D5)

Figure 5-23. Axial forces at beam ends (arrows) and tensile force per length normal to slab edges (filled areas) at ultimate static load for 4 bay $\times 4$ bay floor system from building A under loss of nearpenultimate column (D4): (a) floor slab S20-1.4; (b) floor slab S16-2.5; (c) floor slab S20-1.4 with reinforcing bars from Table 5-6

Figure 5-24. Axial forces at beam ends (arrows) and tensile force per length normal to slab edges (filled areas) at ultimate static load for 3 bay $\times 4$ bay floor system from building $B$ under loss of nearpenultimate column (D3): (a) floor slab S20-1.4; (b) floor slab S16-5; (c) floor slab S16-14 .......... 86

Figure 5-25. Relationships between normalized tie forces in slab and uniform floor load intensity: (a) quasi-static loading; (b) sudden column loss ..... 
This page intentionally left blank. 


\section{LIST OF TABLES}

Table 2-1. Tensile requirements of steel components in prototype buildings.......................................... 6

Table 2-2. Beam spans, cross sections, and number of shear studs in the gravity frames ......................... 7

Table 2-3. Story heights and column cross sections in the gravity frames ............................................. 7



Table 3-1. Equations used to calculate yield and ultimate capacities of single bolt rows in tension and

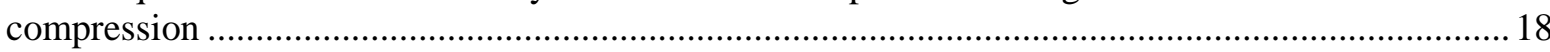

Table 3-2. Parameters of axial load-deformation relationships for springs representing single bolt rows of

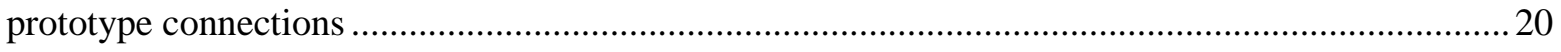

Table 3-3. Comparison of model predictions and experimental measurements (Thompson 2009) of ultimate vertical load $P_{u}$ for two-span beam assemblies............................................................... 28

Table 3-4. Comparison of model predictions and experimental measurements (Thompson 2009) of

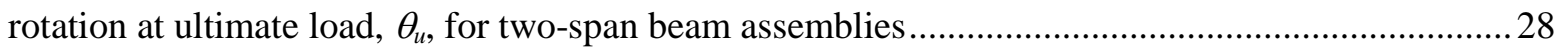

Table 5-1. Minimum specified live loads for different occupancies in an office building ........................69

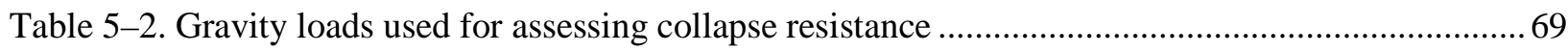

Table 5-3. Comparison of computed and predicted beam chord rotations corresponding to initial

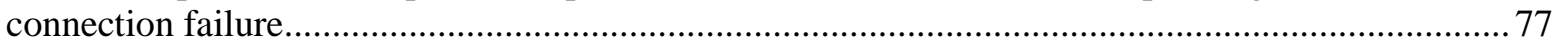

Table 5-4 Comparison of required shear strength and nominal tensile strength values for shear tab

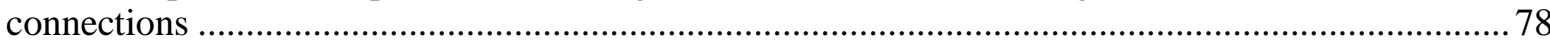

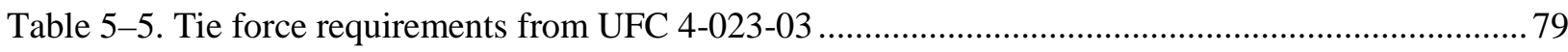

Table 5-6. Additional slab reinforcement used to develop required tie forces.......................................... 80

Table 5-7. Properties of steel deck and welded wire reinforcement for floor slabs .................................. 82

Table 5-8. Calculation of normalized tie forces $F_{i} / L_{1}$ from analyses of near-penultimate column loss for prototype buildings with varying floor slab reinforcement.......................................................... 87

Table 5-9. Ultimate capacities of various floor systems under both quasi-static loading and sudden column loss, with corresponding values of the Dynamic Increase Factor (missing column is nearpenultimate) 
This page intentionally left blank. 


\section{Chapter 1 \\ INTRODUCTION}

From the early 1980s (ANSI 1982) to the present (ASCE 2010), standards for structural design in the United States have included requirements for "general structural integrity." Such requirements are intended to ensure that structures are resistant to disproportionate (or progressive) collapse, wherein local damage spreads progressively, resulting in a partial or total collapse that is disproportionate to the initiating event. The commentary to the American Society of Civil Engineers Standard 7 (ASCE 2010) outlines two basic approaches for providing resistance to disproportionate collapse: (1) direct design, in which structures are designed explicitly to resist collapse by either (a) developing alternate load paths in the event of a local failure or (b) providing sufficient local resistance to prevent local failure and (2) indirect design, in which collapse resistance is addressed implicitly by providing minimum levels of strength, continuity, and ductility. The 2010 version of ASCE 7 (ASCE 2010) also includes "extraordinary event” load combinations, previously in the commentary only, to be used in assessing residual capacity following the notional removal of selected load-bearing elements.

While ASCE 7 (ASCE 2010) does not include specific provisions or criteria for resistance to disproportionate collapse, beyond the general guidance mentioned above, a few other codes and standards have incorporated structural integrity requirements consistent with the indirect design approach. As an example, the American Concrete Institute Building Code 318 (ACI 2008, Section 7.13) includes requirements for minimum integrity reinforcement for concrete frame and bearing wall structures. The 2009 version of the International Building Code (IBC) (ICC 2009, Section 1614) introduced structural integrity requirements for design of high-rise buildings in occupancy categories III (buildings that represent a substantial hazard to human life in the event of a failure) and IV (essential facilities). These new requirements include minimum levels of tensile strength for the end connections of beams in steel frame structures.

The structural integrity requirements in ACI 318 (ACI 2008) and in the 2009 IBC (ICC 2009) were based mainly on engineering judgment, and while the intent of these requirements is to enhance resistance to disproportionate collapse, the enhancements that are actually achieved are not well defined. The tie force requirements for U.S. military buildings in the Unified Facilities Criteria (UFC) 4-023-03 (DOD 2009), in contrast, were developed (Stevens 2008) with the specific objective of preventing collapse under several different column loss scenarios. In the development of these tie force requirements (Stevens 2008), it was noted that most steel connections are not capable of sustaining the magnitudes of rotation necessary to carry the gravity loads through catenary action (i.e., through tensile forces in the beams). For this reason, the 2009 version of the UFC 4-023-03 (DOD 2009) requires that tie forces be carried by the floor system, unless the connections can be shown capable of developing the required tensile forces while sustaining substantial rotations of $0.20 \mathrm{rad}\left(11.3^{\circ}\right)$. This approach contrasts sharply with the integrity requirements in the 2009 IBC, which specify minimum tensile capacities for the end connections of beams, without consideration of the rotational capacity of the connections.

Recent full-scale tests (Sadek et al. 2010) have demonstrated the good performance of seismically designed steel moment-resisting connections (Seismic Design Categories C and D) under simulated column loss, with the connections sustaining rotations almost twice as large as those observed in previous seismic tests and developing significant vertical capacity through a combination of flexural and catenary action. Reduced models of these moment connections have been developed and validated against experimental data (Sadek et al. 2010), and computational models of 10-story buildings incorporating these reduced connection models (Main et al. 2011, Alashker et al. 2011) have shown that seismically designed moment frames are able to sustain the sudden loss of multiple columns without collapse. In 
these studies (Main et al. 2011, Alashker et al. 2011) peak deflections on the order of $500 \mathrm{~mm}$ (20 in) were observed after sudden loss of two columns from perimeter moment frames. Although the rotational capacities of these moment connections were less than the value of $0.20 \mathrm{rad}\left(11.3^{\circ}\right)$ required by the UFC 4-023-03 (DOD 2009) for tie forces to be carried by the beams, these results indicate that seismically designed moment connections are capable of sustaining sudden column loss without collapse.

In contrast, recent computational studies (Sadek et al. 2008, Alashker et al. 2010) have indicated the susceptibility to collapse of gravity frames (i.e., frames designed to carry only vertical loads) with simple shear connections under column loss. A detailed modeling approach was used to study a 2 bay $\times 2$ bay gravity framing system with single-plate shear ("shear tab") connections and a composite concrete slab on steel deck. Under loss of the central column, the composite floor slab was found to significantly enhance the capacity of the system relative to the capacity of the bare steel framing system. However, the capacity of the composite system was still found to be inadequate to sustain the gravity loads under sudden loss of the central column. Alashker et al. (2010) considered the influence of a number of factors on the collapse resistance of the 2 bay $\times 2$ bay system, including thickness of the steel deck, area of the welded wire reinforcement, and the number of bolts in the shear tab connections. The thickness of the steel deck was found to have a particularly significant effect, with a doubling of the thickness enhancing the overall capacity of the system under column loss by $37 \%$.

While the susceptibility to collapse of steel gravity framing systems is of concern, this susceptibility is affected by a number of factors in addition to those previously investigated by Sadek et al. (2008) and Alashker et al. (2010). These previous studies assumed a gradual softening in the post-ultimate response of the shear tab connections, representative of a tear-out failure of the bolts through the beam web. However, recent tests of shear tab connections exhibited sudden fracture rather than gradual softening (Thompson 2009, Weigand et al. 2012). The sudden fractures were associated with either bolt shear rupture or brittle rupture of the connection plate. Sudden fractures of the connections result in a loss of both axial and shear capacity at a smaller rotation than would be sustained due to gradual softening, thus reducing the capacity of the system. On the other hand, while Sadek et al. (2008) and Alashker et al. (2010) considered an isolated 2 bay $\times 2$ bay floor system, continuity of the slab beyond the bays affected by column loss (i.e., for a floor system with more than two bays in each direction) has the potential to enhance the capacity of the system by supporting the development of larger membrane forces in the floor slab. Bay size is also of interest. Sadek et al. (2008) and Alashker et al. (2010) considered a bay size of

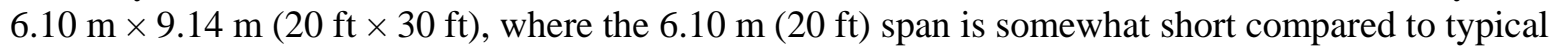
construction. Longer beam spans might be expected to impose larger demands on the connections and the floor slab under column loss scenarios, potentially leading to increased susceptibility to collapse.

Motivated by these considerations, this report presents a reduced modeling approach for the analysis of steel gravity framing systems with composite floor slabs under column loss scenarios and uses this approach to investigate the influence of factors such as bay size, slab continuity, and the mode of connection failure on the capacity of the systems. The reduced modeling approach enables large multibay systems to be analyzed much more efficiently than the detailed approach used previously by Sadek et al. (2008) and Alashker et al. (2010), thus facilitating consideration of various factors in the analyses. The energy-based approximate procedure proposed by Izzuddin et al. (2008) for analysis of sudden column loss is also considered and verified computationally, enabling the structural capacity under sudden column loss to be evaluated using the results of a single quasi-static pushdown analysis, rather than requiring multiple dynamic analyses of sudden column loss at different load levels. The reduced modeling approach is also used to assess the effectiveness of the structural integrity requirements in the 2009 IBC (ICC 2009) and the tie force requirements in UFC 4-023-03 (DOD 2009) in preventing collapse under sudden column loss scenarios and to evaluate the levels of force required for prevention of collapse.

The outline of the report is as follows. Chapter 2 describes the prototype steel frame buildings considered in this study, including alternate designs with different bay size, and presents details of the composite floor system and the shear tab connections used in these buildings. Chapter 3 describes the reduced 
modeling approach used for the shear tab connections and presents comparisons with detailed model results and available experimental data, including two-span beam assembly tests by Thompson (2009), to establish confidence in the reduced models. Simplified spreadsheet procedures for analyzing two-span beam assemblies and predicting rotational capacities of the connections are also presented in Chapter 3 and compared with model predictions and experimental data. Chapter 4 describes the reduced modeling approach used for composite floor systems, including the concrete slab on steel deck, and presents comparisons with the results of detailed models, as used by Sadek et al. (2008) and Alashker et al. (2010), to establish confidence in the reduced models. Chapter 5 presents assessments of the collapse resistance of prototype floor systems, comparing the applicable gravity loads to the capacity evaluated under both quasi-static loading and sudden column loss. Current integrity requirements are also assessed in Chapter 5, and the levels of tying force required for prevention of collapse are evaluated. Finally, Chapter 6 summarizes the key findings and conclusions of this study. 
This page intentionally left blank. 


\section{Chapter 2 \\ PRototyPE GRAVITY FRAMING SYSTEMS}

Working with a panel of practicing structural engineers across the U.S., NIST developed the overall configuration and dimensions of prototype buildings to be considered in this research program. For simplicity of design and analysis, a 10-story building with rectangular plan for office occupancy was chosen as the prototype building. Figure 2-1 shows the plan layout of two prototype steel frame building designs, each having plan dimensions of $30.5 \mathrm{~m} \times 45.7 \mathrm{~m}(100 \mathrm{ft} \times 150 \mathrm{ft})$. The two different plan layouts shown in Figure 2-1 were developed to examine the influence of span length on disproportionate collapse resistance. Both buildings were designed for Seismic Design Category C, and the lateral loads are resisted by seismically designed intermediate moment frames (IMFs) located on the exterior of the buildings. All interior frames were designed to support gravity loads only.


Figure 2-1. Plan layouts for (a) 5 bay $\times 5$ bay building (building A) and (b) 5 bay $\times 3$ bay building (building B)

The buildings were designed according to the American Society of Civil Engineers standard 7-02 (ASCE 2002) and its referenced material design standards, including the American Institute of Steel Construction (AISC) "Load and Resistance Factor Design Specification for Structural Steel Buildings” (AISC 1999) and the AISC "Seismic Provisions for Structural Steel Buildings” (AISC 2002). The various steel components of the buildings, discussed in the following sections, conform to ASTM standard specifications with tensile requirements as listed in Table $2-1$.

\section{$2.1 \quad$ GRAVITY LOADS}

The design loads on the buildings were determined based on the International Building Code (IBC 2003). For typical floors, the dead load consisted of the self-weight of the floor of $2.2 \mathrm{kN} / \mathrm{m}^{2}\left(46 \mathrm{lbf} / \mathrm{ft}^{2}\right)$ and a superimposed dead load of $1.44 \mathrm{kN} / \mathrm{m}^{2}$ (30 lbf/ $/ \mathrm{ft}^{2}$ ), while the design live load was assumed to be $4.79 \mathrm{kN} / \mathrm{m}^{2}\left(100 \mathrm{lbf} / \mathrm{ft}^{2}\right)$. For the roof, the self-weight of the slab was $2.2 \mathrm{kN} / \mathrm{m}^{2}\left(46 \mathrm{lbf} / \mathrm{ft}^{2}\right)$, the superimposed dead load was $0.48 \mathrm{kN} / \mathrm{m}^{2}\left(10 \mathrm{lbf} / \mathrm{ft}^{2}\right)$, and the design live load was $0.96 \mathrm{kN} / \mathrm{m}^{2}\left(20 \mathrm{lbf} / \mathrm{ft}^{2}\right)$. The reduction in live loads was based on Section 1607.9.1 of IBC (2003). The load combinations used in the design were those required by ASCE 7-02. For the sizing of the gravity frame members and their connections, the following load combination governed the design: $1.2 D+1.6 L+0.5 L_{r}$, where $D$ is the dead load, $L$ is the live load, and $L_{r}$ is the roof live load. 
Table 2-1. Tensile requirements of steel components in prototype buildings

\begin{tabular}{|c|c|c|c|c|}
\hline $\begin{array}{l}\text { Building } \\
\text { Component }\end{array}$ & $\begin{array}{c}\text { ASTM } \\
\text { Designation }^{a}\end{array}$ & $\begin{array}{l}\text { Yield Strength, Min. } \\
F_{y}, \mathrm{MPa}(\mathrm{ksi})\end{array}$ & $\begin{array}{c}\text { Tensile Strength, Min. } \\
F_{u}, \mathrm{MPa}(\mathrm{ksi})\end{array}$ & Elongation, Min. \\
\hline Steel plates & A36 & $250(36)$ & $400(58)$ & $20 \%$ in $200 \mathrm{~mm}$ (8 in) \\
\hline Wire reinforcement & $A 82^{b}$ & $450(65)$ & $515(75)$ & not specified \\
\hline Shear studs & $\mathrm{A} 108^{\mathrm{c}}$ & $350(51)$ & $450(65)$ & $20 \%$ in 50 mm (2 in) \\
\hline High-strength bolts & $\begin{array}{l}\text { A325 } \\
\text { A } 490^{\text {e }}\end{array}$ & $\begin{array}{c}635(92) \\
900(130)\end{array}$ & $\begin{array}{c}825(120) \\
1040(150)\end{array}$ & $\begin{array}{l}14 \% \text { in } 4 D \\
14 \% \text { in } 4 D\end{array}$ \\
\hline Steel deck & A653, Grade 33 & $230(33)$ & $310(45)$ & $20 \%$ in 50 mm (2 in) \\
\hline Rolled steel shapes & A992 & $345(50)$ & $450(65)$ & $18 \%$ in 200 mm (8 in) \\
\hline \multicolumn{5}{|c|}{  } \\
\hline
\end{tabular}

\section{$2.2 \quad$ FLOOR SLAB}

The floor slab, illustrated in Figure 2-2, consists of $83 \mathrm{~mm}\left(3^{1} / 4 \mathrm{in}\right)$ lightweight concrete over a $76 \mathrm{~mm}$ (3 in) deep composite steel deck with an average rib width of 152 mm (6 in). ASTM A653 Grade 33 structural steel (see Table 2-1) is used for the 20 gage steel deck, which has a thickness of $0.91 \mathrm{~mm}$ (0.0358 in). The lightweight concrete has a specific weight of $17.3 \mathrm{kN} / \mathrm{m}^{3}\left(110 \mathrm{lbf} / \mathrm{ft}^{3}\right)$ and a nominal compressive strength of $20.7 \mathrm{MPa}$ (3000 psi). The concrete slab has welded wire reinforcement designated $6 \times 6 \mathrm{~W} 1.4 / 1.4$, which indicates a $152 \mathrm{~mm} \times 152 \mathrm{~mm}(6$ in $\times 6$ in) grid spacing with wires having a cross-sectional area of $9.0 \mathrm{~mm}^{2}\left(0.014 \mathrm{in}^{2}\right)$. ASTM A82 steel wire (see Table $\left.2-1\right)$ is used for the reinforcement. Shear connector studs with a diameter of $19 \mathrm{~mm}(3 / 4$ in) are used to develop composite action between the steel beams and the concrete slab. ASTM A108 steel is used for the shear studs, with tensile requirements (see Table 2-1) corresponding to Type B studs as specified in the American Welding Society’s Structural Welding Code - Steel, AWS D1.1 (AWS 2010).

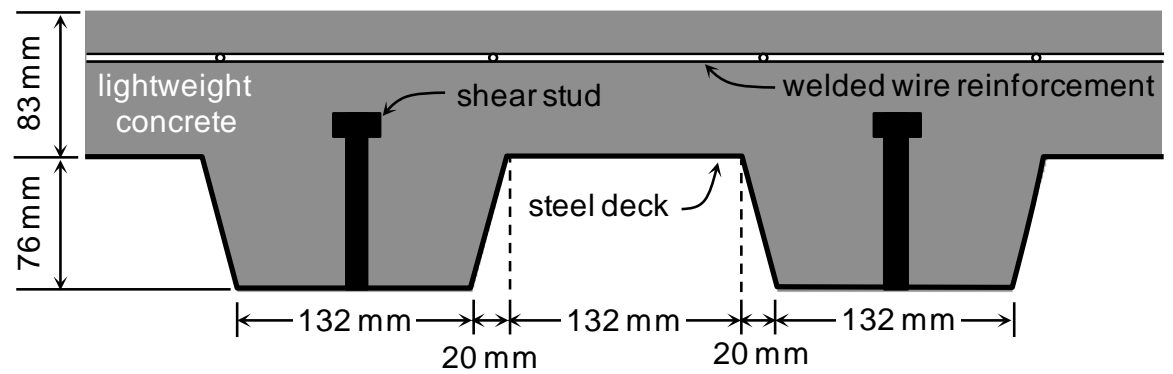

Figure 2-2. Cross sectional view of floor slab 


\section{$2.3 \quad$ GRAVITY FRAMES}

The gravity frame members (members that are not part of the lateral-force resisting system) were designed assuming fully composite action between the steel beams and the concrete slab. ASTM A992 structural steel (see Table 2-1) is used in the beams and columns. The 5 bay $\times 5$ bay building (designated building A) has bay spans of $6.1 \mathrm{~m} \times 9.14 \mathrm{~m}(20 \mathrm{ft} \times 30 \mathrm{ft})$, while the 5 bay $\times 3$ bay building (designated building B) has bay spans of $10.16 \mathrm{~m} \times 9.14 \mathrm{~m}\left(33^{1} / 3 \mathrm{ft} \times 30 \mathrm{ft}\right)$. Beam spans and cross sections for the gravity frames in both buildings are listed in Table 2-2 along with the number of shear studs per span. The structural steel shapes used for the columns in the gravity frames of buildings A and B are listed in Table 2-3.

Table 2-2. Beam spans, cross sections, and number of shear studs in the gravity frames

\begin{tabular}{ccccc}
\hline Building & Beam Orientation & Beam Span & Cross Section & Number of Shear Studs \\
\hline A & East-West & $9.14 \mathrm{~m}(30 \mathrm{ft})$ & W14×22 & 40 per span \\
& North-South & $6.10 \mathrm{~m}(20 \mathrm{ft})$ & W16×26 & 44 per span \\
\multirow{2}{*}{ B } & East-West & $9.14 \mathrm{~m}(30 \mathrm{ft})$ & W21×50 & 86 per span \\
& North-South & $10.16 \mathrm{~m}\left(33^{1} / 3 \mathrm{ft}\right)$ & W16×26 & 46 per span \\
\hline
\end{tabular}

Table 2-3. Story heights and column cross sections in the gravity frames

\begin{tabular}{cccc}
\hline & & \multicolumn{2}{c}{ Cross Section } \\
\cline { 3 - 4 } Floor Range & Story Height & Building A & Building B \\
\hline 1 & $5.33 \mathrm{~m}\left(17^{1} / 2 \mathrm{ft}\right)$ & $\mathrm{W} 14 \times 120$ & $\mathrm{~W} 14 \times 176$ \\
$2-4$ & $4.19 \mathrm{~m}\left(13^{3} / 4 \mathrm{ft}\right)$ & $\mathrm{W} 14 \times 90$ & $\mathrm{~W} 14 \times 145$ \\
$5-7$ & $4.19 \mathrm{~m}\left(13^{3} / 4 \mathrm{ft}\right)$ & $\mathrm{W} 14 \times 74$ & $\mathrm{~W} 14 \times 90$ \\
$8-10$ & $4.19 \mathrm{~m}\left(13^{3} / 4 \mathrm{ft}\right)$ & $\mathrm{W} 14 \times 48$ & $\mathrm{~W} 14 \times 61$ \\
\hline
\end{tabular}

\subsection{SINGLE-PLATE SHEAR CONNECTIONS}

In the gravity frames of both buildings, the steel beams are connected to the columns using single-plate simple shear connections (shear tab connections), illustrated in Figure 2.3. ASTM A36 steel (see Table 2$1)$ is used for the shear tabs, with a thickness of $9.5 \mathrm{~mm}(3 / 8$ in). Shear tabs are welded to the columns using fillet welds with $8 \mathrm{~mm}(5 / 16$ in) throat thickness and are bolted to the beam webs using $22 \mathrm{~mm}(7 / 8$ in) diameter ASTM A325 high strength bolts (H.S.B.) with threads excluded from the shear plane. Shear connections on the east-west beams in building B incorporate four rows of bolts, while all other shear connections incorporate three rows of bolts (see Table 2-4). In all cases, the center of the top bolt is placed $76.2 \mathrm{~mm}$ ( $3 \mathrm{in}$ ) below the top of the beam, which is consistent with typical industry practice (e.g., Liu and Astaneh-Asl 2004, Thompson 2009). Factored shear forces in the connections and shear strength values are listed in Table $2-4$. The shear strength values in Table 2-4 are from Table 10-9 in the LRFD Manual of Steel Construction (AISC 2001), in which design strength values of single-plate connections are tabulated; rigid support conditions are assumed. 


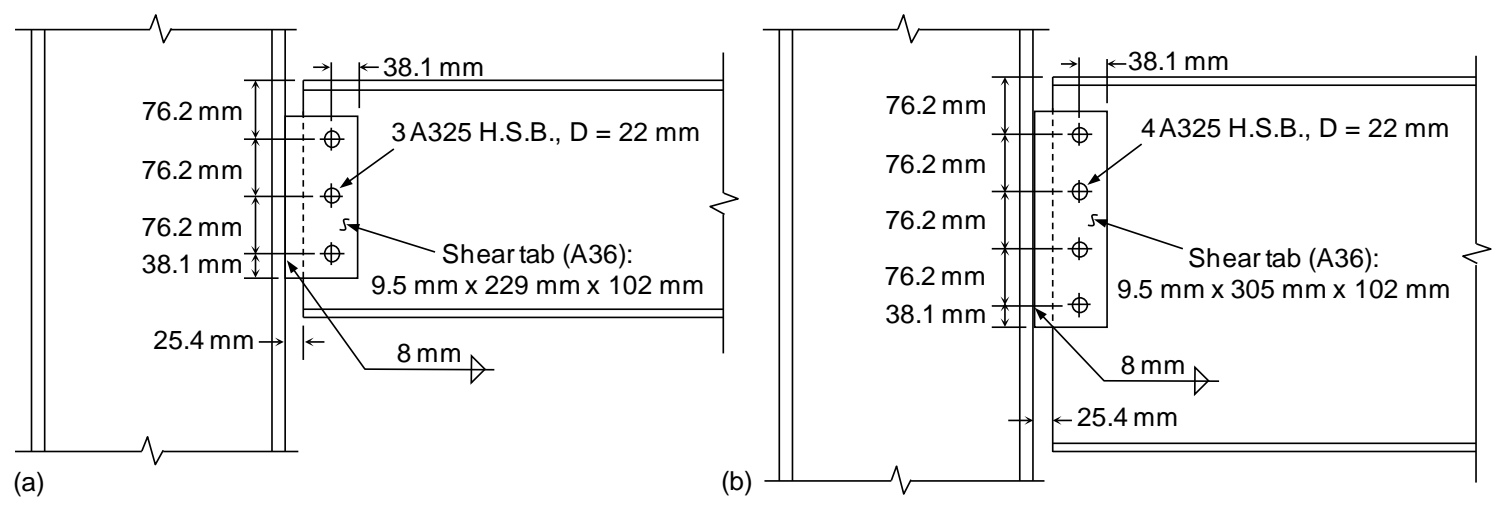

Figure 2-3. Details of single-plate shear connections: (a) three bolt rows; (b) four bolt rows

Table 2-4. Shear connection design parameters

\begin{tabular}{ccccc}
\hline Building & Beam Orientation & Factored Shear Force & Number of Bolt Rows & Shear Strength \\
\hline A & East-West & $153 \mathrm{kN}$ (34.3 kip) & 3 & $252 \mathrm{kN}$ (58.7 kip) \\
& North-South & $153 \mathrm{kN}$ (34.3 kip) & 3 & $252 \mathrm{kN}$ (58.7 kip) \\
\multirow{2}{*}{ B } & East-West & $292 \mathrm{kN}$ (65.6 kip) & 4 & $348 \mathrm{kN}$ (78.3 kip) \\
& North-South & $166 \mathrm{kN}$ (37.4 kip) & 3 & $252 \mathrm{kN}$ (58.7 kip) \\
\hline
\end{tabular}




\section{Chapter 3 \\ Modeling AND ANALysis of Single-Plate ShEAR CONNECTIONS}

This chapter presents modeling and analysis of bare steel framing systems (i.e., no floor slab) with singleplate shear ("shear tab") connections under column loss scenarios. Two-span beam assemblies under "pushdown" loading with an unsupported center column are considered, as illustrated in Figure 3-1, to assess the behavior of the shear connections. This configuration subjects the connections to a combination of vertical shear, bending moment, and axial tension, while imposing substantial rotational demands. Two basic modeling approaches are considered for analyzing the behavior of the connections: (1) detailed finite element modeling, which uses highly refined solid and/or shell element meshes to represent nonlinear material behavior and fracture, and (2) reduced finite element modeling, which uses a smaller number of beam and spring elements to capture the predominant response characteristics and failure modes. Analyses with the reduced models can be performed much more rapidly than with the detailed models, making the reduced models well suited for collapse analysis of complete structural systems. Both detailed and reduced models are analyzed using the LS-DYNA finite element software (Hallquist 2007) with explicit time integration. For the configuration in Figure 3-1, displacement-controlled loading is considered, in which translating boundary conditions are applied slowly to the unsupported center column to achieve a quasi-static response.

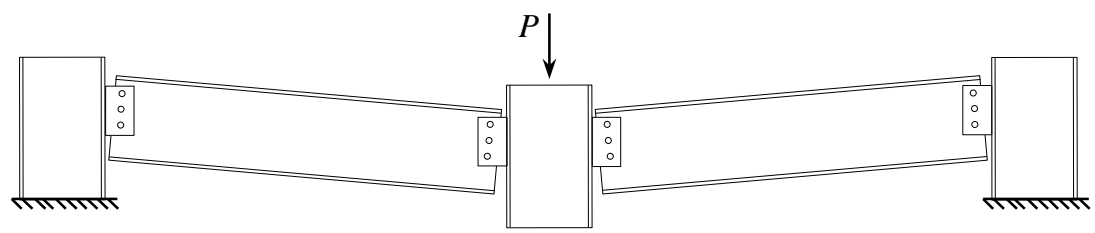

Figure 3-1. Two-span beam assembly under pushdown loading with unsupported center column

Sections 3.1 describes the detailed modeling approach and presents comparisons of detailed model computations with available experimental data for double-shear, single-shear, and bolt-bearing tests, demonstrating the capability of the detailed models to capture both bolt shear deformations and bearinginduced plate deformations. Section 3.2 describes the reduced modeling approach. Section 3.3 presents comparisons of both detailed and reduced model computations with experimental data from Thompson (2009) for two-span beam assemblies under push-down loading of the unsupported center column.

Section 3.4 presents a simplified analysis of two-span beam assemblies under a column removal scenario, based on the assumption that all of the deformation is concentrated in the shear connections, while the beam spans rotate as rigid bodies. This analysis affords insight into the behavior of shear connections under collapse scenarios and provides a fairly accurate calculation procedure that can be implemented in a spreadsheet. Detailed and reduced model computations are compared with results of the simplified spreadsheet calculation. Section 3.5 uses the reduced modeling approach to analyze two-span beam assemblies taken from the gravity framing systems of the prototype buildings described in Chapter 2 under column removal scenarios. The influences of the span length and the connection properties on the ultimate load and rotational capacities of the assemblies are investigated. In Section 3.6, fairly simple analytical expressions are derived for the rotational capacity of the connections as a function of a few parameters including the span length and the connection depth. Finally, Section 3.7 summarizes the key findings of this chapter. 


\subsection{DETAILED MODELING APPROACH}

The detailed modeling approach for single-plate shear connections uses finely meshed solid elements to represent the beam, shear tab, and bolts. Figure 3-2 shows a detailed model of the shear connection used in the N-S frames of building A (see Section 2.4). A typical element size of $3 \mathrm{~mm}(0.12 \mathrm{in})$ was used to represent the beam and shear tab, with three layers of solid elements through the thickness of the beam web and flanges and four layers of solid elements through the thickness of the shear tab. A typical solid element size of $1.5 \mathrm{~mm}$ (0.06 in) was used to represent the bolts. Contact was defined between the bolts, shear tab, and beam web to model the transfer of forces through the bolted connection, including friction (a value of 0.3 was assumed for both the static and dynamic coefficients of friction) and bolt bearing. Because hand calculations indicated that weld failure would not occur, the end nodes of the shear tab were rigidly constrained to nodes on the column web. The column (omitted from Figure 3-2 for clarity) was modeled using a coarser solid element mesh, and contact between the column and the beam flanges was defined, to allow for the possibility of binding under large rotations.

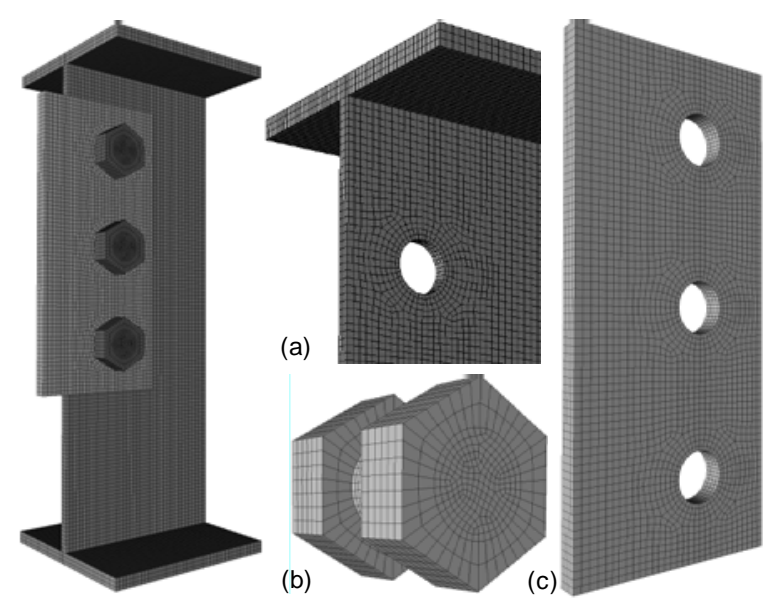

Figure 3-2. Detailed model of single-plate shear connection showing finite element mesh of (a) beam, (b) bolt, and (c) shear tab

\subsubsection{Modeling of plasticity and fracture}

A piecewise-linear plasticity model (material 24 in LS-DYNA) was used to represent the material behavior of the various steel components in the detailed modeling approach. In this material model, an effective stress versus effective plastic strain curve is specified, along with a plastic strain to failure. Fracture is simulated using element erosion, in which elements are removed from the model when the specified failure strain is reached. The material model parameters for each component were developed based on engineering stress-strain curves obtained from tensile tests reported in the literature for each type of steel. Following the procedure described in Sadek et al. (2010), the engineering stress-strain curves were converted to true stress vs. plastic strain curves, and the resulting true stress-strain curves were extrapolated linearly beyond the point of necking onset. The post-necking modulus and the failure strain were adjusted so that engineering stress-strain curves obtained from finite element models of tensile coupons would correspond closely to the coupon test results. Due to mesh-size sensitivity in the modeling of softening behavior, this calibration was performed using finite element models of tensile coupons with the same mesh size as those used in the models of each connection.

For the ASTM A325 and A490 high-strength bolts, the material model parameters were based on typical engineering stress-strain curves from coupon tests reported in Kulak et al. (1986) and shown in Figure 3- 
3(b) (labeled “coupon test”). Corresponding true stress-strain curves for the ASTM A325 and A490 highstrength bolts are shown in Figure 3-3(a). Note that the true stress-strain curves evaluated from coupon test data in Figure 3-3(a) exhibit a drop in stress at a plastic strain of about $8 \%$, which corresponds to the onset of necking; extrapolation was needed beyond this point because the coupon data are not representative of the true stress in the neck region of the coupon. The extrapolated true stress-strain curves, labeled "model” in Figure 3-3(a), were implemented in detailed finite-element models of coupon tests, using the solid-element mesh shown in Figure 3-4 with a gage length of $50 \mathrm{~mm}$ (2 in). Engineering stress-strain curves computed from the detailed models are shown in Figure 3-3(b) along with the coupon test results. The good comparison of the computed and experimental stress-strain curves in Figure 3-3(b) shows that the piecewise linear plasticity model with element erosion accurately represents softening behavior after the onset of necking and captures fracture of the tensile coupons at the appropriate values of engineering strain.

While the shear connections in the prototype buildings use A325 bolts, A490 bolts are also considered to enable an assessment of the modeling approach through comparison with available double-shear test data for different bolt types and sizes (Section 3.1.2) and to enable comparison of detailed model predictions with test results from a two-span beam assembly in which A490 bolts were used as exterior pin supports (Section 3.3). A490 bolts are also used in moment connections in the perimeter moment frames of the prototype buildings, which were investigated by Sadek et al. (2010) and are not considered in this study.
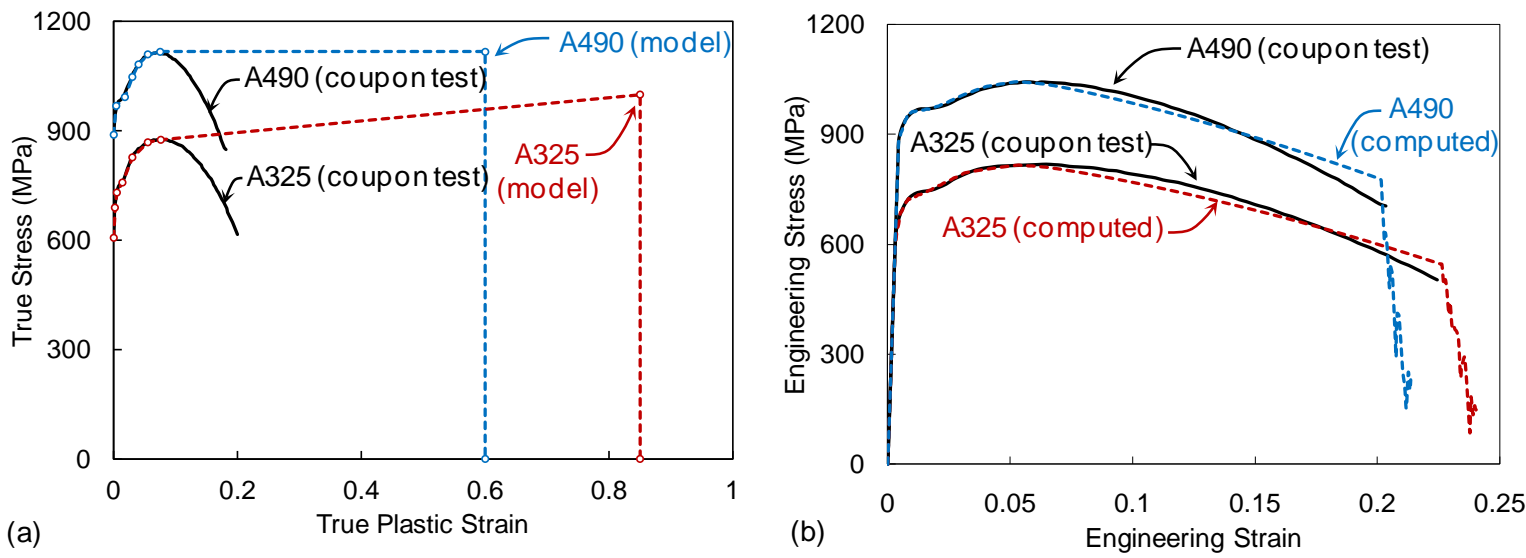

Figure 3-3. (a) True stress-strain and (b) engineering stress-strain curves for A325 and A490 high-strength bolt material: comparison of computed results with coupon tests from Kulak et al. (1986)

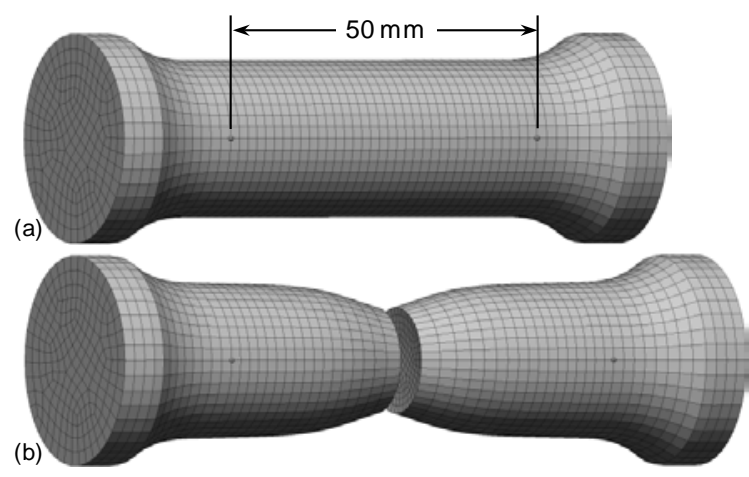

Figure 3-4. Finite element mesh of bolt tensile coupon: (a) prior to loading; (b) after fracture

A similar procedure to that illustrated in Figure 3-3 was used to calibrate the plasticity model for the steel plate components in the bolted connections. A typical engineering stress-strain curve for ASTM A36 steel, reported by Kulak et al. (1986, Fig. 2.2), is shown in Figure 3-5(a), labeled “coupon test”. The yield 
and ultimate strength values from this curve correspond to the minimum specified values of $250 \mathrm{MPa}$ (36 ksi) and $400 \mathrm{MPa}$ (58 ksi), respectively, for A36 steel (ASTM 2008). Also shown in Figure 3-5(a) is a stress-strain curve obtained from a finite element model of a tensile coupon with a gage length of $200 \mathrm{~mm}$ (8 in), shown in Figure 3-6. Linear extrapolation of the true stress-strain curve beyond the onset of necking, as described previously, was used to achieve the good agreement shown in Figure 3-5(a) between the computed and experimental results.

To develop confidence in the detailed modeling approach, the following sections present comparisons of model predictions with available experimental data from connections with a single bolt, including doubleshear tests (Wallaert and Fisher 1965), a test of bolt bearing on a single plate (Rex and Easterling 2003), and a single-shear test (Richard et al. 1980). Because stress-strain curves for the plate materials were not reported from these tests, stress-strain curves for use in the computational models were developed by making use of typical stress-strain curves (e.g., Kulak et al. 1986, Fig. 2.2) and scaling the stresses in the post-elastic range to match the reported yield and ultimate strength values. Yield and ultimate strengths of $296 \mathrm{MPa}$ (43 ksi) and $524 \mathrm{MPa}(76 \mathrm{ksi}$ ), respectively, were reported for the A440 steel plate used by Wallaert and Fisher (1965), and the stress-strain curve calibrated to match these values is shown in Figure 3-5(b). Yield and ultimate strengths of $307 \mathrm{MPa}$ (44.5 ksi) and $452 \mathrm{MPa}$ (65.6 ksi), respectively, were reported for the "mild" steel used by Rex and Easterling (2003, test 41), and the stress-strain curve calibrated to match these values is also shown in Figure 3-5(b). The stress-strain curves shown in Figure 3-5(b) were obtained from finite element models of tensile coupons with gage length of $200 \mathrm{~mm}$ (8 in), similar to that shown in Figure 3-6. Because yield and ultimate strength values were not reported for the A36 plate steel used by Richard et al. (1980), the computational model was based on the typical stressstrain curve shown in Figure 3-5(a), which corresponds to the minimum specified strength values.


Figure 3-5. Stress-strain curves used to represent steel plates in computational models of bolted connection tests



Figure 3-6. Finite element mesh of plate tensile coupon: (a) prior to loading; (b) after fracture

In detailed models of shear tab connections from the prototype buildings, the stress-strain curves were calibrated to match the minimum specified values of yield strength, tensile strength, and elongation, as 
listed in Table 2-1. Computed engineering stress-strain curves for the two types of steel are shown in Figure 3-7. These curves were obtained using a finite element mesh of a tensile coupon with a gage length of $200 \mathrm{~mm}$ (8 in), as shown in Figure 3-6. The stress-strain curve for A36 steel in Figure 3-7 differs from the computed stress-strain curve in Figure 3-5(a) only in that fracture strain has been reduced to match the minimum specified elongation of $20 \%$.



Figure 3-7. Stress-strain curves used to represent A36 and A992 steel in detailed models of shear tab connections from the prototype buildings

\subsubsection{Comparison with double shear test data}

Wallaert and Fisher (1965) present results of double-shear tests for high-strength bolts of different materials and sizes, as well as for different plate materials. Detailed models of selected test specimens were developed. Because the test configuration was symmetric, only one half of each test specimen was modeled, with appropriate boundary conditions on the plane of symmetry. Figure 3-8(a) shows a section view of the detailed model of a test specimen at its ultimate load. Figure 3-8(b) shows the solid element mesh of the bolt after fracture.



Figure 3-8. Detailed model of bolt double-shear test: (a) section view at ultimate load; (b) bolt mesh after fracture

Figure 3-9 shows a comparison of experimental bolt shear stress versus deformation curves with those computed using the detailed model. The deformations plotted correspond to displacements at the loaded end of the translating plate and thus include a combination of bolt shear and bearing deformations. Generally good agreement is observed for the different combinations of bolt size, bolt material, and plate material, demonstrating that the detailed modeling approach is able to capture the influence of these factors on the strength and ductility of the connections. The ultimate strength obtained from the model is within $6 \%$ of the measured value, while the post-ultimate displacement corresponding to $90 \%$ of the ultimate strength is within $11 \%$. The initial stiffness computed by the detailed model is consistently lower than that observed experimentally because frictional clamping due to initial bolt tension was not 
included in the model. However, the initial bolt tension has little effect on the ultimate strength and displacement of the connection, which are of primary interest in this study.
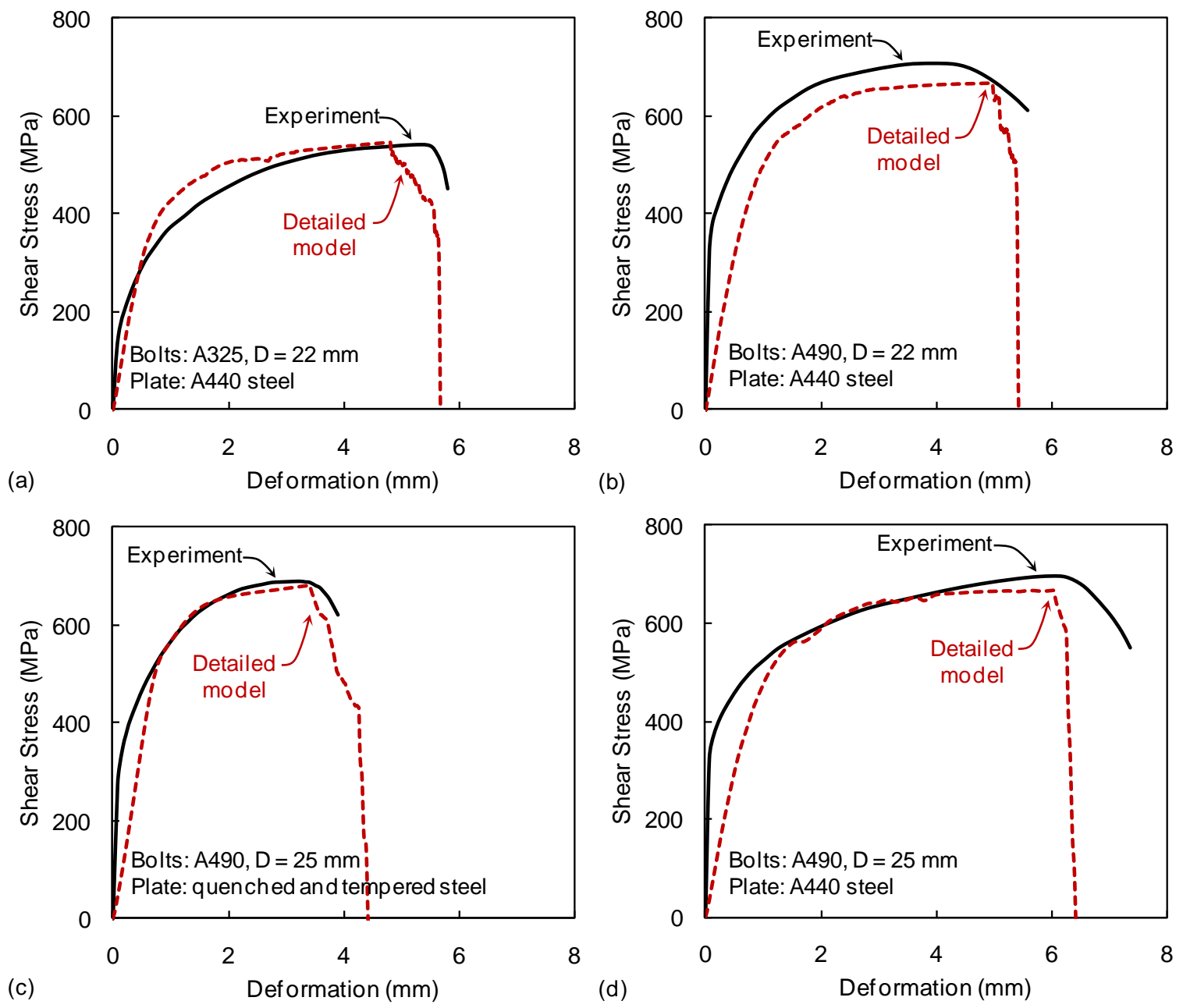

Figure 3-9. Bolt shear stress vs. deformation curves from double-shear specimens: comparison of computed results with experimental data ${ }^{1}$ from Wallaert and Fisher (1965)

Comparison of Figure 3-9(a) and Figure 3-9(b) shows the influence of bolt material, with the A490 bolt exhibiting higher strength than the A325 bolt, with comparable deformations at the ultimate stress. Comparison of Figure 3-9(b) and Figure 3-9(d) shows the influence of bolt diameter, with the $25 \mathrm{~mm}$ ( 1 in) bolt sustaining larger deformations than the $22 \mathrm{~mm} \mathrm{(} 7 / 8 \mathrm{in}$ ) bolt before failure, with comparable values of the ultimate stress. Comparison of Figure 3-9(c) and Figure 3-9(d) shows the influence of plate material, with larger deformations sustained for A440 steel plates than for higher strength quenched and tempered steel plates. The larger deformations for the A440 steel plates were associated with larger bearing-induced deformation of the plates. The detailed model of the plates was able to capture these bearing-induced deformations using a stress-strain curve calibrated to match the reported yield and ultimate strengths of the A440 steel plate material [see Figure 3-5(b)]. The quenched and tempered steel plates were represented using an elastic material model, to preclude bearing-induced plastic deformations. For all specimens, the ultimate limit state was bolt shear failure, resulting in a rapid drop in resistance after the ultimate stress was reached.

\footnotetext{
${ }^{1}$ Experimental curves are best-fit to data from several tests; estimated coefficient of variation in measurements: $4 \%$.
} 


\subsubsection{Comparison with bolt bearing test data}

Figure 3-10(a) shows an experimental load-deformation curve for a bolt bearing against a single plate (Rex and Easterling 2003) compared with results from a detailed model. Figure 3-10(b) shows the detailed model at the ultimate load of the specimen, in which significant bearing-induced deformations are evident and the associated plastic strains are indicated. The results correspond to a bolt diameter of 25 $\mathrm{mm}(1 \mathrm{in})$, plate thickness of $6.5 \mathrm{~mm}\left(\frac{1}{4} \mathrm{in}\right)$, plate width of $127 \mathrm{~mm}(5 \mathrm{in})$, and a distance of $38 \mathrm{~mm}$ (1.5 in) from the center of the bolt hole to the edge of the plate. The stress-strain curve for the plate material was calibrated to match the reported yield and ultimate strengths of the "mild" steel plate [see Figure 3-5(b)]. While the bolt material was not specified by Rex and Easterling (2003), the experiment was designed to develop bearing deformations in the plate, not the bolt, and the bolt was simply represented as linearly elastic in the detailed model. Generally good agreement between the experimental and computed load-deformation curves is observed, and the ultimate load obtained from the model is within $11 \%$ of the measured value.

While the experimental curve terminates at a deformation of $12.7 \mathrm{~mm}$ ( $0.5 \mathrm{in})$ (this value of deformation was used to define bearing failure by Rex and Easterling), the computational analysis was continued further, showing the drop in resistance associated with bolt bearing failure and tearout. Note that the computed post-ultimate response in Figure 3-10(a) is subject to considerable uncertainty, given the significant approximations inherent in modeling fracture propagation using element erosion. (The oscillations in the descending portion of the load-deformation curve are associated with erosion of subsequent layers of elements.) However, by comparing Figure 3-10(a) with the results in Figure 3-9, it can be seen that the drop in resistance associated with bearing failure and tearout is more gradual than that associated with bolt shear failure. The resistance of the connection drops to near zero at a deformation of $36.5 \mathrm{~mm}$ (1.4 in), corresponding closely to the edge distance of $38 \mathrm{~mm}$ (1.5 in).


(b)

Figure 3-10. (a) Load-displacement curves for bolt tearout: comparison of computed results with experimental data $^{2}$ from Rex and Easterling (2003); (b) contours of effective plastic strain from detailed model at ultimate load

\subsubsection{Comparison with single shear test data}

Figure 3-11(a) shows an experimental load-deformation curve from a single-shear test reported in Richard et al. (1980), plotted with computed results from a detailed model. The single-shear test specimen consisted of two $9.5 \mathrm{~mm}(3 / 8$ in) thick A36 steel plates connected by a single $19 \mathrm{~mm}(3 / 4$ in) A325 bolt,

\footnotetext{
${ }^{2}$ Estimated coefficient of variation in measurements: $0.8 \%$
} 
with plate widths of $102 \mathrm{~mm}$ (4 in), and a distance of $38 \mathrm{~mm}$ (1.5 in) between the center of each bolt hole and the edge of the plate. Figure 3-11(b) shows a section view of the detailed model at the ultimate load of the specimen. The deformations plotted correspond to displacements at the loaded end of the translating plate and thus include a combination of bolt shear and bearing deformations. Because the yield and ultimate strengths of the A36 steel plate material were not reported by Richard et al. (1980), a typical stress-strain curve having the minimum specified strength values [see Figure 3-5(a)] was used in the model. An initial bolt tension consistent with that reported by Richard et al. was applied in the model by defining a thermal expansion coefficient for the bolt and reducing the bolt temperature to develop the preload. Applying this preload allowed for good agreement in the initial stiffness of the specimen, as shown in Figure 3-11(a). The computed ultimate load is within $0.5 \%$ of the measured value. The experimental load-deformation curve terminates at a deformation of $9 \mathrm{~mm}(0.35 \mathrm{in})$, which exceeds the deformation of $7.6 \mathrm{~mm}$ (0.3 in) used by Richard et al. (1980) as their criterion for desired ductility. Richard et al. (1980) did not report that fracture occurred at this deformation, and the computational analysis was continued further, showing additional displacement associated with the combined effects of bolt shear and bearing-induced plate deformations [see Figure 3-11(b) and (c)]. The final sudden drop in resistance in the computational model was associated with bolt shear failure.
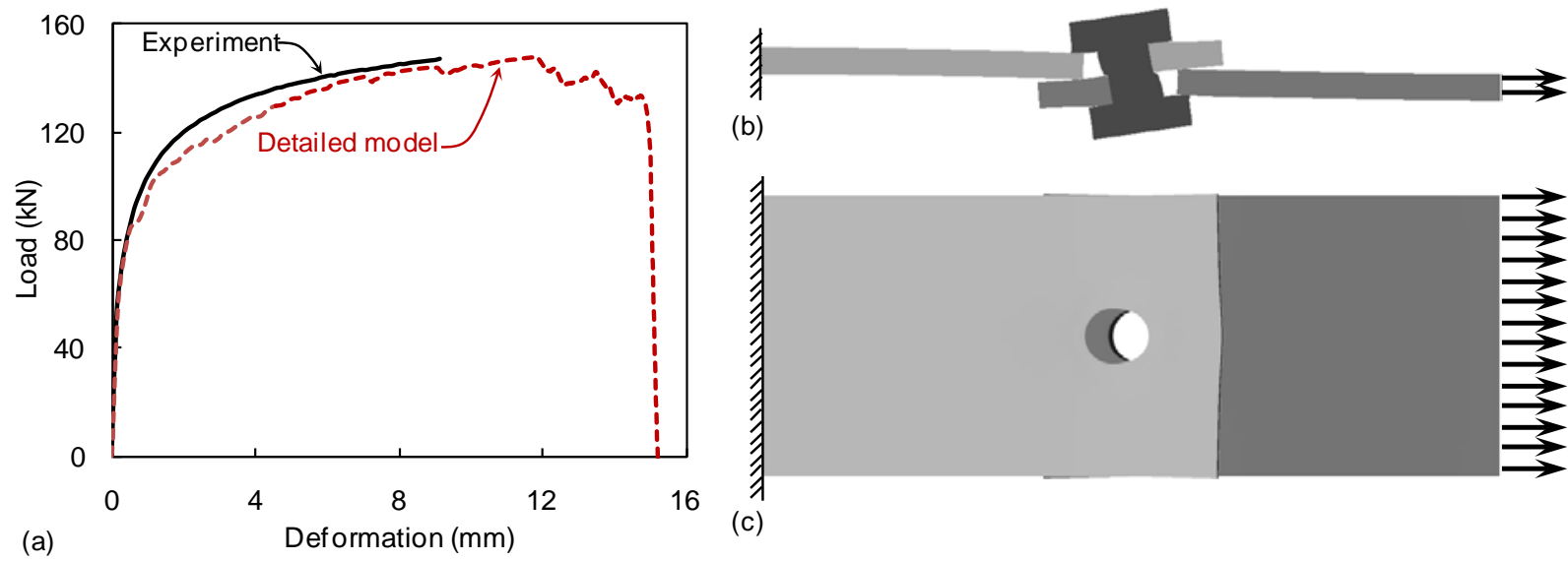

Figure 3-11. (a) Load-deformation curves for single-shear specimen: comparison of detailed model predictions with experimental results ${ }^{3}$ from Richard et al. (1980); (b) section view through bolt centerline and (c) side view (with bolt hidden) of detailed model at ultimate load

\subsection{REDUCED MODELING APPROACH}

The reduced modeling approach for single-plate shear connections, illustrated in Figure 3-12, uses nonlinear springs, one for each bolt row in the connection, to represent the combined effects of bolt shear and bearing-induced deformation. Each nonlinear spring element has distinct load-deformation curves to represent yielding and failure (1) along the beam axis and (2) in the vertical direction. The loaddeformation behavior of the discrete beam elements in the axial direction captures the interaction of bending moment and axial force for the connection, while the load-deformation behavior in the vertical direction captures vertical shear. The nonlinear springs are implemented using a zero-length discrete beam element formulation in LS-DYNA (beam element formulation 6) with material model 119, which allows arbitrary load-deformation curves to be defined along orthogonal coordinate axes (Hallquist 2007). Each nonlinear spring is deleted when the specified failure displacement is reached along either axis. To maintain the proper connection geometry, rigid links connect the ends of the spring elements to nodes along the beam and column centerlines. Beams and columns in the reduced models are represented using

\footnotetext{
${ }^{3}$ Experimental curve is best-fit to data from several tests; estimated coefficient of variation in measurements: $3 \%$.
} 
Hughes-Liu beam elements with cross-section integration, and a piecewise linear plasticity model (material model 24 in LS-DYNA) was used to represent the steel material of the beam and column, with stress-strain curves corresponding to the minimum yield and ultimate strengths listed in Table $2-1$.



Figure 3-12. Reduced model of single-plate shear connection

\subsubsection{Load-deformation relationships for nonlinear springs}

The axial load-deformation relationship used for the nonlinear springs in the reduced connection model is based on that presented by Sadek et al. (2008). Alternate load-deformation relationships are shown in Figure 3-13, in which forces and deformations along the beam axis are plotted on the vertical and horizontal axes, respectively. Positive values of deformation (corresponding to tensile forces) denote displacements away from the column, and negative values of deformation (corresponding to compressive forces) correspond to displacements toward the column. Note that both tensile and compressive forces in a bolt spring (or bolt row) are developed through shear forces in the bolt itself.


(b)

Figure 3-13. Axial load-deformation relationships for bolt springs controlled by: (a) bearing failure; (b) bolt shear failure

Figure 3-13(a) shows a load-deformation relationship of the form proposed by Sadek et al. (2008) for axial behavior controlled by bolt tear out, which exhibits gradual drop in resistance after the ultimate load in tension $\left(t_{u}\right)$ is reached and no drop in resistance after the ultimate load in compression $\left(c_{u}\right)$ is reached. The gradual drop in resistance for bolt tear out is consistent with that shown in Figure 3-10(a) from detailed model simulations of a bolt-tear out test. For axial behavior controlled by bolt shear failure, a load-deformation relationship of the form shown in Figure 3-13(b) is proposed, which exhibits a steeper drop in resistance after the ultimate load is reached in both tension and compression. The steeper drop in resistance for bolt shear failure is consistent with the load-deformation curves shown in Figure 3-9 and Figure 3-11(a) from detailed model simulations of connections governed by bolt shear failure. If bolt tear 
out controls in tension while bolt shear controls in compression, then the curve in Figure 3-13(a) can be used in tension, while the curve in Figure 3-13(b) can be used in compression.

In both cases, the initial stiffness $k$ of the bolt spring is estimated based on a linear regression of rotational stiffness data from seismic testing. The initial rotational stiffness of a shear tab connection, here denoted $\kappa$, is given in Eq. (5-19) of FEMA 355D (FEMA 2000):

$$
\kappa= \begin{cases}124550\left(d_{b g}-142 \mathrm{~mm}\right) & (\mathrm{kN} \cdot \mathrm{mm} / \mathrm{rad}) \\ 28000\left(d_{b g}-5.6 \mathrm{in}\right) & (\mathrm{kip} \cdot \mathrm{in} / \mathrm{rad})\end{cases}
$$

where $d_{b g}=s(N-1)$ is the depth of the bolt group, $s=76.2 \mathrm{~mm}$ (3 in) is the vertical spacing between bolts, and $N$ is the number of bolts. Eq. (3.1) does not include any stiffening contribution from the floor slab. The initial translational stiffness of a spring element representing a single bolt row, denoted $k$, can then be estimated as:

$$
k=\frac{\kappa}{\sum_{i} y_{i}^{2}}
$$

where $y_{i}$ is the vertical distance of the ith bolt row from the center of the bolt group.

The yield and ultimate capacities of each spring in tension ( $t_{y}$ and $t_{u}$, respectively) and in compression ( $c_{y}$ and $c_{u}$, respectively) are calculated based on the governing failure mode of the connection under axial loading, using equations in the AISC Specification (AISC 2010) with a resistance factor of $\phi=1$. Minimum specified values of yield strength $F_{y}$ and ultimate strength $F_{u}$ for each type of steel are used in these equations, as listed in Table $2-1$. Connection capacities are divided by the number of bolts to obtain the capacity corresponding to a single bolt row. While other failure modes may potentially govern, such as fillet weld failure (AISC 2010, Section J2.4) or block shear failure (AISC 2010, Section J4.3), the governing failure modes for the shear tab connections in the prototype buildings (see Section 2.4) are bearing failure at bolt holes (AISC 2010, Section J3.10) and bolt shear failure (AISC 2010, Section J3.6).

The equations used to calculate the yield and ultimate capacities of a single bolt row for these limit states are listed in Table $3-1$, in which $t$ is the thickness of the connected material (beam web or shear tab), $L_{c}$ is the clear distance between the edge of the bolt hole and the edge of the connected material, and $d$ and $A_{b}$ are the diameter and cross-sectional area of the bolt, respectively (see AISC 2010). $F_{v}$ is used to denote the ultimate strength of the bolt in shear. Values of $F_{v}$ listed in the footnote of Table 3-1 were obtained by dividing the values reported in Table 5.1 of the Research Council on Structural Connections Specification (RCSC 2004) by a factor of 0.80 to eliminate the reduction in strength that accounts for non-uniform shear force distribution, since for axial loading the connections under consideration have only one bolt in the line of force. The factor of 0.75 in the expression for the bolt shear yield capacity is the approximate ratio of the yield strength to the ultimate strength of the bolts.

\begin{tabular}{|c|c|c|c|c|}
\hline \multirow[b]{2}{*}{ Failure Mode } & \multicolumn{2}{|c|}{ Tensile Capacities } & \multicolumn{2}{|c|}{ Compressive Capacities } \\
\hline & $t_{y}$ (yield) & $t_{u}$ (ultimate) & $c_{y}($ yield $)$ & $c_{u}$ (ultimate) \\
\hline Bearing at bolt hole & $1.5 L_{c} t F_{y} \leq 3.0 d t F_{y}$ & $1.5 L_{c} t F_{u} \leq 3.0 d t F_{u}$ & $3.0 d t F_{y}$ & $3.0 d t F_{u}$ \\
\hline Bolt shear* & $0.75 F_{v} A_{b}$ & $F_{v} A_{b}$ & $0.75 F_{v} A_{b}$ & $F_{v} A_{b}$ \\
\hline
\end{tabular}

Table 3-1. Equations used to calculate yield and ultimate capacities of single bolt rows in tension and compression 
The spring displacement corresponding to the ultimate load, denoted $\delta_{u}$, is estimated using Eq. (5-17a) in FEMA 355D (FEMA 2000), which gives the plastic rotational capacity of simple shear connections designed using the AISC Specifications, and with adequate clearance between beam flanges from column to prevent binding. Adding an estimated elastic rotation of 0.02 rad to Eq. (5-17a) from FEMA 355D gives the following estimated total rotational capacity (in rad):

$$
\theta_{\text {max }}= \begin{cases}0.17-0.00014 d_{b g} & \left(d_{b g} \text { in mm }\right) \\ 0.17-0.0036 d_{b g} & \left(d_{b g} \text { in in }\right)\end{cases}
$$

Since the tests in FEMA 355D (FEMA 2000) subjected the connections to rotation with no axial extension, the deformation at ultimate load for a bolt spring element can be estimated as $\delta_{u}=y_{\max } \theta_{\max }$, where $y_{\max }=d_{b g} / 2$ represents the distance from the center of the bolt group to the most distant bolt. Substituting Eq. (3.3) for $\theta_{\max }$ yields the following expression for $\delta_{u}$ :

$$
\delta_{u}= \begin{cases}0.085 d_{b g}-0.00007 d_{b g}^{2} & \left(d_{b g} \text { in mm }\right) \\ 0.085 d_{b g}-0.0018 d_{b g}^{2} & \left(d_{b g} \text { in in }\right)\end{cases}
$$

Note that $\delta_{u}$ increases with $d_{b g}$, as shown in Figure 3-14, from $\delta_{u}=11.3 \mathrm{~mm}(0.445 \mathrm{in})$ for a 3-bolt connection to $\delta_{u}=19.3 \mathrm{~mm}(0.761 \mathrm{in})$ for a 5-bolt connection.

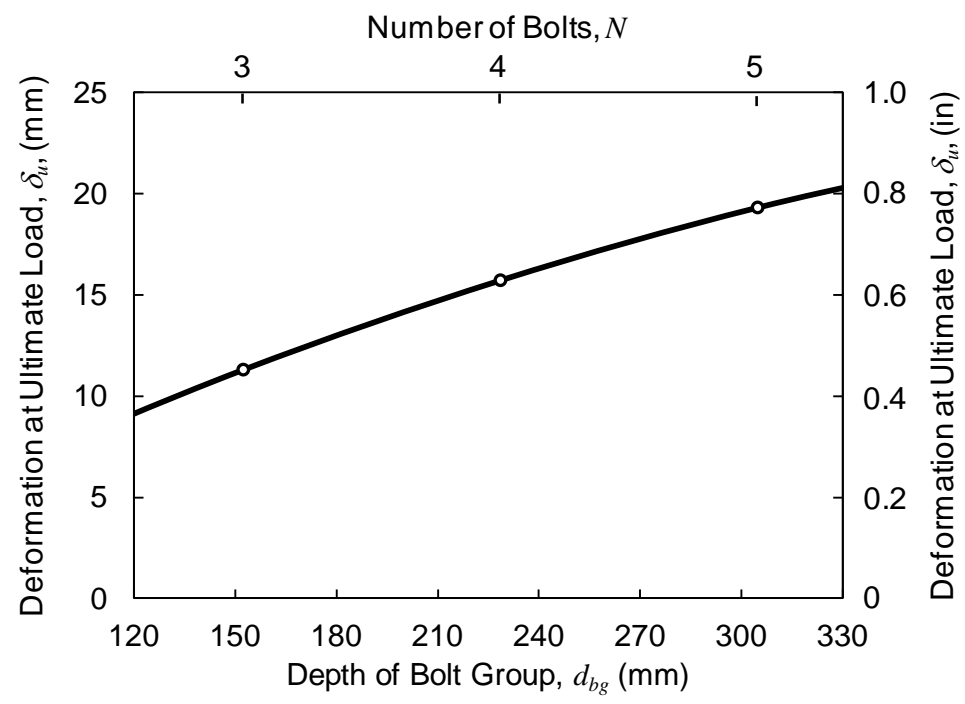

Figure 3-14. Deformation at ultimate load vs. depth of bolt group

For axial behavior governed by bearing failure, the failure displacement of the spring in tension $\left(\delta_{f, t}\right)$, at which the resistance drops to zero and the element is deleted, is selected as the edge distance, which in this case is $38.1 \mathrm{~mm}$ (1.5 in), as shown in Figure 2-3. No softening or element deletion is considered for bearing failure in compression. For axial behavior governed by bolt shear failure, a more sudden drop in resistance after the ultimate load is considered, and the failure displacements of the spring in tension and compression ( $\delta_{f, t}$ and $\delta_{f, c}$, respectively) are set equal to $1.15 \delta_{u}$. In the case of load reversal (e.g., if initial compressive forces in a bolt spring due to flexural action later change to tensile forces due to catenary action), unloading follows a quadratic curve with no permanent offset. Quadratic unloading was found to give somewhat better agreement with experimental data (see Section 3.3) than linear unloading with the initial stiffness $k$. 
Table 3-2 lists the parameters of the axial load-deformation curves for single bolt rows from each of the shear tab connections in the prototype buildings (see Section 2.4). The connections with three bolts are governed by bearing failure of the beam web in both tension and compression, with slightly larger yield and ultimate capacities for the N-S beam connections than for the E-W beam connections, due to the slightly thicker beam web. Due to the significantly thicker beam web of the connection with four bolts (E$\mathrm{W}$ beam connection in building $\mathrm{B}$ ), the tensile behavior is governed by bearing failure of the shear tab, while the compressive behavior is governed by bolt shear failure.

Table 3-2. Parameters of axial load-deformation relationships for springs representing single bolt rows of prototype connections

\begin{tabular}{|c|c|c|c|}
\hline \multirow[b]{2}{*}{ Property } & \multicolumn{3}{|c|}{ Connection Location } \\
\hline & $\begin{array}{l}\text { Building A } \\
\text { E-W beams }\end{array}$ & $\begin{array}{c}\text { Buildings A \& B } \\
\text { N-S beams }\end{array}$ & $\begin{array}{l}\text { Building B } \\
\text { E-W beams }\end{array}$ \\
\hline Number of bolts, $N$ & 3 & 3 & 4 \\
\hline Beam web thickness, mm (in) & $5.8(0.23)$ & $6.4(0.25)$ & $9.7(0.38)$ \\
\hline Initial stiffness, $k, \mathrm{kN} / \mathrm{mm}$ (kip/in) & $110(620)$ & $110(620)$ & $370(2120)$ \\
\hline Displacement at ultimate load, $\delta_{u}$, mm (in) & $11.4(0.45)$ & $11.4(0.45)$ & $15.7(0.62)$ \\
\hline Controlling limit state in tension & bearing, beam web & bearing, beam web & bearing, shear tab \\
\hline Yield capacity in tension, $t_{y}, \mathrm{kN}$ (kip) & 79 (17.8) & $86(19.3)$ & $92.9(20.9)$ \\
\hline Ultimate capacity in tension, $t_{u}$, $\mathrm{kN}$ (kip) & $103(23.1)$ & $112(25.1)$ & $150(33.6)$ \\
\hline Failure displacement in tension, $\delta_{f, t}, \mathrm{~mm}$ (in) & $38.1(1.5)$ & $38.1(1.5)$ & $38.1(1.5)$ \\
\hline Controlling limit state in compression & bearing, beam web & bearing, beam web & bolt shear \\
\hline Yield capacity in compression, $c_{y}, \mathrm{kN}$ (kip) & $134(30.2)$ & $146(32.8)$ & $150(33.8)$ \\
\hline Ultimate capacity in compression, $c_{u}$, kN (kip) & $175(39.2)$ & $190(42.7)$ & $201(45.1)$ \\
\hline Failure displacement in compression, $\delta_{f, c}, \mathrm{~mm}$ (in) & none & none & $18.1(0.71)$ \\
\hline
\end{tabular}

The vertical shear behavior of each bolt spring is represented using the load-deformation curve illustrated in Figure 3-15, which is symmetric for upward (positive) and downward (negative) displacement of the beam. The yield and ultimate capacities of each spring ( $v_{y}$ and $v_{u}$, respectively) are obtained by dividing the vertical yield and ultimate capacities of the connection, calculated using equations in the AISC Specification (AISC 2010) with $\phi=1$, by the number of bolts. While other failure modes may potentially govern, such as fillet weld failure (AISC 2010, Section J2.4), block shear failure (AISC 2010, Section J4.3), or bolt shear failure (AISC 2010, Section J3.6), the governing failure modes for the shear tab connections in the prototype buildings are shear yielding of the gross section of the shear tab for $v_{y}$ (AISC 2010, Eq. J4-3) and shear rupture of the net section of the shear tab for $v_{u}$ (AISC 2010, Eq. J4-4).

The initial stiffness $k$ and the displacement at the ultimate load, $\delta_{u}$, are assumed to be the same in the vertical and axial directions, given by Eqs. (3.2) and (3.4), respectively. While these parameters were developed to represent the axial and bending response of the connections, they are applied to the vertical shear response as well, in the absence of empirical equations comparable to Eqs. (3.1) to (3.4) for shear stiffness and deformation capacity. The deformation capacities in the two directions certainly may differ, particularly if the failure modes are different. Detailed model simulations for the N-S beam connections in buildings $\mathrm{A}$ and $\mathrm{B}$ have shown that the deformation at ultimate load is about $50 \%$ larger in the vertical 
direction than in the axial direction. However, the overall structural response in column removal scenarios is much less sensitive to vertical shear deformations of the connections than to axial and bending deformations, which relate directly to the development of catenary action. The vertical shear capacity is represented correctly in the reduced model, and any discrepancies in the modeling of vertical shear deformations are not expected to significantly affect the structural response. The failure displacement in vertical shear $\left(\delta_{f, v}\right)$ is set equal to $1.15 \delta_{u}$, as for axial failure governed by bolt shear in Figure 3-13(b). While some failure modes (e.g., bearing and tearout) could result in a more gradual drop in resistance, a rapid drop after the ultimate load is conservatively assumed for the vertical shear response.

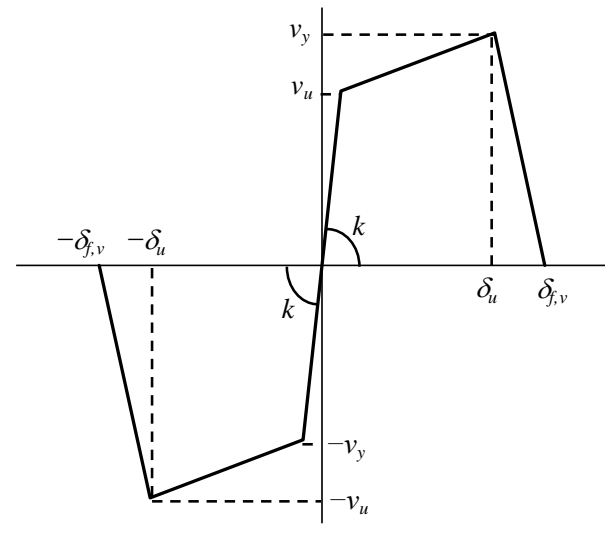

Figure 3-15. Vertical shear load-deformation relationship for bolt springs

Interaction of the axial and vertical failure modes is handled by deleting the bolt spring from the model if the following inequality is satisfied:

$$
\left(\frac{\delta_{i}}{\delta_{f, t}}\right)^{2}+\left(\frac{\delta_{v, i}}{\delta_{f, v}}\right)^{2} \geq 1
$$

where $\delta_{i}$ denotes the axial deformation and $\delta_{v, i}$ denotes the shear deformation of the $i$ th bolt spring element. If axial failure in compression is permitted, then a corresponding inequality is also considered for compression, in which $\delta_{f, t}$ is replaced by $\delta_{f, c}$. Failure of the connection is represented in the reduced model by successive failure of each bolt spring element.

\subsubsection{Comparison with detailed modeling of axial extension}

Predictions of the detailed and reduced connection models are first compared under the simple case of axial extension. Detailed models of shear tab connections from the prototype buildings are shown in Figure 3-16, with bolts hidden to reveal bearing-induced bolt hole deformations at the ultimate tensile load. Figure 3-16(a) corresponds to a N-S beam connection in buildings A and B, and Figure 3-16(b) corresponds to an E-W beam connection in building B. Beam segments of length $143 \mathrm{~mm}$ (5.6 in) were considered in both cases, and all nodes on the cross section at the end of the segment were subjected to displacement-controlled translation along the beam axis. The failure modes observed in the detailed models were consistent with calculations based on the AISC specification (see Table 3-2): the detailed model of the N-S connection in buildings A and B, with a beam web thickness of $6.4 \mathrm{~mm}(0.25 \mathrm{in})$, exhibited bearing failure of the beam web, while the $\mathrm{E}-\mathrm{W}$ connection in building $\mathrm{B}$, with a beam web thickness of $9.7 \mathrm{~mm}$ (0.38 in), exhibited bearing failure of the shear tab connection. 




(a)



(b)

Figure 3-16 Detailed models of prototype connections under axial tension showing deformations at ultimate tensile load (bolts hidden): (a) N-S connection in buildings A and B; (b) E-W connection in building B

Figure 3-17 shows a comparison of axial load-displacement relationships predicted by the reduced model with corresponding curves obtained computationally from the detailed models shown in Figure 3-16. Figure 3-17(a) corresponds to the N-S beam connection in buildings A and B, while Figure 3-17(b) corresponds to the E-W beam connection in building B. The reduced model curves in Figure 3-17 were calculated as described in Section 3.2.1, with the load values for a single bolt row multiplied by the number of bolts to obtain the total axial resistance of the connection. The detailed model curves in Figure 3-17 show no resistance until bolt bearing is engaged at a displacement of $1.6 \mathrm{~mm}(1 / 16 \mathrm{in})$, because standard bolt holes are considered in the model, with a hole diameter $1.6 \mathrm{~mm}(1 / 16$ in) larger than the bolt diameter, and because zero initial tension in the bolts is assumed, resulting in no frictional resistance initially.
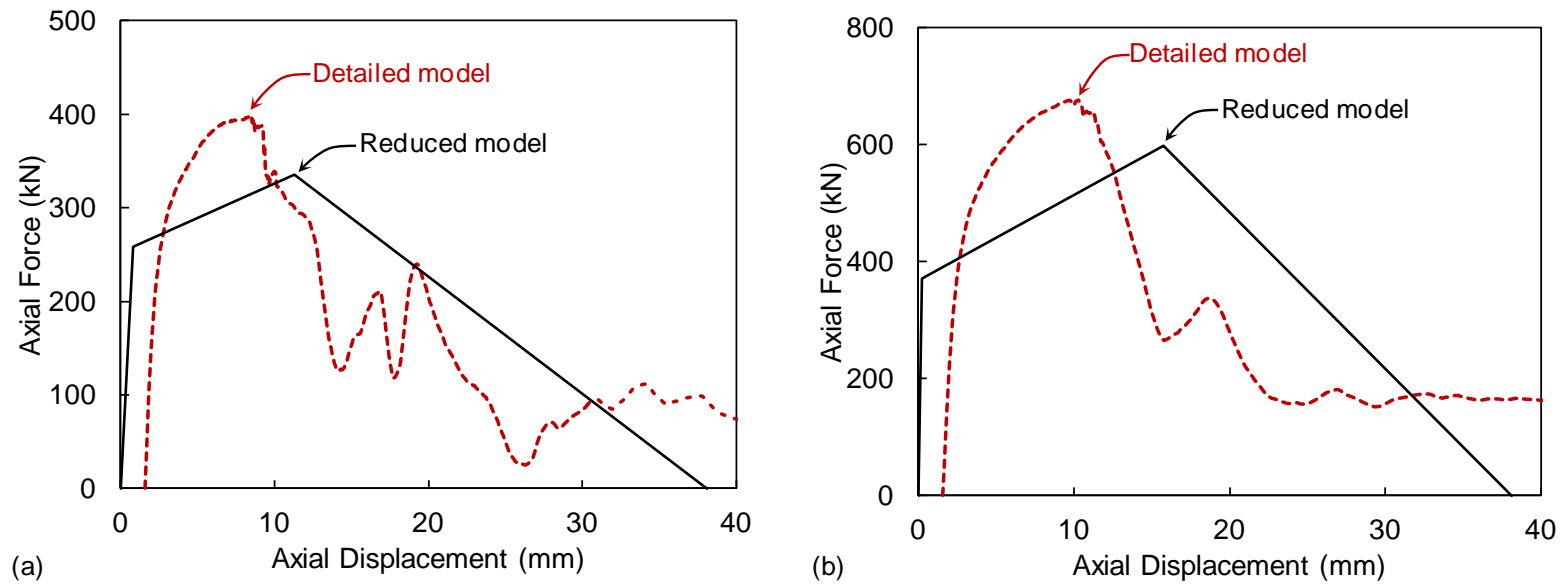

Figure 3-17 Comparison of reduced and detailed model results for tensile behavior of a single bolt row: (a) N-S beam connection in buildings A and B; (b) E-W beam connection in building $\mathrm{B}$.

The ultimate tensile capacity computed from the detailed model exceeds the tensile capacity from the reduced model by 19 \% in Figure 3-17(a) and by $13 \%$ in Figure 3-17(b). As discussed in Section 3.2.1, the capacity calculations in the reduced modeling approach are based on equations from the AISC specification (AISC 2010), and this comparison indicates that these capacities are somewhat conservative relative to the detailed model computations. However, the displacements at ultimate load computed from the detailed models are less than the values predicted by the reduced model, being $25 \%$ less in Figure 3- 
17(a) and $38 \%$ less in Figure 3-17(b). It is noted that the stress-strain curves used in the detailed models for the A36 steel shear tab and the A992 steel beam web are based on minimum specified values of elongation at fracture (see Figure 3-7), while steel components used in practice typically exhibit larger elongations than these minimum values. Detailed models based on a more typical elongation of $25 \%$ at fracture (not presented herein) yield displacements at the ultimate load that are more consistent with the reduced models. These observations suggest that the reduced model approximation in Eq. (3.4) for the displacement at ultimate load $\delta_{u}$ may be a good estimate for typical material properties but may not always be conservative.

\subsection{MODELING OF TWO-SPAN BEAM ASSEMBLY TESTS}

Thompson (2009) tested two-span beam assemblies in the configuration illustrated in Figure 3-18, with shear tab connections to the center column, exterior "true pin" connections at beam mid-height, and concentrated loading applied to the unsupported center column. A fairly short beam with a chord length ${ }^{4}$ of $L=1.89 \mathrm{~m}(6.21 \mathrm{ft})$ was used in these tests, and three different connection sizes were considered, having three bolts, four bolts, and five bolts per shear tab. Three tests were conducted for each connection size for a total of nine tests.

The same beams were used in all nine tests, with doubler plates welded to the beam webs in the connection regions to prevent bearing-induced deformations around the bolt holes in the beam web. At the exterior pin connections, $9.5 \mathrm{~mm} \mathrm{(3/8}$ in) A36 steel doubler plates were welded to each side of the beam web, and at the shear tab connections, one $9.5 \mathrm{~mm} \mathrm{(} 3 / 8$ in) A36 steel doubler plate was welded to the side opposite the shear tab. Threads were excluded from the shear plane for both the $32 \mathrm{~mm}\left(1 \frac{1}{4} \mathrm{in}\right)$ A490 bolts at the exterior pin connections and the $19 \mathrm{~mm}\left(\frac{3}{4} \mathrm{in}\right)$ A325 bolts in the shear tab connections. Two A36 steel shear plates at each exterior pin connection placed the A490 bolts into double shear. These plates, shown with fixed edges in Figure 3-18, were welded to an end plate, which was in turn bolted to a rigid test frame. The thickness of the shear tabs at the center column was $9.5 \mathrm{~mm}(3 / 8$ in), the horizontal distance from the centerline of the bolts to the edge of the shear tab was $38.1 \mathrm{~mm}(1.5 \mathrm{in})$, and the depth of the shear tabs was $229 \mathrm{~mm}$ (9 in) for the 3-bolt connection, $305 \mathrm{~mm}$ (12 in) for the 4-bolt connection, and $381 \mathrm{~mm}$ (15 in) for the 5-bolt connection.

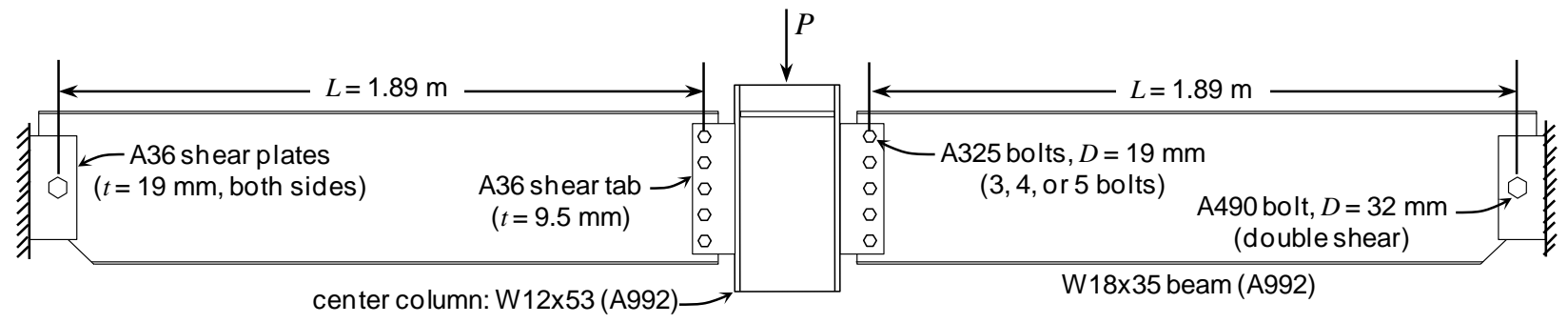

Figure 3-18. Configuration of two-span beam assemblies tested by Thompson (2009)

\subsubsection{Detailed modeling}

Figure 3-19 shows a detailed model of the assembly with 5 bolts per shear connection, in which only half of the assembly was modeled, with appropriate boundary conditions on the plane of symmetry through the center column. Modeling of the connection regions, including the center column, shear tab, beam,

\footnotetext{
${ }^{4}$ Note that the "chord length" of a beam, denoted $L$, is used throughout this report to represent the horizontal distance between the bolt centerlines at each end of the beam. This is in contrast with the "span length," which is measured between the centerlines of the columns.
} 
doubler plates, and bolts, followed the detailed modeling approach described in Section 3.1, using solid element meshes and contact with friction. The beam span between connections, where stresses remain in the elastic range, was modeled using shell elements, with nodal constraints linking the degrees of freedom of the solid and shell elements at their interface, indicated in Figure 3-19. Similar models were developed for the 3-bolt and 4-bolt assemblies.

Because tensile test data were not provided for the steel components used in these tests, representative stress-strain curves and failure strain values were used for the various types of steel, calibrated as described previously in Section 3.1.1. Stress-strain curves used for the A325 and A490 bolts were shown previously in Figure 3-3, for the A36 steel shear tabs in Figure 3-5, and for the A992 steel beams and columns in Figure 3-7.

The test specimens used standard hole sizes for all bolts, for which the hole diameter is $1.6 \mathrm{~mm}(1 / 16$ in) larger than the bolt diameter. This gap was represented accurately in the solid element mesh, with the bolts initially centered in the holes, allowing some slippage before bolt bearing is engaged. Zero initial tension in the bolts is assumed, resulting in no frictional resistance initially.
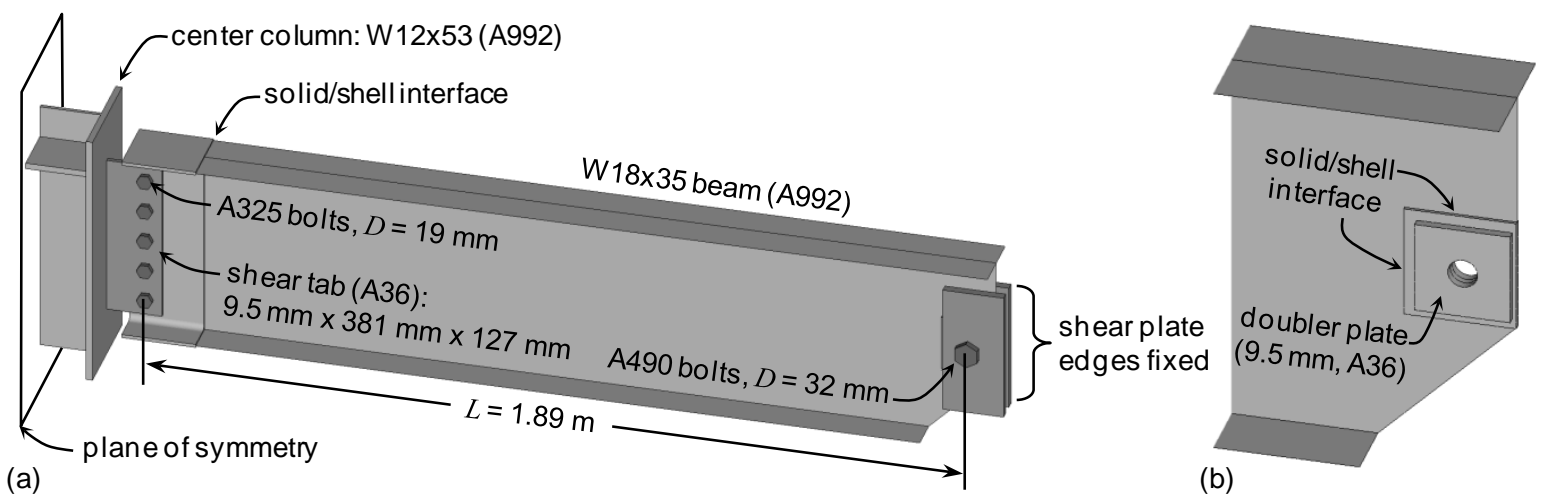

Figure 3-19. Detailed model of two-span beam assembly tested by Thompson (2009): (a) overview; (b) region near exterior pin connection

\subsubsection{Reduced modeling}

Figure 3-20(a) shows a reduced model of the assembly with 5 bolts per shear connection, which follows the modeling approach outlined in Section 3.2, using beam elements for the beams and columns, nonlinear springs for each bolt row of the shear connection, and rigid links to maintain proper connection geometry. As with the detailed model, only half of the assembly was modeled, with appropriate boundary conditions on the plane of symmetry. Similar models were developed for the 3-bolt and 4-bolt assemblies.

Load-deformation relationships used to represent the bolt springs in the reduced model are shown in Figure 3-20(b). These load-deformation relationships were developed as described in Section 3.2.1, except for the initial flat portion of the curves, which has zero load until a deformation of $1.6 \mathrm{~mm}(1 / 16$ in) in both tension and compression. This flat portion was intended to represent the initial gaps between the bolt shank and the standard size bolt holes, which allow some slippage to occur before bolt bearing is engaged. Including this initial gap is consistent with the detailed model described previously and yields better agreement with the experimental data (see Section 3.3.3) than if the gap is neglected. Initial gaps were included only in the axial load-deformation relationship for the bolt springs, not in the vertical shear load-deformation relationship. Following the initial flat portion, the load increases with stiffness $k$ from Eq. (3.2) and, after yielding, reaches the ultimate load at a deformation of $\delta_{u}$ from Eq. (3.4). The loaddeformation relationships differ depending on the number of bolts in the connection, since both $k$ and $\delta_{u}$ depend on $d_{b}$, the depth of the bolt group, according to Eqs. (3.2) and (3.4) (see Figure 3-14). A "gap 
element” was also introduced at the exterior pin support, which allows slippage of $1.6 \mathrm{~mm}(1 / 16$ in) before forces are developed, representing initial gaps at the bolt holes for the exterior pin connection.

The yield and ultimate capacities of the bolt springs were calculated using equations in Table 3-1, which do not depend on the number of bolts in the connection. The ultimate capacity was found to be governed by bolt shear failure in both tension and compression and was calculated as $147 \mathrm{kN}$ (33.1 kip). Because bolt shear failure was found to govern, the failure displacements in both tension and compression were set to $1.15 \delta_{u}$. While the calculations indicated that bolt shear failure would govern, it is noted that the ultimate bearing capacity of the shear tab in tension was calculated as $159 \mathrm{kN}$ (35.7 kip), which is only $8 \%$ larger than the bolt shear capacity. This helps to explain why the failure mode differed from test to test, as is discussed subsequently. The yield capacity in compression was calculated as $111 \mathrm{kN}$ (24.9 kip), corresponding to yielding of the bolt in shear, while an $11 \%$ smaller yield capacity $98.5 \mathrm{kN}$ (22.1 kip) in tension was calculated, corresponding to bearing-induced yielding at the bolt hole in the shear tab.

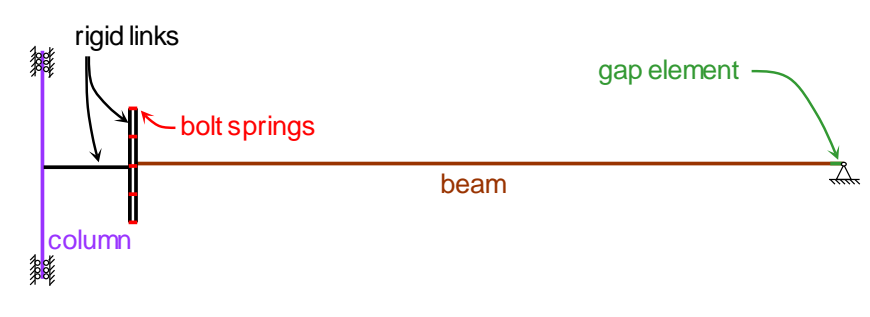

(a)

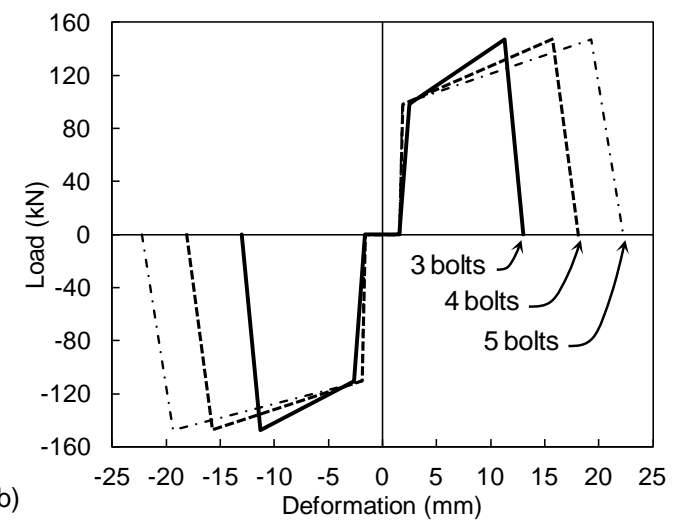

Figure 3-20. (a) Reduced model of two-span beam assembly tested by Thompson (2009); (b) load-displacement curves used for bolt springs

\subsubsection{Comparison of experimental and computational results}

Figure 3-21 shows comparisons of experimental measurements with detailed and reduced model computations of (a) the vertical load $P$ and (b) the beam axial force $T$ versus the vertical displacement of the center column for the two-span beam assemblies. The measured axial force $T$ is an average of the axial forces measured in the two beam spans. Each row of plots in Figure 3-21 corresponds to a different connection size, and results are presented for 3-bolt, 4-bolt, and 5-bolt connections. Three tests were conducted for each connection size, and the numerical labels on curves in Figure 3-21 indicate the test number for a given connection size. Measurements from test 1 for the 5-bolt connection are not presented because data from the initial portion of this test were missing due to a problem with the test setup.

Figure 3-21 shows fairly good correspondence between the computational results and the experimental measurements, given the variability in the experimental data. Quantitative comparisons of the computed and measured values of the ultimate vertical load $P_{u}$ are presented in Table 3-3, which shows that the detailed model predictions are within $15 \%$ of the mean measured values and the reduced model predictions are within $21 \%$, while the coefficient of variation in the measured values is as large as $20 \%$. This indicates that the deviations of the model predictions from the experimental measurements are comparable to the variability in the experimental measurements themselves. The detailed models consistently underestimate $P_{u}$, which is conservative, while the reduced model overestimates $P_{u}$ in one case by $10.6 \%$.

Table 3-4 shows similar comparisons of the rotation at the ultimate load, $\theta_{u}$, in which somewhat larger discrepancies are observed, with the computed results always being conservative. Note that the measured 
rotation values in Table 3-4, as well as those along the upper axes in Figure 3-21, are about 5 \% larger than the values reported by Thompson (2009). This is because the rotations in this study were calculated using the span length of $L=1.89 \mathrm{~m}(6.21 \mathrm{ft})$ between bolt centerlines, as illustrated in Figure 3-18, while


center column. The span length between bolt centerlines was used in this study for consistency with analytical models presented subsequently in Sections 3.4 and 3.6.

Both the detailed and reduced models were able to capture the following primary stages in the response of the assemblies: (1) connection slippage, in which both the vertical load and the beam axial forces remain small before bolt bearing is engaged, (2) flexural action, in which the vertical load increases due to the development of bending moments in the shear tab connections, while the axial forces remain small, and (3) catenary action, in which tensile forces develop in the beams, accompanied by further increases in the vertical load until failure occurs.

The detailed model computations showed that plastic deformations were concentrated in the bolts and in bearing-induced deformations around the bolt holes, as evidenced by the substantial shear deformation of the bottom bolt shown in Figure 3-22(b) and the significant elongation of bolt holes in the shear tabs shown in Figure 3-23. (Note that the same beams were used in all tests by Thompson (2009), and therefore, five bolt holes in the beam web are evident in Figure 3-23 even for the tests with fewer bolts.) The remainder of the beam remained in the elastic range, essentially rotating as a rigid body, as evidenced by the straight-line deflected shape of the 4-bolt assembly at ultimate load, shown in Figure 3-22(a). While the failure mode predicted by the detailed and reduced models was bolt shear fracture in all cases [the onset of bolt fracture is evidenced by eroded elements in Figure 3-22(b)], the failure mode varied from test to test in the experiments, being bolt shear failure in some cases, tensile rupture of the shear tab in other cases, and block shear failure of the shear tab in still other cases. The closeness of the calculated capacities for bolt shear failure and plate bearing failure helps to explain this observed variability in the failure mode, since typical variations in material strength could shift the failure from one component to another.

In all cases, the failures were characterized by a fairly steep drop in resistance after the ultimate load, which was captured by the detailed and reduced models. In the 4-bolt and 5-bolt assembly tests, successive failures were observed, in which the resistance increased after an initial failure until a secondary failure occurred. These successive failures were captured by both the detailed and reduced models, for which the peak computed vertical load $P_{u}$ always corresponded to the initial failure. In the experiments, two cases were observed in which the peak load corresponded to a secondary failure rather than the initial failure (test 1 for the 4-bolt assembly and test 3 for the 5-bolt assembly).

It is noted that the correspondence between the computational results and the experimental measurements in Figure 3-21 is generally better for the vertical load $P$ than for the beam axial force $T$. The beam axial forces are more sensitive than the vertical load to axial restraint conditions, including such factors as the initial gaps in the connections. Daneshvar and Driver (2011) compared detailed model predictions with experimental measurements from the 3-bolt assembly tested by Thompson (2009) and found that improved agreement could be achieved by introducing axial springs at the exterior pin connections to represent the unknown stiffness of the testing frame. These axial springs reduced the magnitude of an initial compressive axial force that was observed in the models but not in the tests. In this study, it was found that introducing initial gaps at both the shear tab and exterior pin connections, to represent the actual dimensions of standard size bolt holes, reduced the initial compressive axial forces without the need for axial springs.

In the reduced modeling approach, the unloading procedure used in the case of load reversal was also found to have a noticeable effect on the beam axial forces. In the initial flexural response of the assembly, yielding of the upper bolt springs in compression was observed. Later in the response, as catenary action developed, the forces in the upper bolt springs changed from compression to tension. Two unloading 
procedures were considered in the reduced modeling: (1) linear unloading with the initial stiffness $k$ and (2) quadratic unloading with no permanent offset. The latter approach was found to give somewhat better agreement with the experimental measurements and was adopted in the simulations presented herein.
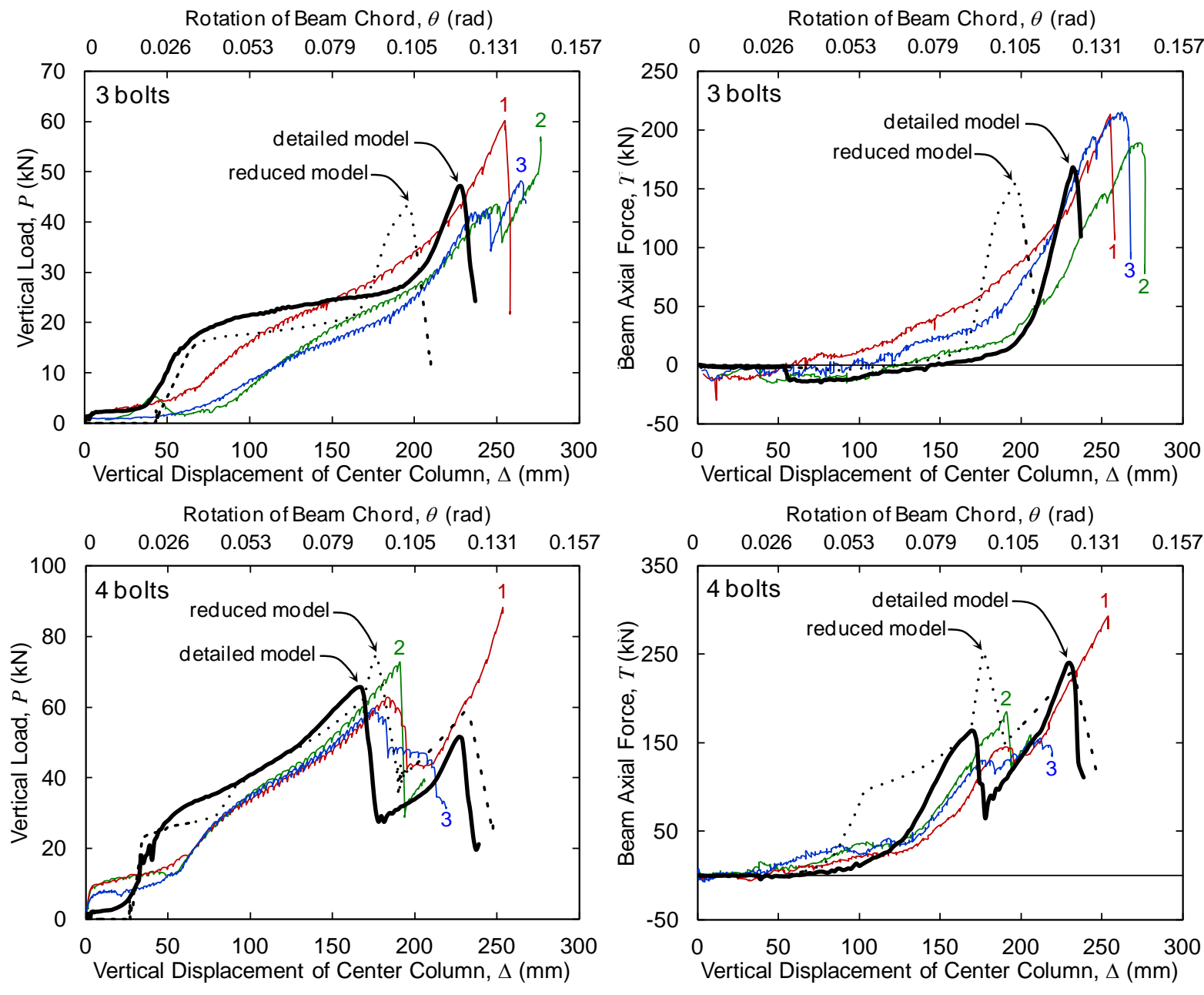

Rotation of Beam Chord, $\theta$ (rad)
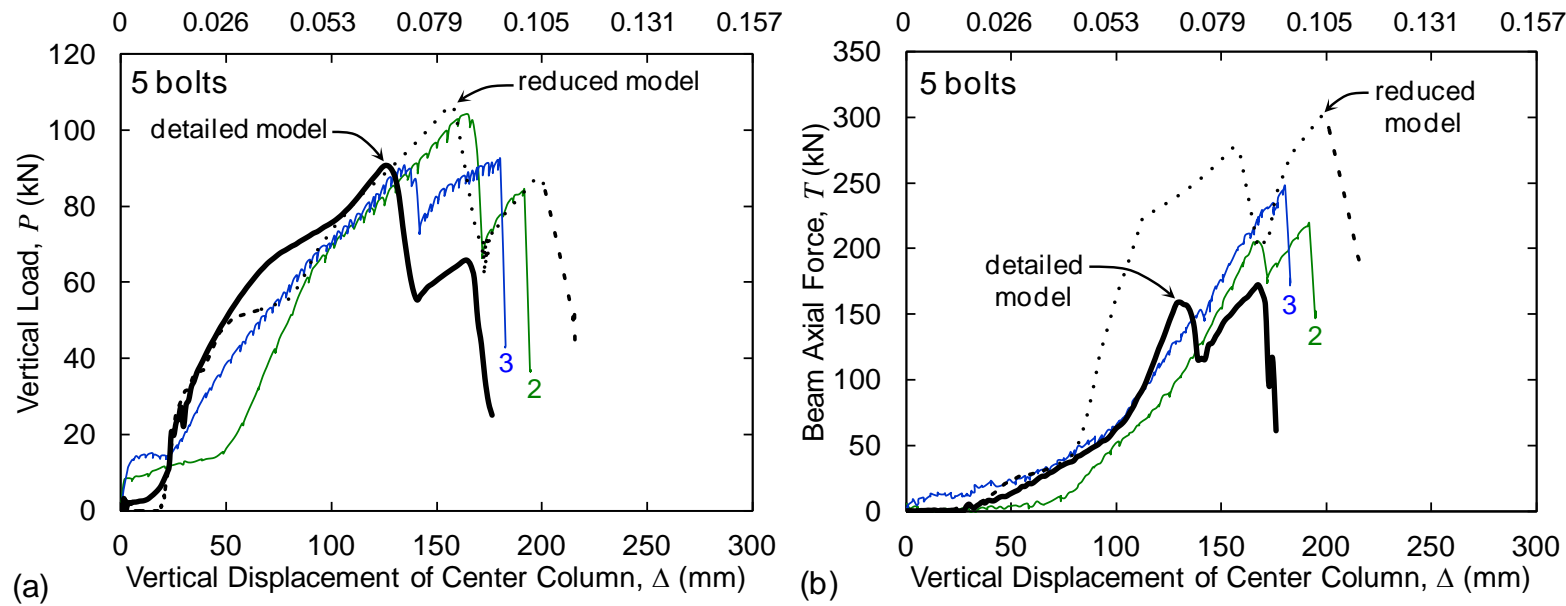

Figure 3-21. Comparison of detailed and reduced model results with experimental measurements (Thompson 2009) for two-span beam assemblies: (a) vertical load and (b) axial force versus vertical column displacement (numerical labels on curves indicate the test number for a given connection size) 
Table 3-3. Comparison of model predictions and experimental measurements (Thompson 2009) of ultimate vertical load $P_{u}$ for two-span beam assemblies

\begin{tabular}{lcccccc}
\hline & \multicolumn{2}{c}{ Detailed Model } & \multicolumn{2}{c}{ Reduced Model } & \multicolumn{2}{c}{ Experiment } \\
\cline { 2 - 7 } Connection Size & $P_{u}$ & {$[$ [Deviation*] } & $P_{u}$ & {$[$ Deviation*] } & Mean $P_{u}$ & {$\left[\mathrm{COV}^{\dagger}\right]$} \\
\hline 3 bolts & $47.1 \mathrm{kN}$ & {$[-14.6 \%]$} & $43.4 \mathrm{kN}$ & {$[-21.3 \%]$} & $55.1 \mathrm{kN}$ & {$[11.3 \%]$} \\
4 bolts & $65.7 \mathrm{kN}$ & {$[-10.6 \%]$} & $74.8 \mathrm{kN}$ & {$[+1.8 \%]$} & $73.5 \mathrm{kN}$ & {$[19.5 \%]$} \\
5 bolts & $90.7 \mathrm{kN}$ & {$[-5.8 \%]$} & $106.6 \mathrm{kN}$ & {$[+10.6 \%]$} & $96.4 \mathrm{kN}$ & {$[7.1 \%]$} \\
\hline
\end{tabular}

* Percentage deviation from mean experimental value

${ }^{\dagger}$ Coefficient of Variation $=[$ standard deviation $] /[$ mean $]$

Table 3-4. Comparison of model predictions and experimental measurements (Thompson 2009) of rotation at ultimate load, $\theta_{u}$, for two-span beam assemblies

\begin{tabular}{lcccccc}
\hline \multirow{2}{*}{ Connection Size } & \multicolumn{2}{c}{ Detailed Model } & \multicolumn{2}{c}{ Reduced Model } & \multicolumn{2}{c}{ Experiment } \\
\cline { 2 - 7 } & $\theta_{u}$ & {$[$ Deviation*] } & $\theta_{u}$ & {$[$ Deviation*] } & Mean $\theta_{u}$ & {$\left[\mathrm{COV}^{\dagger}\right]$} \\
\hline 3 bolts & $0.120 \mathrm{rad}$ & {$[-13.8 \%]$} & $0.103 \mathrm{rad}$ & {$[-26.1 \%]$} & $0.139 \mathrm{rad}$ & {$[3.4 \%]$} \\
4 bolts & $0.087 \mathrm{rad}$ & {$[-21.5 \%]$} & $0.093 \mathrm{rad}$ & {$[-16.6 \%]$} & $0.111 \mathrm{rad}$ & {$[18.8 \%]$} \\
5 bolts & $0.066 \mathrm{rad}$ & {$[-24.3 \%]$} & $0.082 \mathrm{rad}$ & {$[-5.6 \%]$} & $0.087 \mathrm{rad}$ & {$[9.6 \%]$} \\
\hline
\end{tabular}

* Percentage deviation from mean experimental value

${ }^{\dagger}$ Coefficient of Variation $=[$ standard deviation $] /[$ mean $]$

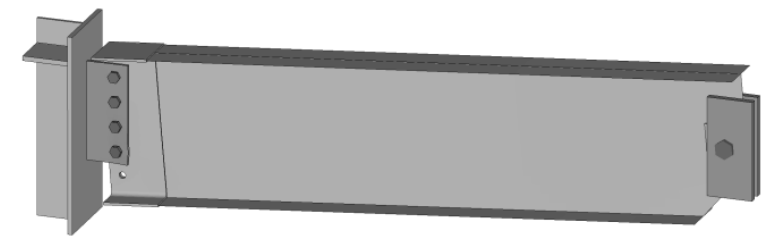

(a)

(b)

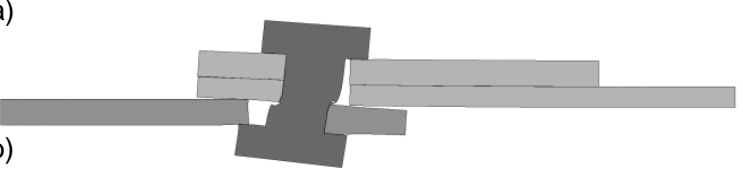

Figure 3-22. Deformations of 4-bolt assembly at ultimate load: (a) overview; (b) section view through bottom bolt
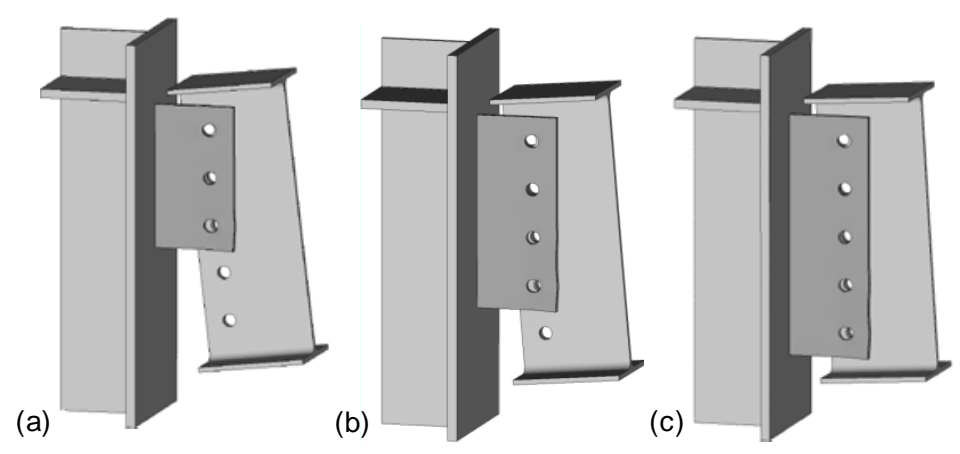

Figure 3-23. Connection regions of detailed models at ultimate load: (a) 3 bolts; (b) 4 bolts; (c) 5 bolts (bolts hidden to show bearing-induced elongation of bolt holes in shear tabs) 


\subsection{SIMPLIFIED SPREADSHEET CALCULATIONS}

A simple but fairly accurate calculation procedure for the load-deformation response of two-span beam assemblies can be developed based on the assumption that all of the deformation is concentrated in the connections, while the beam spans rotate as rigid bodies with negligible bending or axial deformations. This is consistent with the behavior illustrated in Figure 3-22 and Figure 3-23 for detailed models of the two-span beam assemblies tested by Thompson (2009). This simplified analysis affords insight into the mechanics of the shear connection behavior and allows calculations to be performed in a spreadsheet. It is noted that this analysis procedure is not limited to shear tab connections, but could also be applied to other types of connections, such as double angle connections, for which a load-deformation relationship for each bolt row can be defined. Initially, in Section 3.4.1, the outer ends of the beams are assumed to be pin supported, while in Section 3.4.2 the influence of having two shear connections per span is considered.

\subsubsection{Two-span beam assembly with exterior pin supports}

Two beam spans connected to an unsupported center column by shear tab connections are considered, as depicted in Figure 3-24(a). The outer ends of the beams are assumed to be pin supported, with the elevation of the pin supports corresponding to mid-height of the shear tab connections. Two loading scenarios are considered, including a concentrated load $P$ on the center column (Figure 3-24(b)) and a uniform load with intensity $w$ distributed along the beam spans (Figure 3-24(c)). Equilibrium of vertical forces in both cases yields the following expression for the total applied vertical load:

$$
\left.\begin{array}{lr}
\text { concentrated load: } \quad P \\
\text { uniform load: } \quad 2 w L
\end{array}\right\}=2(T \sin \theta+V \cos \theta)
$$

where $T$ is the axial force and $V$ is the shear force in the beams at the pin supports. The rotation of the beam chord, $\theta$, (in rad) is given by

$$
\theta=\tan ^{-1}(\Delta / L)
$$

where $\Delta$ is the vertical displacement of the center column and $L$ is the chord length of the beam, or the distance between the centerlines of the bolts at one end of the beam and the pin support at the other, as shown in Figure 3-25(a). Based on the geometry shown in Figure 3-25(a), the axial extension of the connection at mid-height of the bolt group, denoted $\delta$, can be expressed as

$$
\delta=\sqrt{L^{2}+\Delta^{2}}-L
$$

The axial extension of the ith bolt row of the connection, denoted $\delta_{\mathrm{i}}$, can then be calculated as:

$$
\delta_{i}=\delta+\frac{\Delta}{L} y_{i}
$$

where $y_{i}$ is the distance of the ith bolt row from mid-height of the bolt group, positive downwards for convenience, as shown in Figure 3-25(b). Note that $\delta_{2}=\delta$ for the connection shown in Figure 3-25, because $y_{2}=0$. The axial component of the force in each bolt row, denoted $t_{i}$, can then be calculated as a function of the axial extension $\delta_{i}$, as $t_{i}=f\left(\delta_{i}\right)$, where the function $f\left(\delta_{i}\right)$ represents the axial load vs. deformation relationship for a single bolt row of the shear tab connection, described in Section 3.2.1 for the reduced model of the connection. Positive values of $t_{i}$ correspond to tension in the bolt row, where it is noted that tension in the bolt row produces shear in the bolt itself. 
(a)
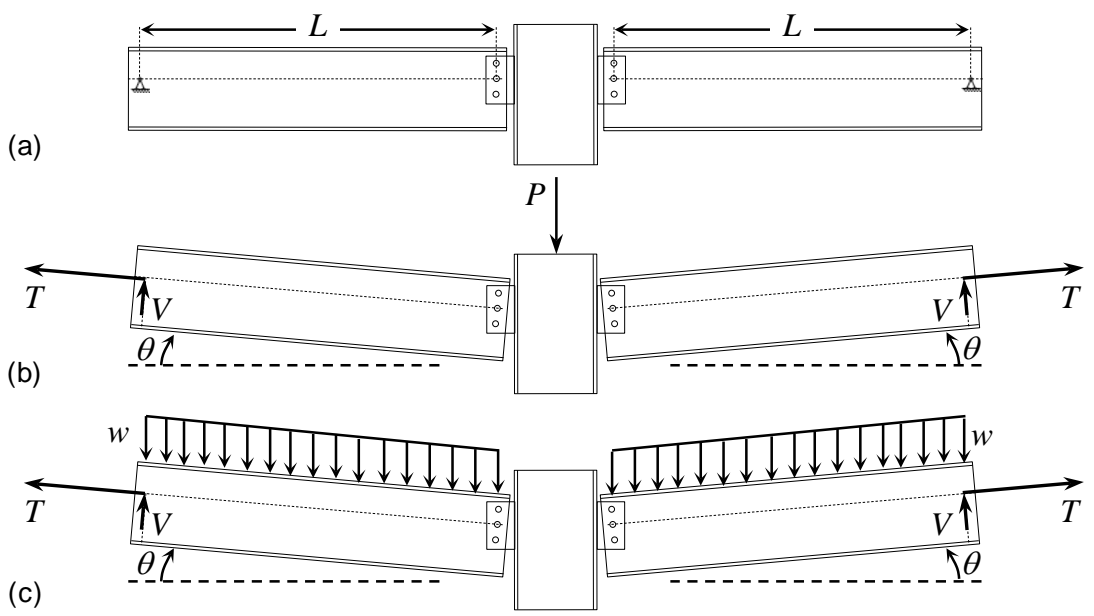

Figure 3-24. (a) Two-span beam assembly with exterior pin supports; (b) concentrated load; (c) uniform load
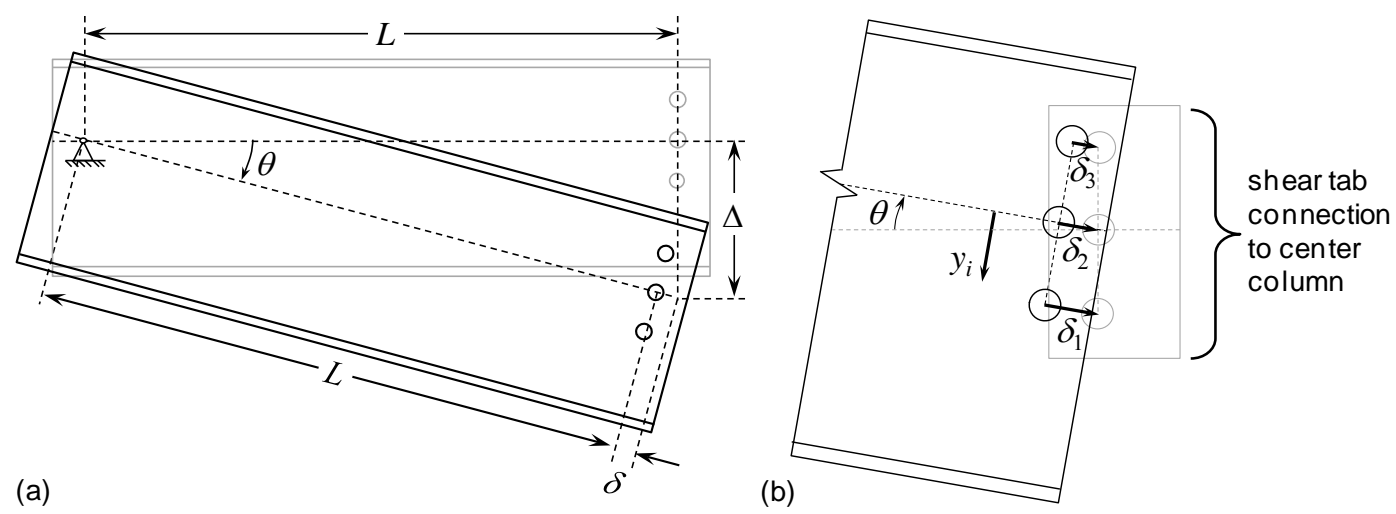

Figure 3-25. Deformed geometry of beam span with exterior pin support: (a) overview; (b) near shear tab connection to center column

Considering a free-body diagram of a single beam span, as shown in Figure 3-26, equilibrium of forces along the beam axis yields the following expressions for the axial force $T$ at the pin support:

$$
T=\left\{\begin{array}{lr}
\sum_{i}^{N} t_{i} & \text { (concentrated load) } \\
w L \sin \theta+\sum_{i}^{N} t_{i} & \text { (uniform load) }
\end{array}\right.
$$

where $N$ is the number of bolts in the shear tab connection. Equilibrium of moments about the center of the bolt group yields the following expressions for the shear force $V$ at the pin support:

$$
V=\left\{\begin{array}{lr}
\sum_{i}^{N} \frac{t_{i} y_{i}}{L} & \text { (concentrated load) } \\
\frac{w L}{2} \cos \theta+\sum_{i}^{N} \frac{t_{i} y_{i}}{L} & \text { (uniform load) }
\end{array}\right.
$$


where the bending moment in the shear tab connection, calculated about the center of the bolt group, can be expressed as follows:

$$
M_{t a b}=\sum_{i}^{N} t_{i} y_{i}
$$

Substituting Eqs. (3.10) and (3.11) into Eq. (3.6) and grouping terms on $w L$ for the case of the uniform load yields the following expressions for the total applied load:

$$
\begin{aligned}
& \text { concentrated load: } \quad P=2\left(\sum_{i}^{N} t_{i} \sin \theta+\sum_{i}^{N} \frac{t_{i} y_{i}}{L} \cos \theta\right) \\
& \text { uniform load: } \quad 2 w L=\frac{4}{\cos ^{2} \theta}\left(\sum_{i}^{N} t_{i} \sin \theta+\sum_{i}^{N} \frac{t_{i} y_{i}}{L} \cos \theta\right)
\end{aligned}
$$



Figure 3-26. Free body diagram of beam

The preceding equations can be easily implemented in a spreadsheet as follows:

1. Define a column of values of the center column displacement $\Delta$ spanning from zero to the maximum displacement of interest.

2. Calculate a column of values of the beam chord rotation, $\theta$, from Eq. (3.7).

3. Calculate a column of values of axial extension at mid-height of the bolt group, $\delta$, from Eq. (3.8).

4. Calculate columns of values of axial extension of each bolt row, $\delta_{i}$, from Eq. (3.9).

5. Calculate columns of values of axial force in each bolt row, $t_{i}$, based on the axial loaddeformation relationship of the bolt row. Piecewise-linear load-deformation relationships, such as those illustrated in Figure 3-13, can be implemented using conditional formulas.

6. Calculate a column of values of the concentrated load $P$ from Eq. (3.13) or the uniform load $w$ from Eq. (3.14).

A load-displacement curve for the two-span beam assembly can then be generated by plotting the values of $P$ or $w$ from step 6 against the values of $\Delta$ from step 1. Plots of $T, V$, and $M_{\text {tab }}$ against $\Delta$ can be generated similarly using Eqs. (3.10), (3.11), and (3.12). Figure 3-27 shows examples of such plots, 
calculated for a chord length of $L=5.97 \mathrm{~m}(19.6 \mathrm{ft})$, corresponding to a N-S beam from building A, using a bolt force-deformation relationship of the form illustrated in Figure 3-13(a) with the parameters listed in Table 3-2 for N-S beam connections.

Since $\cos ^{2} \theta \approx 1$ for small angles, it is noted that the right-hand side of Eq. (3.14) is approximately two times larger than the right-hand side of Eq. (3.13). This indicates that for a given center column displacement $\Delta$, the total applied load that can be sustained in the case of a uniform load is approximately twice the load that can be sustained in the case of a concentrated load. This is illustrated in Figure 327(a), in which $P$ from Eq. (3.13) and $w L$, which is half of the applied load from Eq. (3.14), are plotted together against the vertical column displacement $\Delta$ and are seen to be virtually equivalent.

The additional load capacity in the case of a uniform load is due to the fact that approximately half of the applied load is transferred directly to the pin supports by shear in the beams, as indicated by the term ( $w L / 2) \cos \theta$ in Eq. (3.11). Figure 3-27(b) shows the shear force $V$ at the pin support plotted against the vertical column displacement $\Delta$ for both concentrated and uniform loads. In the case of a concentrated load, the shear force $V$ is relatively small, and a fairly good approximation for $P$ can be obtained by neglecting $V$, in which case Eq. (3.6) becomes $P \approx 2 T \sin \theta$. This approximation is also plotted in Figure 3-27(a) along with the more accurate expression for $P$, and the two curves agree quite well. Discrepancies are largest in the early stages of loading, in which the axial force $T$ is relatively small and the contribution of shear in the beams is most significant.
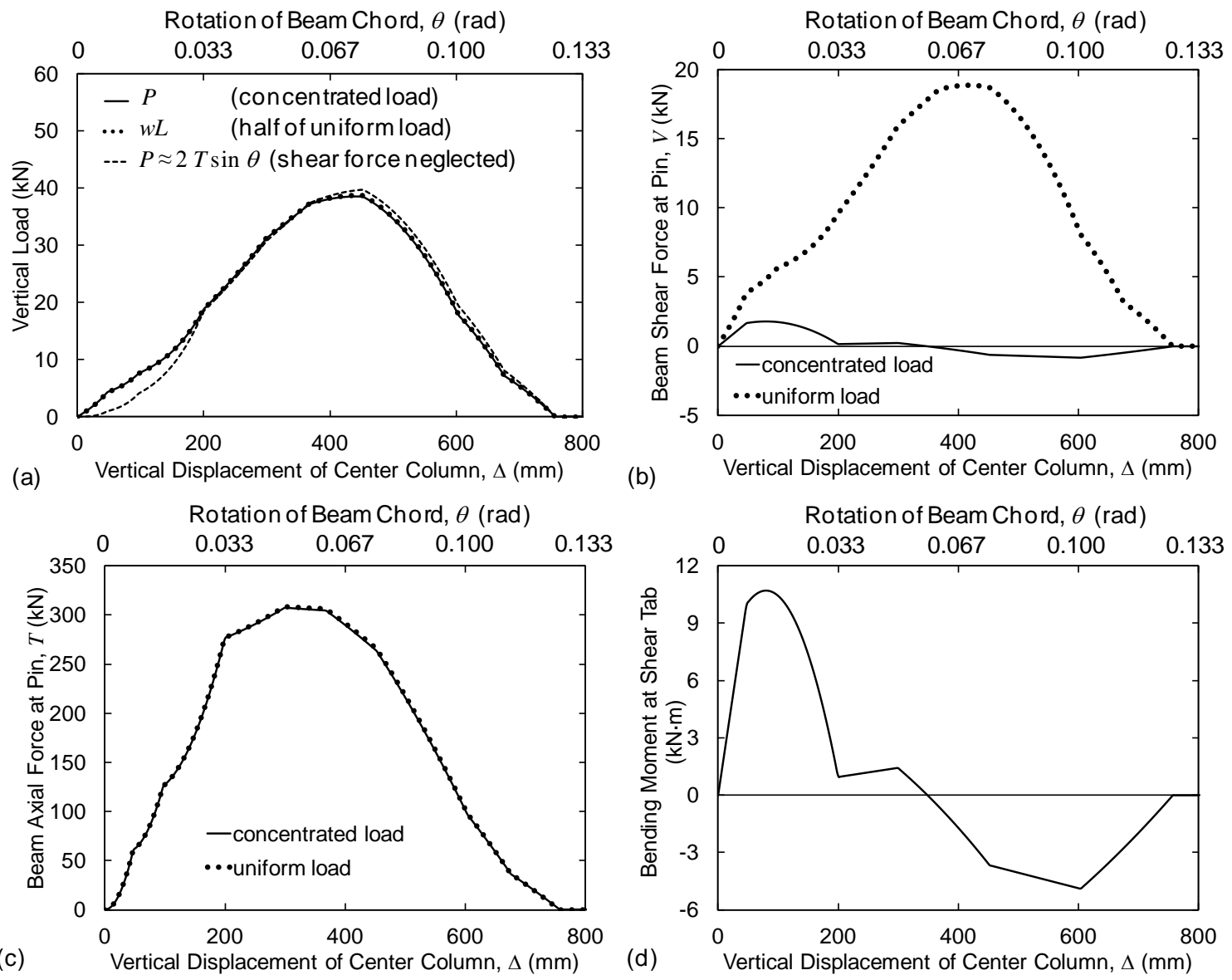

Figure 3-27 (a) Applied vertical load, (b) shear force at pin support, (c) beam axial force at pin support, and (d) bending moment at shear tab vs. vertical column displacement for two-span beam assembly with pin supports. 
Figure 3-27(c) shows the beam axial force $T$ at the pin support, from Eq. (3.10), plotted against the vertical column displacement $\Delta$ for both concentrated and uniform loads. The two curves in Figure 327(c) are virtually indistinguishable, indicating that the axial force for a given column displacement $\Delta$ is essentially the same under both types of loading. While Eq. (3.10) indicates that $T$ for a uniform load exceeds $T$ for a concentrated load by an amount equal to $w L \sin \theta$, this difference is small relative to $T$. In the case of a concentrated load, the axial force is constant along the beam span. In the case of a uniform load, the axial force varies linearly along the beam span, increasing by the amount $w L \sin \theta$ from the center connection to the pin support. However, because the quantity $w L \sin \theta$ is small relative to $T$, as just noted, the axial force is essentially constant in the case of a uniform load as well.

Figure 3-27(d) shows the bending moment at the shear tab connection, which is the same for both concentrated and uniform loading, plotted against the vertical column displacement $\Delta$. The bending moment is initially positive, as the lowest bolt row is in tension and the uppermost bolt row is in compression. The bending moment remains positive as deflections increase and tension develops in all of the bolt rows, since the largest extension, and thus the largest tension, is developed in the lowest bolt row, below the center of the bolt group (see Figure 3-25). However, the bending moment eventually changes sign to negative after the ultimate capacity of the lowest bolt row is exceeded, and larger tension develops in the upper bolt rows. Note that the shear force $V$ in the case of a concentrated load, plotted in Figure 327(b), can be expressed as $V=M_{t a b} / L$, where $M_{t a b}$ is defined in Eq. (3.12), and thus these two curves are proportional.

Figure 3-28 shows a comparison of the simplified spreadsheet calculations with computations using the detailed and reduced modeling approaches. As in Figure 3-27, the beam and connections considered in Figure 3-28 correspond to a N-S beam span in building A, with $L=5.97 \mathrm{~m}$ (19.5 ft). The detailed model is shown in Figure 3-29, and in both the detailed and reduced models, symmetry is exploited by considering only a single beam span, with a pin support at one end and a shear tab connected to a column on the plane of symmetry at the other end. The column is translated downward under displacement control, with horizontal displacements constrained to maintain symmetry, and the vertical load obtained computationally is multiplied by two for comparison with the vertical load on a two-span beam assembly.

In the detailed model (see Figure 3-29), the connection region is represented using finely meshed solid elements, as described in Section 3.1, while the remainder of the beam span, where deformations are expected to be small, is represented using fairly coarse shell elements. The shell element mesh transitions to match the element size of the solid element mesh at their interface, where constraints are used to tie the edges of the shell elements to nodes of the solid elements. Material models corresponding to minimum specified strength properties (see Figure 3-7) are used for the A36 steel of the shear tab and the A992 steel of the W16x26 beam. An elastic material model is used for the shell elements surrounding the pin support, to preclude plastic deformations at that location. 



Figure 3-28 Comparison of spreadsheet calculation with detailed and reduced model results for two-span beam assembly with exterior pin supports: (a) vertical load and (b) axial force versus vertical column displacement.

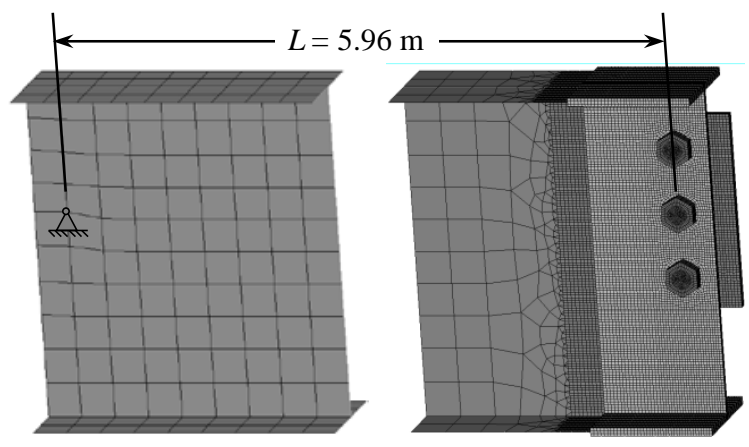

Figure 3-29. Detailed model of N-S beam span in building A with pin support at one end

Figure 3-28 shows fairly good correspondence between the detailed and reduced model predictions and the spreadsheet calculations. Differences of about $5 \%$ are observed among the predictions of the peak vertical load in Figure 3-28(a), while differences of about $1 \%$ are observed among the predictions of the peak axial force in Figure 3-28(b). Some sources of the discrepancies observed in Figure 3-28 are discussed in the following paragraphs.

Figure 3-28(b) shows that the axial force from the spreadsheet calculation increases more quickly than predicted by the detailed and reduced models. The discrepancy between the reduced model and the spreadsheet calculation may at first be surprising, since the same load-deformation relationship is used for the bolt springs in both models. However, recall that the spreadsheet calculation procedure is based on the approximation that the beam span behaves as a rigid body except at the connections. This approximation neglects the axial flexibility of the beam, resulting in an overestimation of the axial stiffness of the system. Using the reduced modeling approach, an analysis was performed in which the beam span was modeled as rigid, and the computed values of vertical load and axial force were found to be virtually indistinguishable from the spreadsheet calculations. This confirms that the small discrepancies in Figure 3-28 between the reduced model and the spreadsheet calculations are due to the axial flexibility of the beam.

Figure 3-28 shows that the vertical load and axial force from the detailed model do not begin to increase significantly until the vertical column displacement exceeds about $80 \mathrm{~mm}$ (3.1 in). This occurs because the diameter of the bolt holes was modeled as $1.6 \mathrm{~mm}(1 / 16$ in) larger than the bolt diameter, while no pretension was applied to the bolts to introduce frictional clamping, so that some sliding occurs before the bolts come into bearing, as was observed previously in Figure 3-17. Figure 3-28 also shows that the 
vertical load and the axial force from the detailed model drop more quickly after the ultimate load than predicted by the reduced model and the spreadsheet calculation. This occurs because the stress-strain curves used in the detailed model are based on minimum specified values of elongation (see Figure 3-7), resulting in a smaller deformation at ultimate load than predicted by the reduced model, as observed previously in Figure 3-17.

\subsubsection{Two-span beam assembly with two shear connections per span}

While Eqs. (3.8) - (3.14) apply for a two-span beam assembly with pin supports at the outer beam ends, of greater interest is the more typical situation shown in Figure 3-30(a), with shear connections at both ends of each beam span. It is assumed here that the exterior columns are restrained from lateral motion at the level of the beams. The presence of two shear connections introduces an additional degree of freedom associated with deformation of the second shear connection. However, if it is assumed that the shear connections at both ends of each beam experience the same mid-height extension $\delta$ (limitations of this assumption are discussed later in this section), then $\delta$ can be expressed as follows, based on the deformed geometry shown in Figure 3-30(b):

$$
\delta=\frac{\sqrt{L^{2}+\Delta^{2}}-L}{2}
$$

It is noted that an equation similar to Eq. (3.15) was obtained by Weigand et al. (2012) in their development of an experimental setup for testing of connection subassemblages.

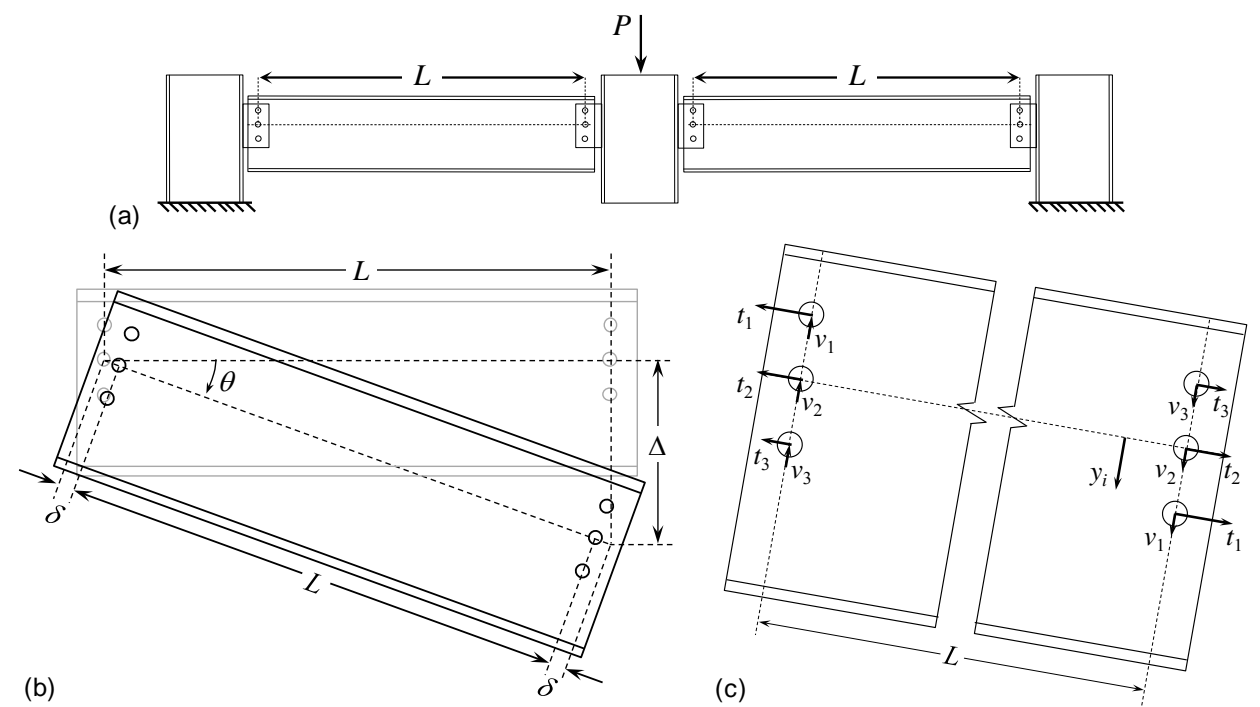

Figure 3-30 (a) Two-span beam assembly with two shear connections per span; (b) deformed geometry of beam; (c) free body diagram of beam.

For simplicity, only the case of a concentrated load is considered in Figure 3-30, in which case the axial force is constant and is given by the expression in Eq. (3.10). Assuming an antisymmetric distribution of bolt forces at the two ends of the beam span, as illustrated in Figure 3-30(c), equilibrium of moments about the center of a bolt group yields the following expression for the shear force $V$ in the beam: 


$$
V=\sum_{i}^{N} v_{i}=2 \sum_{i}^{N} \frac{t_{i} y_{i}}{L}
$$

Note that the shear force in Eq. (3.16) is twice its value in Eq. (3.11), due to the presence of bending moment at two shear connections rather than just one. Substitution of Eqs. (3.10) and (3.16) into Eq. (3.6) then yields the following expression for the vertical load $P$ :

$$
P=2\left(\sum_{i}^{N} t_{i} \sin \theta+2 \sum_{i}^{N} \frac{t_{i} y_{i}}{L} \cos \theta\right)
$$

Figure 3-31 shows (a) the vertical load $P$ from Eq. (3.17) and (b) the axial tension $T$ plotted against the vertical column displacement $\Delta$. Also plotted in Figure 3-31(a) is the simplified approximation $P \approx 2 T \sin \theta$, which neglects the contribution of the shear forces. Comparison with Figure 3-27(a) shows that neglecting shear forces results in a larger discrepancy for this case, with two shear connections per span, than it did for the case with exterior pin supports. The discrepancies are most significant in the early stages of loading, while the simplified approximation still captures the ultimate load fairly well. As in Figure 3-27, the numerical results in Figure 3-31 correspond to a chord length of $L=5.97 \mathrm{~m}(19.6 \mathrm{ft})$ and a bolt force-deformation relationship of the form illustrated in Figure 3-13(a), with the parameters listed in Table 3-2 for N-S beam connections.

The ultimate vertical load in this case is $50.7 \mathrm{kN}$ (11.4 kip), which is about $31 \%$ larger than the ultimate load of $38.5 \mathrm{kN}$ (8.7 kip) for the case with exterior pin supports, shown in Figure 3-27(a). The beam chord rotation at the ultimate load in this case is $0.0971 \mathrm{rad}$, which is also about $31 \%$ larger than the rotation at ultimate load of 0.0739 rad for the case with exterior pin supports. While the peak axial force is about the same in both cases, the beam chord rotation corresponding to the peak axial force in this case is 0.0654 rad (see Figure 3-31(b)), which is about 31 \% larger than the rotation of $0.0501 \mathrm{rad}$ corresponding to the peak axial force for the case with exterior pin supports (see Figure 3-27(c)). The peak axial force is attained at a larger rotation in this case due to the greater axial deformation capacity of two shear connections compared with a single shear connection. Since the vertical component of the beam axial forces is given by $2 T \sin \theta$, it is noted that the same axial force occurring at a larger rotation results in a larger vertical load. It is therefore observed that the greater axial deformation capacity of two shear connections per span, as compared with a single shear connection per span, results in substantial increases in both the ultimate load and the corresponding column displacement.

Figure 3-32 shows a comparison of the simplified spreadsheet calculations, for the two-span beam assembly with two shear connections per span, with computations using the detailed and reduced modeling approaches. The detailed model for this case is shown in Figure 3-33, and in both the detailed and reduced models, symmetry is exploited to model only a single beam span, as described previously. Figure 3-32 shows fairly good correspondence between the results of the detailed and reduced models and the spreadsheet calculation, although not quite as good as for the single shear tab connection in Figure 3-28. Differences of about $3 \%$ are observed among the predictions of the peak vertical load in Figure 332(a), while differences of about $5 \%$ are observed among the predictions of the peak axial force in Figure 3-32(b). 



Figure 3-31 (a) Applied vertical load and (b) beam axial force vs. vertical column displacement for two-span beam assembly with two shear connections per span.
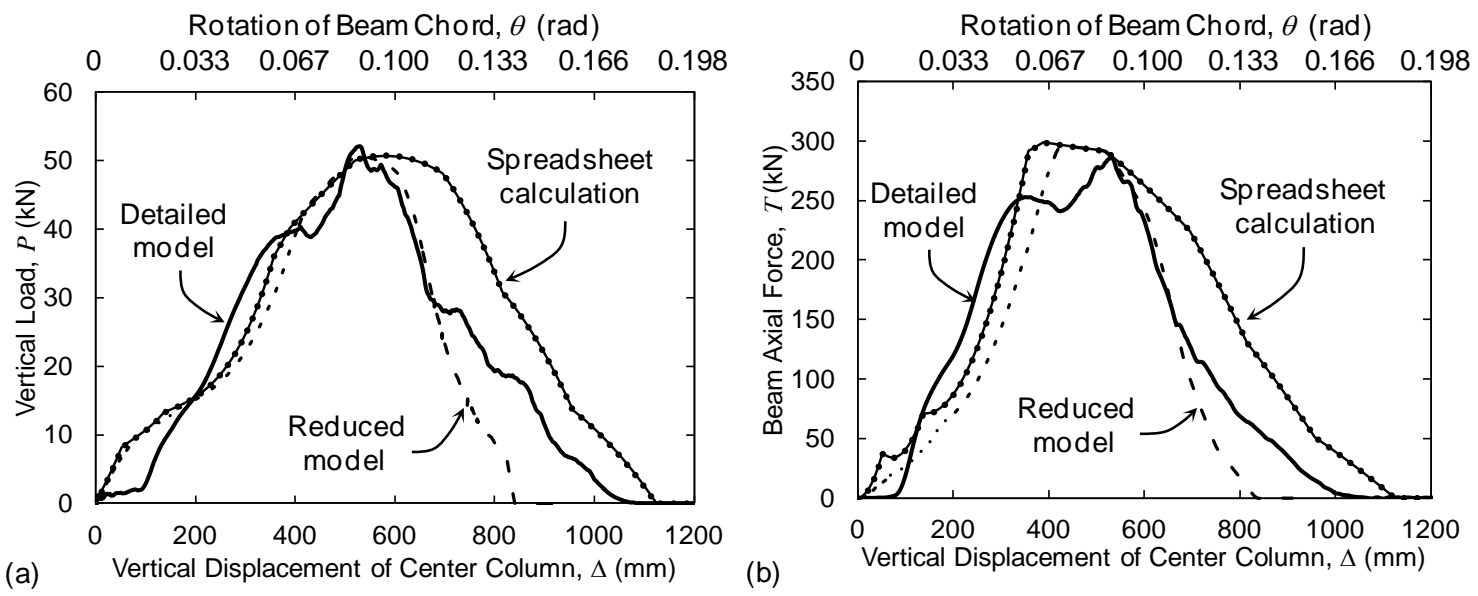

Figure 3-32 Comparison of detailed model, reduced model, and spreadsheet calculation results for a two-span beam assembly with two shear connections per span: (a) vertical load and (b) axial force versus vertical displacement of center column.



Figure 3-33. Detailed model of N-S beam span in building A with shear connections at both ends

One notable discrepancy in Figure 3-32 is that after the ultimate load is reached, the spreadsheet calculation consistently overestimates both the vertical load and the axial force relative to the detailed and reduced models. This is a consequence of the assumption, noted in Section 3.4.2, that the shear connections at both ends of the beam experience the same mid-height extension. As illustrated using 
detailed model results in Figure 3-34, this assumption is appropriate up until the ultimate load is reached, but is not appropriate thereafter, because deformations tend to localize at one connection in the softening segment of the response. Figure 3-34(a) shows bolt hole deformations at the two ends of the beam at a vertical column displacement of $500 \mathrm{~mm}$ (20 in), which corresponds closely to the ultimate load of the assembly. At this displacement, the bolt hole deformations at the two ends of the beam are comparable. However, Figure 3-34(b) shows bolt hole deformations at the two ends of the beam at a vertical column displacement of $800 \mathrm{~mm}$ (31 in), in the softening segment of the response after the ultimate load has been reached. At this displacement, deformations have clearly localized, and Figure 3-34(b) shows significantly larger deformations at the right-hand connection than at the left hand connection. The reduced model is able to capture this localization of deformation as well, as shown in Figure 3-35, and thus matches the detailed model more closely than the spreadsheet calculation in the softening portion of the response.

(a)



Figure 3-34 Localization of deformation in post-ultimate softening response of detailed model: (a) $\Delta=500 \mathrm{~mm}$ (20 in), near ultimate load; (b) $\Delta=800 \mathrm{~mm}$ (31 in), post ultimate load. 


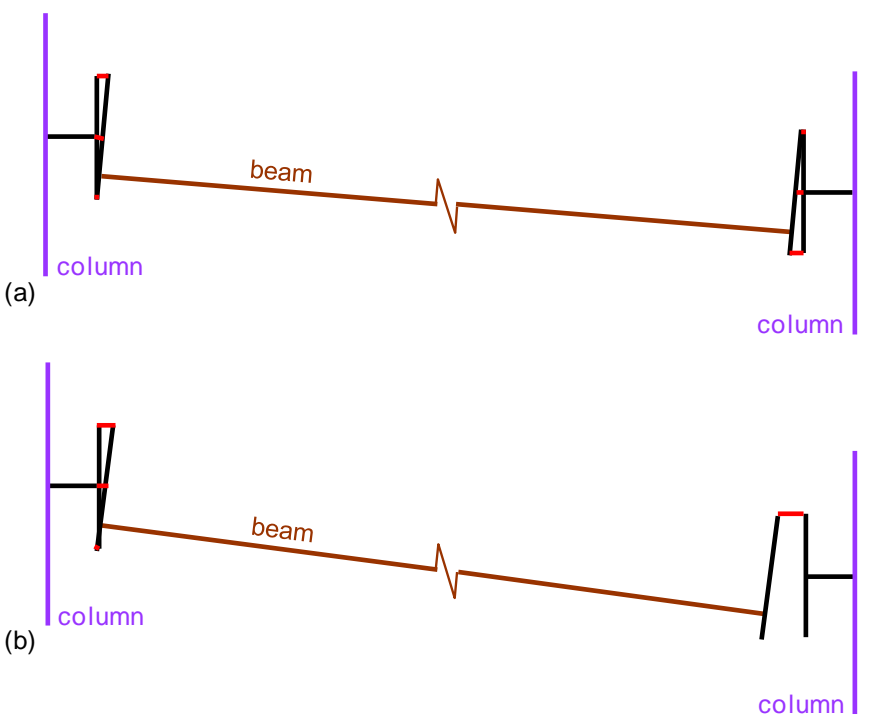

Figure 3-35 Localization of deformation in post-ultimate softening response of reduced model: (a) $\Delta=500 \mathrm{~mm}$ (20 in), near ultimate load; (b) $\Delta=800 \mathrm{~mm}$ (31 in), post ultimate load.

\subsection{BEHAVIOR OF PROTOTYPE SHEAR CONNECTIONS}

In Section 3.4, fairly good agreement was observed between the results of the detailed and reduced models, including the localization of deformation in the post-ultimate softening segment of the response. In this section, the reduced modeling approach is used to investigate the behavior of the shear tab connections in the prototype buildings (see Section 2.4) under column loss scenarios. Two-span beam assemblies with two shear connections per span, as depicted in Figure 3-30, are analyzed under displacement controlled loading of the unsupported center column. By considering two-span beams from different gravity frames in the prototype buildings, the influences of the span length and the connection strength can be considered.

\subsubsection{Influence of span length}

Both the N-S and the E-W shear tab connections in building A have three A325 bolts and are nominally equivalent, except that the N-S beam has a slightly thicker web than the E-W beam, resulting in a bearing capacity in tension that is about $9 \%$ greater (see Table 3-2). However, the span of the N-S beams is

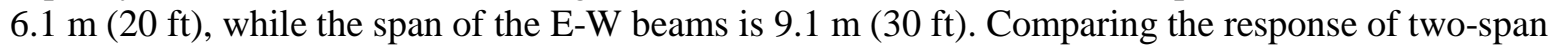
beam assemblies from the N-S and E-W gravity frames of building A thus enables an assessment of the influence of span length on the behavior of the shear tab connections.

Figure 3-36 shows a comparison of (a) the vertical load and (b) the beam axial force plotted against the rotation of the beam chord for the two assemblies with different span lengths (note the dual horizontal axes above the plots showing the vertical displacement of the center column for the different span lengths). While the peak axial force for the shorter span is only $7 \%$ greater than for the longer span (a consequence of the slightly larger bearing capacity of the beam web), the difference in the vertical load capacity is significant, with the peak vertical load for the shorter span being $28 \%$ greater than that for the longer span.

The displacement at ultimate load for the shorter span is about $20 \%$ less than for the longer span. However, when beam chord rotations are considered, as indicated below the plots in Figure 3-36, the rotation at ultimate load for the shorter span is actually about $18 \%$ greater than that for the longer span. 
The rotational capacity is greater for the shorter span because the axial force for a given rotation is smaller, as shown in Figure 3-36(b). Because the connections eventually fail primarily due to axial extension, the smaller axial forces for the shorter span enable the connection to sustain larger rotations prior to failure. Recalling that the vertical component of the beam axial forces is given by $2 T \sin \theta$ (see Section 3.4.2), it is noted that the same axial force occurring at a larger rotation results in a larger vertical load. It is thus observed that the greater rotational capacity of the shorter beam spans results in a substantial increase in the ultimate vertical load.
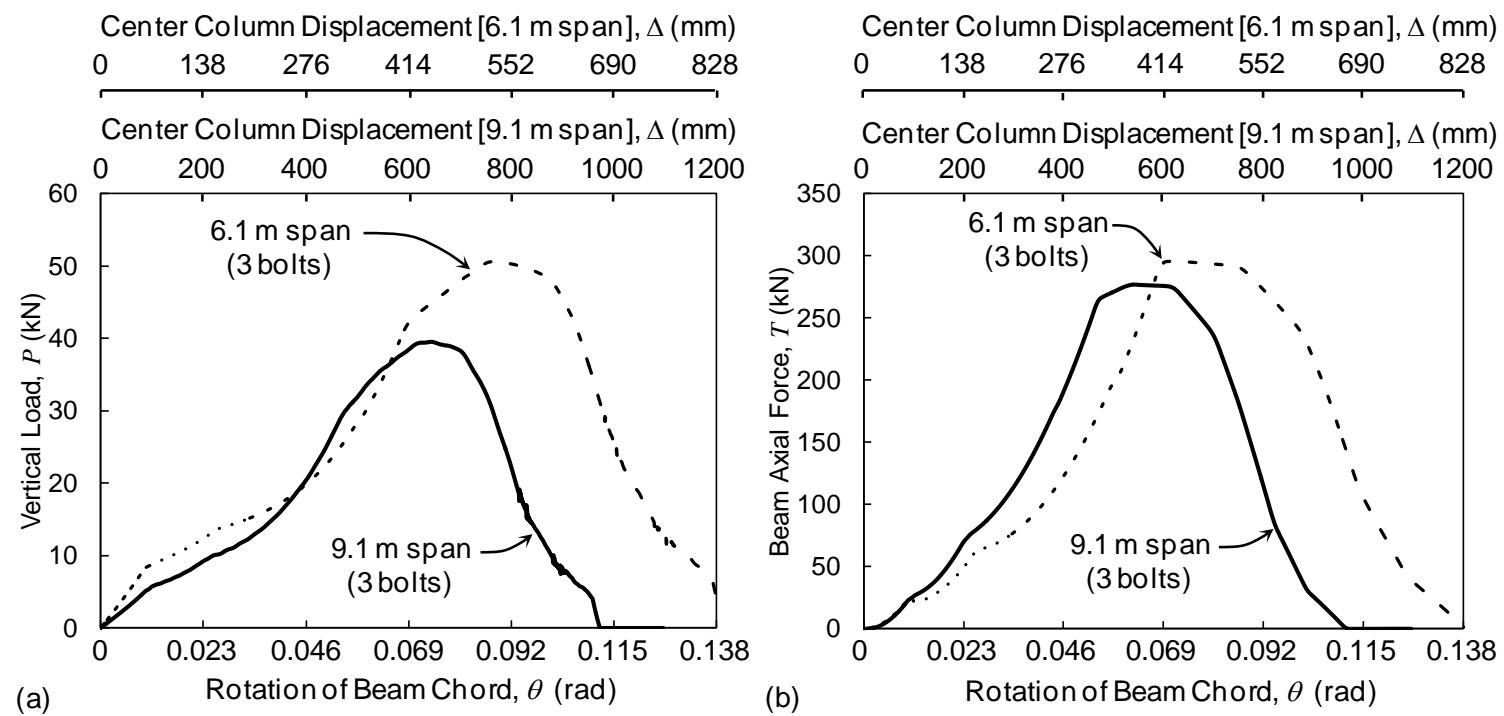

Figure 3-36 (a) Vertical load and (b) beam axial force vs. vertical displacement of center column for different span lengths with three bolts per shear tab connection.

\subsubsection{Influence of connection strength}


shear tab connections in building A have three bolts each, while those in building B have four bolts each. Comparing the response of two-span beam assemblies from the E-W gravity frames of buildings A and B thus enables an assessment of the influence of the number of bolts, or the connection strength, on the behavior of the shear tab connections.

Figure 3-37 shows a comparison of (a) the vertical load and (b) the beam axial force plotted against the vertical displacement of the center column for the two assemblies with different numbers of bolts per connection. The peak vertical load for the four-bolt connection is almost exactly twice as large as that of the three-bolt connection, while the peak axial force is 1.8 times larger. It is thus observed that the vertical capacity of the assembly with four-bolt connections is substantially larger than that of the assembly with three-bolt connections, due primarily to the increased axial capacity of the connections. Note that the axial capacity of the four-bolt connection is more than $1 \frac{1}{3}$ times that of the three-bolt connection because, in addition to the larger number of bolts, the four-bolt connection has a thicker beam web (the beam web thickness, denoted $t_{w}$, is indicated in Figure 3-37). This changes the failure mode from tear-out through the beam web to tear-out through the shear tab, resulting in bearing capacities for each bolt that are $45 \%$ larger (see Table 3-2). The displacement (or rotation) at ultimate load is comparable in the two cases, being about $6 \%$ larger for the four-bolt connection than for the three-bolt connection. 

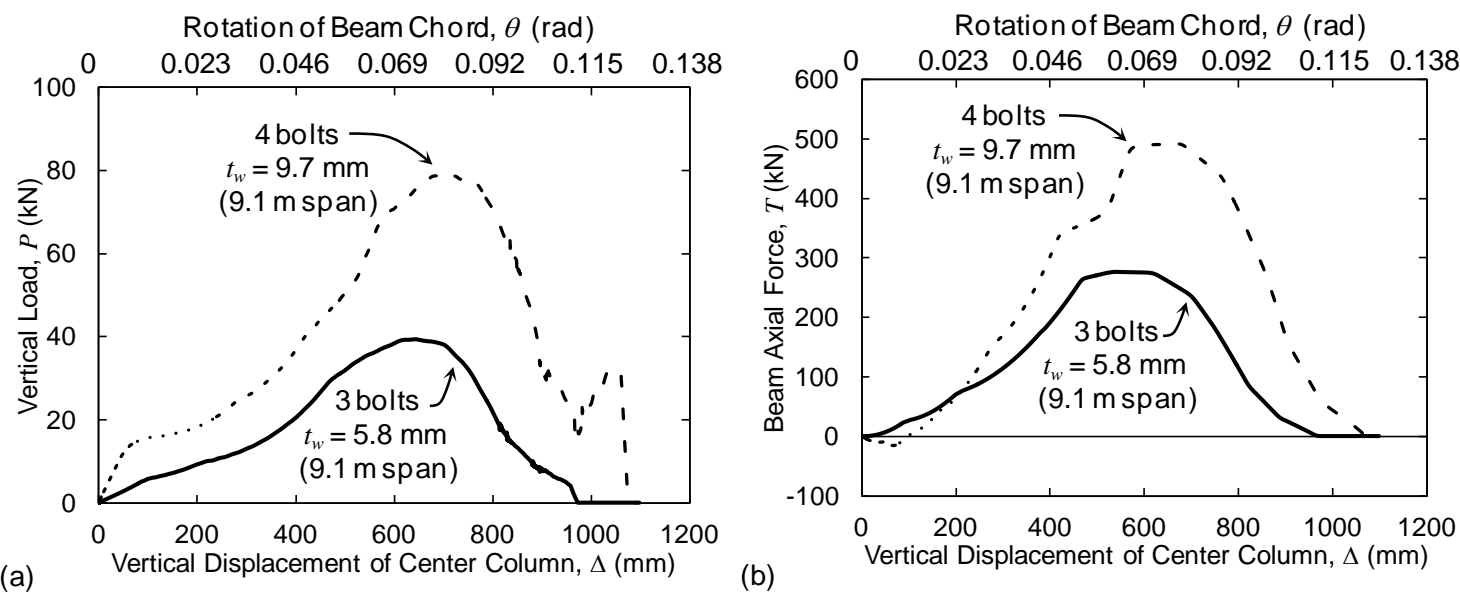

Figure 3-37 (a) Vertical load and (b) beam axial force versus vertical displacement of center column for $9.1 \mathrm{~m}$ (30 ft) beam spans with different numbers of bolts per shear tab connection.

\subsubsection{Influence of post-ultimate behavior}

In Section 3.2.1, alternate axial load-deformation relationships were presented for the bolt springs in the reduced model, depending on whether the controlling limit state was bearing failure or bolt shear failure. These alternate relationships differ in their post-ultimate behavior, with bearing failure characterized by a gradual softening and bolt shear producing a sudden drop in resistance. This distinction is illustrated in Figure 3-38, in which the curve labeled "gradual softening" corresponds to the parameters listed in Table 3-2 for the E-W connections in building A, governed by bearing failure of the beam web, and the curve labeled "sudden fracture" is identical except that the failure displacement in tension has been reduced to $1.15 \delta_{u}$, which is the value used when bolt shear failure governs.

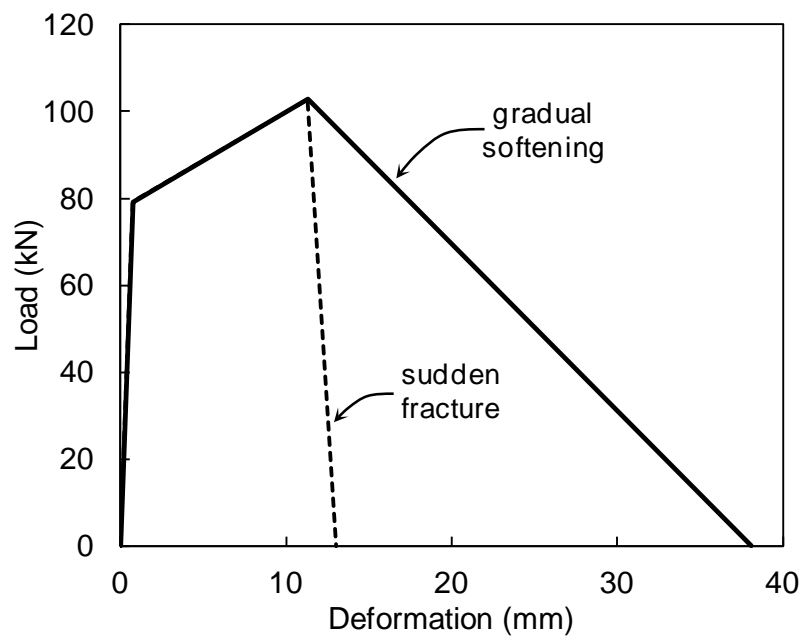

Figure 3-38. Alternate post-ultimate behaviors of a single bolt row in a shear tab connection under axial tension

For the shear tab connections in the prototype buildings, both calculations based on design equations (see Section 3.2.1) and detailed model computations (see Section 3.2.2) indicate that tensile failure is controlled by bearing failure. However, for other shear tab connections, bolt shear failure, or other failure modes characterized by sudden fracture, may certainly control. For the shear tab connections tested by Thompson (2009), three nominally identical specimens were tested for each connection size, and the 
failure mode differed from test to test, being shear rupture of the bolts in some cases and tensile rupture or block shear failure of the shear tab in other cases. The observed tensile ruptures of the shear tabs were described as brittle, rather than ductile. While extensive bearing-induced elongations of the bolt holes were observed in all cases, the eventual failure modes were characterized by a sudden, rather than gradual, drop in resistance. Because such sudden fractures can occur, it is important to understand their effect on the overall structural response under column removal scenarios.

To investigate this, the two-span beam assemblies from the prototype buildings, which were analyzed previously assuming a gradual softening behavior, were analyzed again assuming that sudden fracture occurs when the ultimate load of each bolt row is reached. The reduced connection model parameters used in these analyses were the same as those listed in Table 3-2, except for the failure displacement in tension, which was reduced to $1.15 \delta_{u}$ in all cases.

Figure 3-39 shows a comparison of (a) the vertical load and (b) the beam axial force plotted against the vertical displacement of the center column for two-span beam assemblies with the alternate post-ultimate behaviors. These results correspond to the E-W gravity frames of building A, with a bay spacing of $9.1 \mathrm{~m}$ (30 ft) and with three A325 bolts per connection. Figure 3-40 and Figure 3-41 show similar results for the N-S gravity frames of building A and the E-W gravity frames of building B, respectively. In all cases the peak vertical load is significantly less for sudden fracture than for gradual softening, being $15 \%$ less in Figure 3-39(a), 23 \% less in Figure 3-40(a), and 16 \% less in Figure 3-41(a). The peak axial forces are only slighty less for sudden fracture than for gradual softening, being $1 \%$ less in Figure 3-39(b), 7 \% less in Figure 3-40(b), and 2 \% less in Figure 3-41(b). However, the axial forces are sustained for larger rotations in the case of gradual softening, resulting in larger vertical loads since the vertical component of the beam axial forces is given by $2 T \sin \theta$. It is thus observed that the connections characterized by gradual softening achieve increased vertical load capacity by sustaining comparable levels of axial tension under larger rotations. Rotational capacities of the connections are further discussed in the following section.
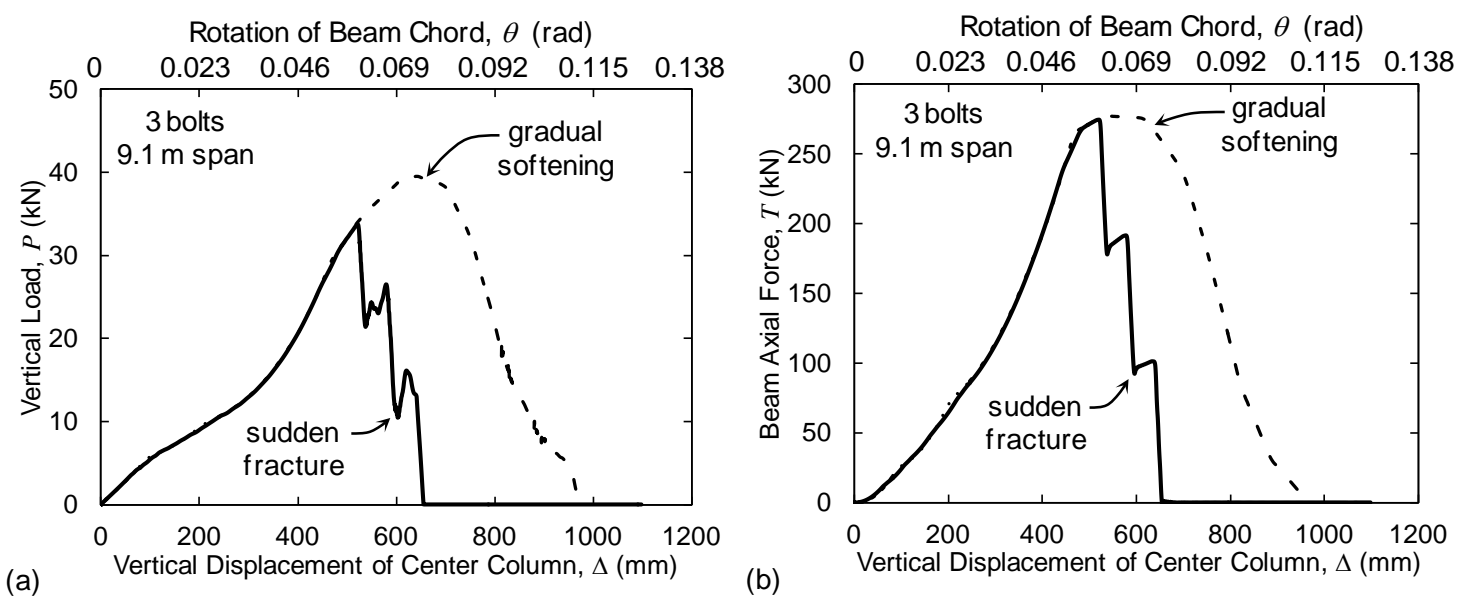

Figure 3-39 (a) Vertical load and (b) beam axial force versus vertical displacement of center column for different post-ultimate behaviors with $9.1 \mathrm{~m}(30 \mathrm{ft})$ beam spans and three bolts per connection. 

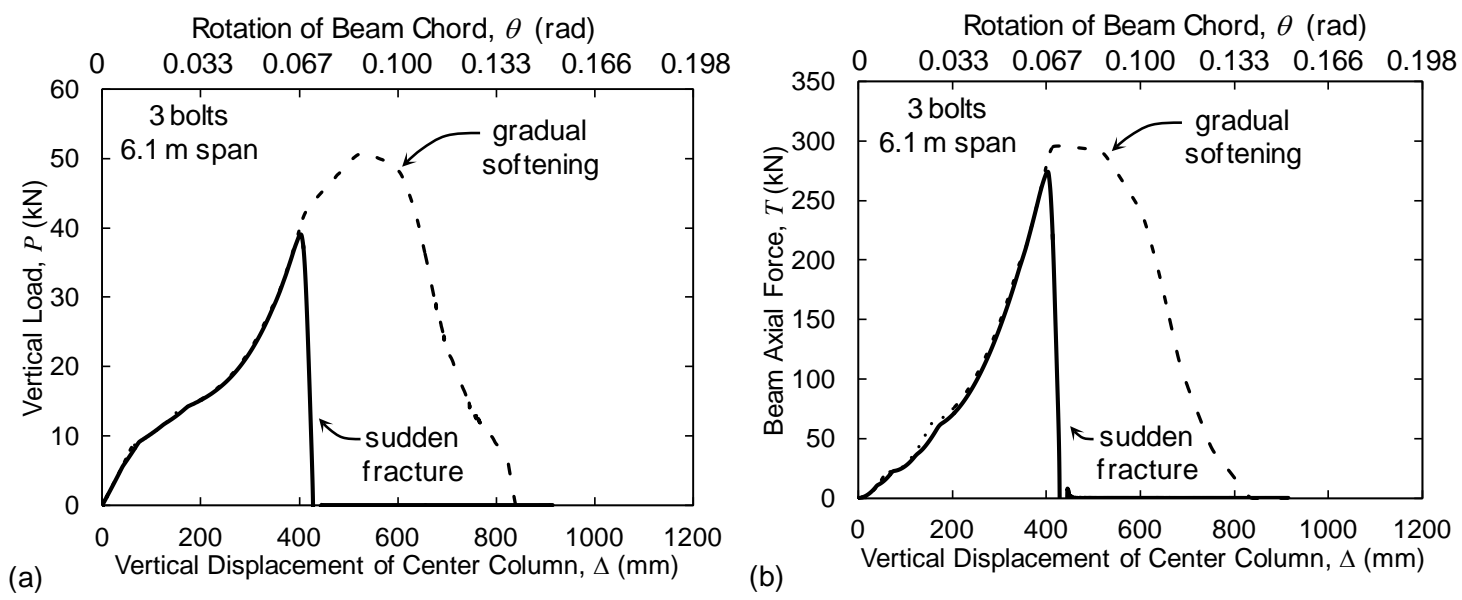

Figure 3-40 (a) Vertical load and (b) beam axial force versus vertical displacement of center column for different

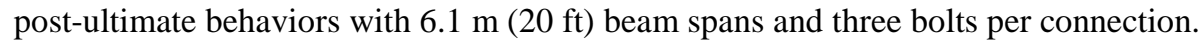
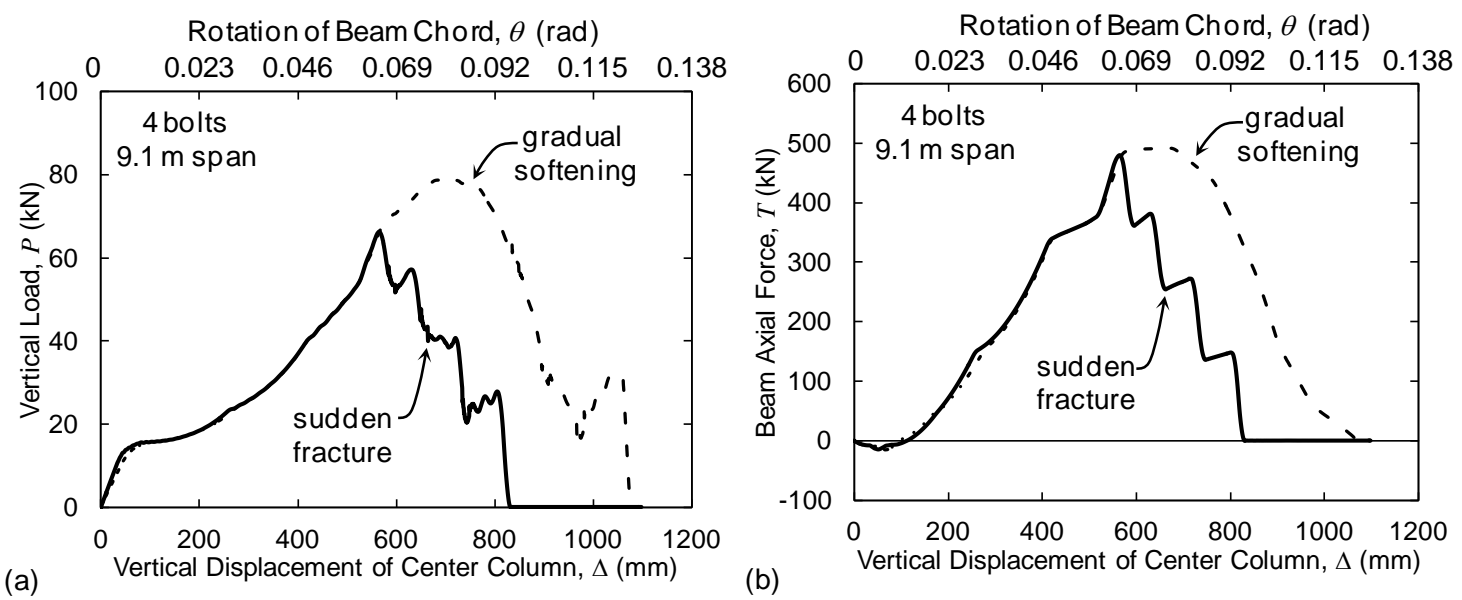

Figure 3-41 (a) Vertical load and (b) beam axial force versus vertical displacement of center column for different



\subsection{ROTATIONAL CAPACITIES}

In the spreadsheet calculation approach described in Section 3.4, the deformed geometry of two-span beam assemblies was used to derive kinematic relationships between the connection deformations and the overall deflections and rotations of the assemblies. In the following sections, such kinematic relationships are used to obtain expressions for the rotational capacity of the connections as functions of the span length and deformation capacity of the connections. Section 3.6.1 considers two-span beam assemblies with exterior pin supports, for comparison with the experimental data of Thompson (2009) (see Section 3.3), while Section 3.6.2 considers two-span beam assemblies with two shear connections per span, for comparison with the reduced model results for the prototype shear tab connections (see Section 3.5).

For both types of exterior support conditions, the axial extension of the ith bolt row in the connection to the center column, denoted $\delta_{i}$, can be calculated using Eq. (3.9). In assessing rotational capacities, cases in which $\delta_{i}=\delta_{u}$ are of interest, where $\delta_{u}$ is the deformation at the ultimate load of the bolt row, defined in Eq. (3.4) as a function of $d_{b g}$, the depth of the bolt group. Substituting $\delta_{i}=\delta_{u}$ into Eq. (3.9) and 
introducing the approximation $\theta \approx \Delta / L$, applicable for small angles, yields the following expression for the axial extension $\delta$ at the center of the connection when the ith bolt row reaches its ultimate load:

$$
\frac{\delta}{L}=\frac{\delta_{u}}{L}-\frac{y_{i}}{L} \theta_{u, i}
$$

The subscript on $\theta_{u, i}$ indicates the rotation at the ultimate load of the ith bolt row. Alternate expressions for the axial extension $\delta$ as a function of rotation $\theta$ are presented for different support conditions in the following sections, allowing Eq. (3.18) to be solved for $\theta_{u, i}$.

\subsubsection{Two-span beam assembly with exterior pin supports}

The deformed geometry of a beam span with an exterior pin support was shown previously in Figure 325, in which the elevation of the pin support was assumed to be at mid-height of the bolt group at the opposite end of the span. In the tests conducted by Thompson (2009), the exterior pin support was located at mid-height of the beam, not at mid-height of the bolt group. This results in an initial vertical offset, denoted $\bar{y}$, between the pin support and the center of the bolt group, as illustrated in Figure 3-42. Accounting for the influence of this offset on the rotation of the system, the extension $\delta$ at mid-height of the connection can be expressed as follows:

$$
\delta=\sqrt{(L-\bar{y} \theta)^{2}+\Delta^{2}}-L
$$

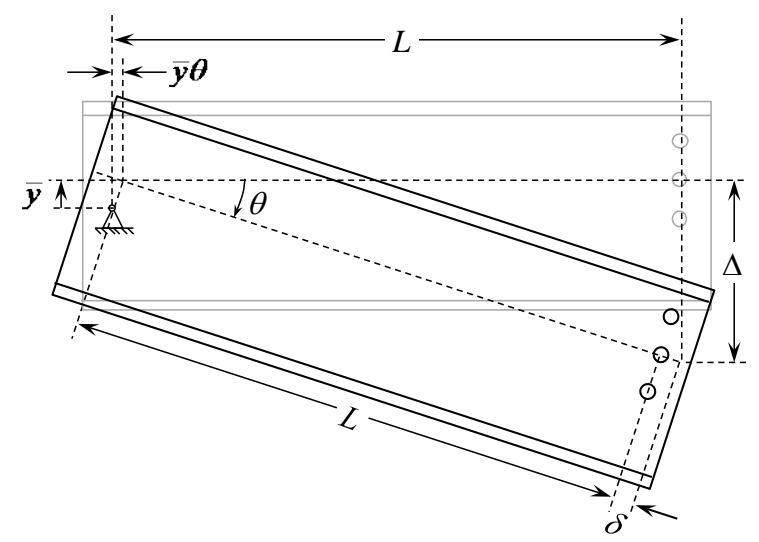

Figure 3-42. Deformed geometry of beam span with exterior pin support at beam mid-height

Introducing the approximation $\theta \approx \Delta / L$, applicable for small angles, Eq. (3.19) can be expressed as

$$
\frac{\delta}{L}=\sqrt{1-2\left(\frac{\bar{y}}{L}\right) \theta+\theta^{2}}-1
$$

in which a term $(\bar{y} / L)^{2} \theta^{2}$ has been dropped inside the radical, because it is negligibly small relative to the other terms. Substituting Eq. (3.20) into Eq. (3.18) and rearranging yields the following quadratic equation for $\theta_{u, i}$ : 


$$
\theta_{u, i}^{2}+2\left(\frac{y_{i}-\bar{y}}{L}\right) \theta_{u, i}-\frac{\delta_{u}}{L}\left(2+\frac{\delta_{u}}{L}\right)=0
$$

in which the terms $\left(y_{i} / L\right)^{2} \theta_{u, i}^{2}$ and $2\left(y_{i} / L\right)\left(\delta_{u} / L\right) \theta_{u, i}$ have been dropped, retaining terms up to the second order in quantities $\ll 1$. Solving the quadratic equation and taking the positive root yields the following expression for the rotation $\theta_{u, i}$ :

$$
\theta_{u, i}=\sqrt{\left(\frac{y_{i}-\bar{y}}{L}\right)^{2}+\frac{\delta_{u}}{L}\left(2+\frac{\delta_{u}}{L}\right)}-\left(\frac{y_{i}-\bar{y}}{L}\right)
$$

Figure 3-43 shows $\theta_{u, 1}$, the rotation at ultimate load of the bottom bolt row, and $\theta_{u, 2}$, the rotation at ultimate load of the second bolt row from the bottom, plotted against the depth of the bolt group, $d_{b g}$, for a beam span of $L=1.89 \mathrm{~m}$ (6.21 ft), corresponding to the tests of Thompson (2009). Plotted with these analytical curves is the expression for $\theta_{\max }$ from Eq. (3.3), which is based on linear regression of data from cyclic flexural testing of simple shear connections reported in FEMA 355D (FEMA 2000). Recall that $\delta_{u}$, defined in Eq. (3.4), was obtained directly from $\theta_{\max }$ by assuming pure rotation of the connection about the center of the bolt group in the cyclic testing. Figure 3-43 shows that $\theta_{u, 1}$ is significantly less than $\theta_{\max }$, being $28 \%$ less for the 3-bolt connection, $32 \%$ less for the 4-bolt connection, and $35 \%$ less for the 5-bolt connection. This indicates that the combination of rotation and axial extension in the configuration of Figure 3-42 causes the bottom bolt row to reach its ultimate load at a smaller rotation than under pure rotation. For the 4-bolt and 5-bolt connections, even the second bolt row from the bottom reaches its ultimate load at a rotation smaller than $\theta_{\max }$, due to the axial component of deformation imposed on the connection.

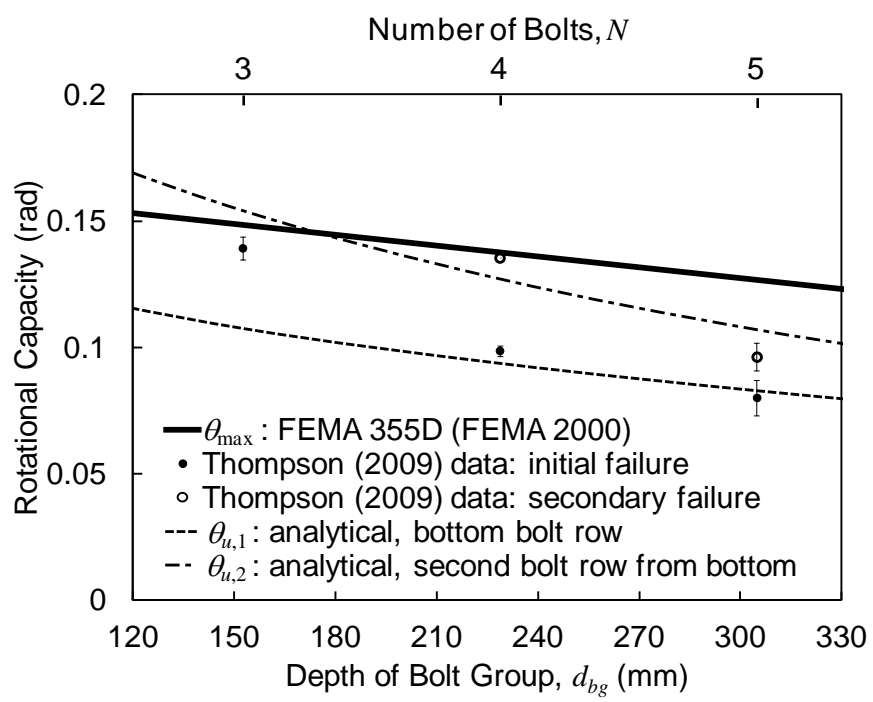

Figure 3-43. Comparison of experimental and analytical rotational capacity values for $L=1.89 \mathrm{~m}$ (6.21 ft) with exterior pin supports (circles indicate mean values, while error bars indicate maximum and minimum values from a series of three tests) 
Also plotted in Figure 3-43 are beam rotations corresponding to the initial and secondary failures reported by Thompson (2009), from tests described previously in Section 3.3. Load-displacement curves corresponding to the failure rotations in Figure 3-43 were presented in Figure 3-21, and in all but two cases (test 1 for the 4-bolt connection and test 3 for the 5-bolt connection), the peak reported vertical load was associated with the initial failure.

The rotation values corresponding to initial failure in Figure 3-43 correspond quite well with $\theta_{u, 1}$, the analytical result for the rotation at which the bottom bolt row reaches its ultimate load. While $\theta_{u, 1}$ underestimates the mean initial failure rotation of the 3-bolt connection by $23 \%$, it is within $6 \%$ of the mean initial failure rotation of the 4-bolt connection and within $3 \%$ of the mean initial failure rotation of the 5-bolt connection. Similarly, the rotation values corresponding to secondary failure correspond quite well with $\theta_{u, 2}$, the analytical result for the rotation at which the second bolt row from the bottom reaches its ultimate load. Although the secondary failure data is more limited, $\theta_{u, 2}$ is within $7 \%$ of the secondary failure rotation of the 4-bolt connection (test 1 ) and within $11 \%$ of the mean secondary failure rotation of the 5-bolt connection. This comparison indicates that the analytical expression in Eq. (3.22) captures fairly well both the initial and secondary failures observed experimentally. Because the vertical capacity in most tests was associated with the initial failure mechanism, it would seem prudent to estimate the rotational capacity of the connections based on failure of the bottom bolt row, using $\theta_{u, 1}$ rather than $\theta_{u, 2}$ as the rotational capacity estimate.

\subsubsection{Two-span beam assembly with two shear connections per span}

The deformed geometry of a beam span with two shear connections was shown previously in Figure 330, and an expression for the extension of the connection at the center of the bolt group was presented in Eq. (3.15). Introducing the small-angle approximation $\theta \approx \Delta / L$, Eq. (3.15) can be approximated as

$$
\frac{\delta}{L}=\frac{1}{2}\left(\sqrt{1+\theta^{2}}-1\right)
$$

Substituting Eq. (3.23) into (3.18) and rearranging yields the following quadratic equation for $\theta_{u, i}$ :

$$
\theta_{u, i}^{2}+4\left(\frac{y_{i}}{L}\right) \theta_{u, i}-4\left(\frac{\delta_{u}}{L}\right)\left(1+\frac{\delta_{u}}{L}\right)=0
$$

in which the terms $4\left(y_{i} / L\right)^{2} \theta_{u, i}^{2}$ and $8\left(y_{i} / L\right)\left(\delta_{u} / L\right) \theta_{u, i}$ have been dropped, retaining terms up to the second order in quantities $\ll 1$. Solving the quadratic equation and taking the positive root yields the following expression for $\theta_{u, i}$ :

$$
\theta_{u, i}=2 \sqrt{\left(\frac{y_{i}}{L}\right)^{2}+\frac{\delta_{u}}{L}\left(1+\frac{\delta_{u}}{L}\right)}-2\left(\frac{y_{i}}{L}\right)
$$

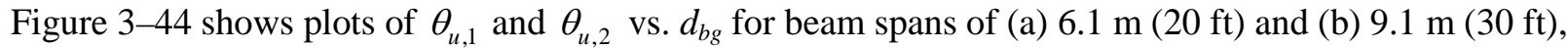
along with the linear regression equation for $\theta_{\max }$ in Eq. (3.3), from FEMA 355D (FEMA 2000). Plotted with these analytical curves are values of rotational capacity corresponding to the peak vertical loads from the reduced model results shown in Figure 3-39, Figure 3-40, and Figure 3-41, for both gradual 
softening and sudden fracture. The rotation values corresponding to sudden fracture in Figure 3-44 correspond well with $\theta_{u, 1}$, the analytical result for the rotation at which the bottom bolt row reaches its ultimate load, while the rotation values corresponding to gradual fracture correspond well with $\theta_{u, 2}$, the analytical result for the rotation at which the bottom bolt row reaches its ultimate load.

Comparing Figure 3-44(a) and Figure 3-44(b) shows that the rotational capacities are smaller for the longer span. This is because, for a given rotation $\theta$, the axial extension $\delta$ increases linearly with $L$, according to Eq. (3.23), thus imposing greater deformations on the connections for longer spans. Note also that the rotational capacities in Figure 3-44 are lower than those shown in Figure 3-43 for a shorter beam span of $L=1.89 \mathrm{~m}(6.21 \mathrm{ft})$, even though the shorter beam span has only one shear connection per span, resulting in reduced axial deformation capacity (see Section 3.4.2). Figure 3-44 shows a slight increasing trend of $\theta_{u, 1}$ and $\theta_{u, 2}$ with $d_{b g}$ for both span lengths, in contrast with the decreasing trend shown in Figure 3-43 for exterior pin supports at beam mid-height. The rotational capacities in Figure 344 are significantly less than predicted by FEMA 355D (FEMA 2000), with $\theta_{u, 1}$ being as much as $62 \%$ less than $\theta_{\max }$ for the 3-bolt connection with $9.1 \mathrm{~m}(30 \mathrm{ft})$ span.
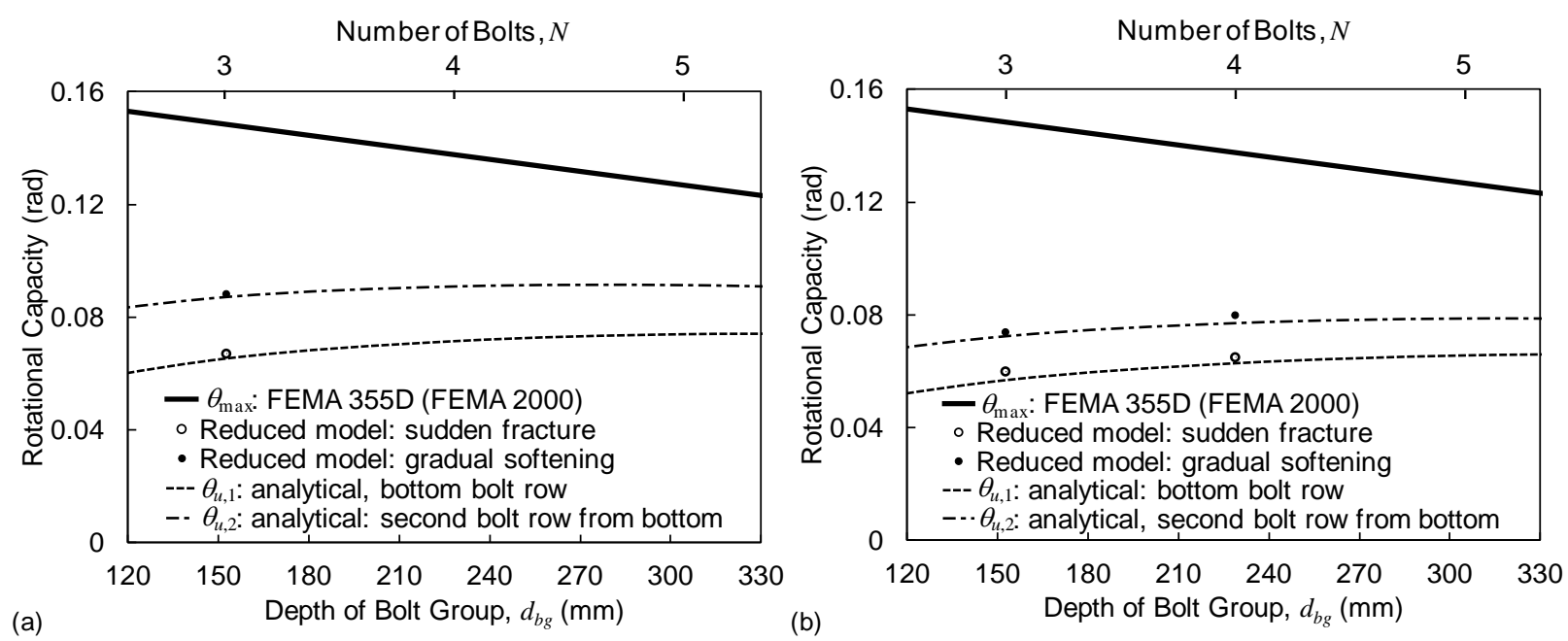

Figure 3-44. Comparison of analytical rotational capacities to values obtained from reduced models with two shear connections per span: (a) $6.1 \mathrm{~m}$ (20 ft) span; (b) $9.1 \mathrm{~m}$ (30 ft) span

\subsection{SUMMARY AND CONCLUSIONS}

Two alternative finite element modeling approaches were described for analysis of single plate "shear tab” connections under column loss scenarios: (1) detailed modeling and (2) reduced modeling. The detailed modeling approach used finely meshed solid elements, contact algorithms, and plasticity models calibrated to match stress-strain curves and fracture strains from tensile tests. Comparison with experimental data from bolted connections showed that detailed models are able to capture both bolt shear deformations and bearing-induced plate deformations, including the combination of these mechanisms that contributes to the overall deformation in shear tab connections. The reduced modeling approach used an assembly of nonlinear spring elements, one for each bolt row in a shear tab connection, with nonlinear load-deformation relationships that represent the combination of bolt shear and bearing-induced deformations. Yield and ultimate capacities of the nonlinear springs were calculated from equations in the AISC specification (AISC 2010), while the initial stiffness and the deformation at ultimate load are 
calculating using empirical equations based on seismic testing of shear connections (FEMA 2000). Detailed model computations showed a steep drop in resistance after the ultimate load for connections governed by bolt shear failure but a more gradual softening behavior after the ultimate load for connections governed by bolt tearout. This distinction was reflected in the reduced models by using a steeper post-ultimate descent in the load-deformation curve for connections governed by bolt fracture than for those governed by bolt tearout.

Both detailed and reduced models were compared with experimental data from a series of two-span beam assemblies subjected to displacement-controlled loading of the unsupported center column (Thompson 2009). Assemblies with 3-bolt, 4-bolt, and 5-bolt shear tab connections were considered, and fairly good agreement was observed between the computed and experimental results, with deviations in the ultimate vertical load being generally less than $20 \%$, comparable to the variability in the measurements themselves. The detailed and reduced models were able to capture the successive stages of the measured responses, including (1) connection slippage, (2) flexural action, and (3) catenary action, in which tensile forces developed in the beams and increased until failure occurred.

Detailed model simulations of the two-span beam assembly tests showed that plastic deformations were concentrated in the bolts and in bearing-induced elongations of the bolt holes, while the remainder of the beam remained in the elastic range. Motivated by this observation, a simple but fairly accurate spreadsheet calculation procedure for the load-deformation response of two-span beam assemblies was developed, based on the assumption that all of the deformation is concentrated in the connections, while the beam spans rotate as rigid bodies with negligible bending or axial deformations. Equations were derived for two-span beam assemblies with two different end support conditions: (1) exterior pin supports, as in the tests by Thompson (2009), and (2) two shear connections per span, as in a typical gravity framing system. The simplified spreadsheet calculations were compared with detailed and reduced model results for both types of end support conditions, and fairly good agreement was observed. The additional axial deformation capacity of two shear connections, as opposed to just one, was found to increase both the ultimate vertical load and the corresponding rotational capacity by about $30 \%$, while the peak axial tension remained about the same. This significant increase highlights the importance of axial deformation capacity on the collapse resistance of connections. The simplified spreadsheet calculation procedure was found to overestimate the post-ultimate capacity of the assembly with two shear connections per span, because it does not account for localization of deformation in the postultimate softening response. Both the detailed and reduced models predicted localization of deformation at one end connection after the ultimate load was attained, resulting in a steeper drop in resistance.

With confidence in the reduced modeling approach established through comparisons with experimental measurements and detailed model computations, reduced models were used to assess the resistance of two-span beam assemblies from the prototype buildings (see Section 2.4) under "pushdown" loading of an unsupported center column. By considering two-span beam assemblies from different gravity frames in the prototype buildings, the influences of span length and number of bolts could be considered. Comparing the response of two assemblies with span lengths of $6.1 \mathrm{~m}(20 \mathrm{ft})$ and $9.1 \mathrm{~m}(30 \mathrm{ft})$ and comparable 3-bolt connections, it was found that the ultimate vertical load was about $28 \%$ greater for the assembly with the shorter span, while the peak value of the axial force was comparable in the two cases. The larger vertical capacity was due to the fact that the axial tension for a given rotation was smaller for the shorter span, enabling the connections to sustain larger rotations prior to exceeding their tensile capacity. Comparing the response of two assemblies with 3-bolt and 4-bolt connections and the same span 
length of $9.1 \mathrm{~m}$ (30 ft), it was found that the ultimate vertical load was about twice as large for the assembly with the 4-bolt connections, due to primarily to the increased tensile capacity of the connections.

The influence of post-ultimate softening behavior on the resistance of the two-span beam assemblies was also investigated using the reduced models, and it was found that changing the post-ultimate behavior from gradual softening (typical of bolt tearout) to sudden fracture (typical of bolt shear rupture) could reduce the ultimate vertical capacity by as much as $23 \%$, while the peak axial forces were reduced by only $7 \%$ or less. Given the significant reduction in the ultimate vertical capacity associated with sudden fracture rather than gradual softening, it would seem prudent in assessing collapse resistance to assume that sudden fracture will occur, even if design calculations indicate that tearout failure controls. This conservative approach is supported by noting that all of the failures observed by Thompson (2009) exhibited sudden fracture rather than gradual softening and that factors such as plate overstrength could potentially shift the failure mode from bolt tearout to bolt shear rupture.

Finally, kinematic relationships between the connection deformations and the overall deflections and rotations of the assemblies were used to derive expressions for the rotational capacity of the connections as functions of the span length and deformation capacity of the connections. Expressions were derived for two-span beam assemblies with (a) exterior pin supports at beam mid-height, for comparison with the experimental data of Thompson (2009) and (b) two shear connections per span, for comparison with the reduced model results for the prototype two-span beam assemblies. In both cases, fairly simple expressions were obtained for the rotation at which the $i$ th bolt row reaches its ultimate load. Beam rotations corresponding to initial and secondary failures reported by Thompson (2009) were found to correspond quite well to the analytical results for the rotations at which the bottom bolt row and the second bolt row from the bottom, respectively, would reach their ultimate loads. Similarly, reduced model results corresponding to sudden fracture and gradual softening were found to correspond well with the analytical results for the rotations at which the bottom bolt row and the second bolt row from the bottom, respectively, would reach their ultimate loads. Rotational capacities were found to be as much as $62 \%$ less than those based on seismic testing of shear connections (FEMA 2000), due to the axial component of extension imposed in addition to the rotations. This result is in contrast with experimental data from steel moment frames (Sadek et al., 2010), for which rotational capacities under simulated column loss were found to be about twice as large as those based on seismic test data. Even smaller rotational capacities are observed in subsequent analyses, when the contribution of the composite floor slab is included (see Section 5.3.3). 
This page intentionally left blank. 


\section{Chapter 4 \\ MODELING AND ANALYSIS OF COMPOSITE FLOOR SYSTEMS}

This chapter considers the modeling and analysis of the floor framing system, including the composite slab. As in the modeling of shear connections presented in Chapter 3, both detailed and reduced modeling approaches are considered for analyzing the behavior of the floor system under a column loss scenario. In presenting the modeling approaches and comparing the computed responses, a 2 bay $\times 2$ bay portion of the floor system from prototype building A is considered, as illustrated in Figure 4-1. The slab in this floor system is assumed to be connected to the beams and girders (including those along the perimeter) by shear studs designed for fully composite action (see Table 2-2). The center column is unsupported vertically, and loads are applied gradually, as described in Section 4.1, to simulate quasi-static column loss. The detailed modeling approach, described in Section 4.2, follows the approach of Sadek et al. (2008) and Alashker et al. (2010) and uses a large number of solid, shell, and beam elements. The reduced modeling approach, described in Section 4.3, uses a smaller number of beam and spring elements, with a fairly coarse mesh of shell elements to represent the floor slab. Section 4.4 presents a comparison of computed results from the detailed and reduced models.

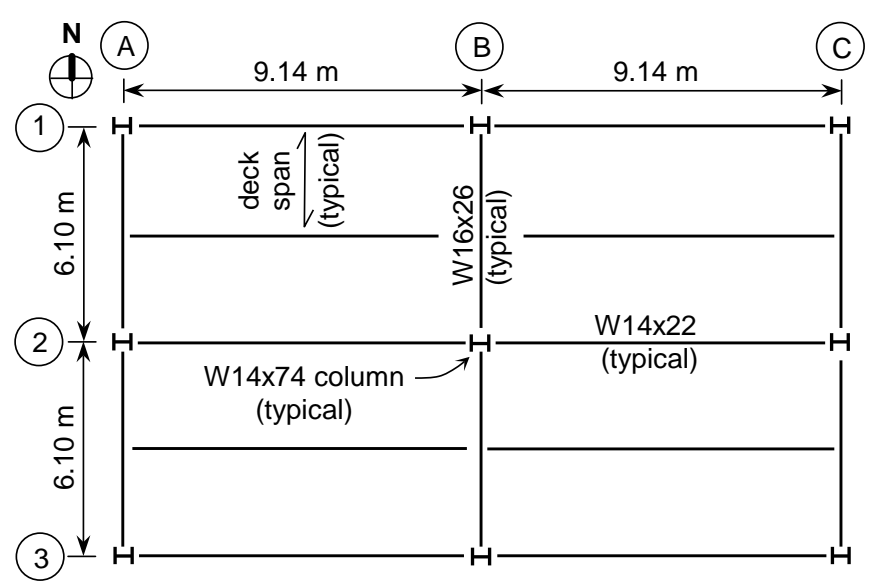

Figure 4-1. 2 bay $\times 2$ bay gravity framing system from prototype building $A$

\subsection{QUASI-STATIC COLUMN LOSS}

In analyzing the behavior of the floor systems in this chapter, two different methods of loading are considered, as described in Alashker et al. (2010). The first method involves applying a concentrated load to the center column under displacement control, while the second method involves applying a gradually increasing uniform load to the entire slab under force control. The analyses are performed dynamically, using explicit time integration in LS-DYNA (Hallquist 2007), while both the prescribed displacement (under concentrated loading) and the applied load (under uniform loading) are increased gradually to maintain quasi-static loading conditions.

Figure 4-2 shows force-displacement curves obtained from the two loading methods for the floor system in Figure 4-1(a), using the detailed model described in the following section. In both cases, the E-W connections to the center column have completely failed (i.e., all three bolt rows have reached their failure displacement and can no longer carry tension or shear) at a center column displacement of about $600 \mathrm{~mm}$ (24 in). Under concentrated loading of the center column, the N-S connections have also 
completely failed at a displacement of about $650 \mathrm{~mm}$ (26 in), after which no further load can be applied to the system, as shown in Figure 4-2(a). Under uniform loading of the floor slab, the N-S connections have completely failed at a displacement of about $800 \mathrm{~mm}$ (31 in), after which the system continues to carry load, as shown in Figure 4-2(b). Since the displacement of the center column is not meaningful after the column has completely detached from the beams and girders, the vertical displacement plotted on the horizontal axes in Figure 4-2 (and in subsequent figures) is the largest vertical displacement of the beam and girder ends originally attached to the center column. Prior to connection failure, this displacement matches very closely the displacement of the center column. Values of load intensity are plotted on the vertical axis for both concentrated and uniform loading, and the load intensity in the case of concentrated loading is calculated by dividing the applied load by the tributary area of $55.7 \mathrm{~m}^{2}\left(600 \mathrm{ft}^{2}\right)$ for the center column. As noted by Alashker et al. (2010), the capacity of the system obtained using the two loading methods is comparable when presented in terms of load intensity.

Both the applied load and the total vertical reaction at the column bases are shown in Figure 4-2. In this study the load carried by the system is calculated as either the applied load or the total reaction, whichever value is smaller. Under static conditions, the reaction must equal the applied load. However, because dynamic analyses are performed, local failures can lead to acceleration of the structure, resulting in a difference between the applied load and the reaction that is balanced by inertial forces. Such inertial effects under concentrated loading are illustrated in Figure 4-2(a), in which a pulses in the vertical reaction are observed at displacements of about $600 \mathrm{~mm}$ (24 in) and $650 \mathrm{~mm}$ (26 in), as the floor system rebounds after failure of the connections to the center column. The peak reaction force in this case is not representative of the capacity of the system. Under uniform loading the reaction force can drop below the applied force when local failures occur, as illustrated in Figure 4-2(a), where dips in the reaction force at central column displacements of about $700 \mathrm{~mm}$ (28 in) and $1100 \mathrm{~mm}$ (43 in) are associated with downward acceleration of the structure. In such cases, the applied force is not representative of the capacity of the system. These examples illustrate that both the applied force and the reaction force can overestimate the capacity of the system under different conditions. Taking the smaller of the two values ensures that the capacity of the system is not overestimated due to dynamic effects associated with local failures.

(a)
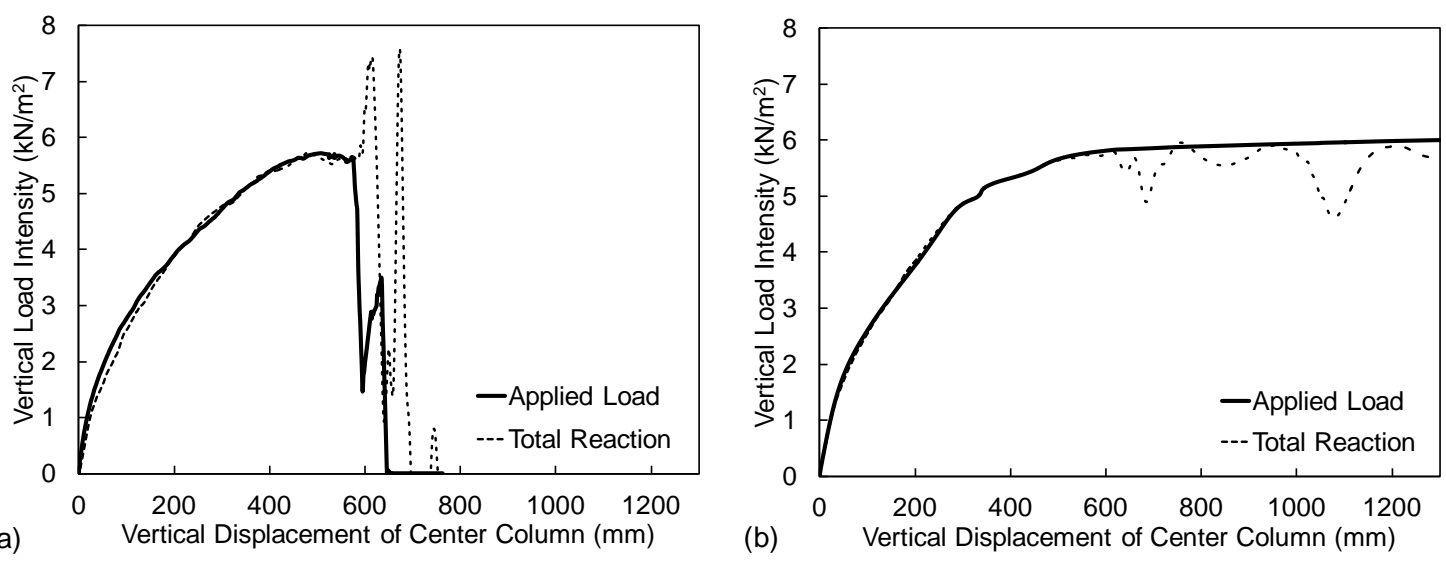

Figure 4-2 Comparison of applied load and total reaction computed from detailed model: (a) concentrated load; (b) uniform load. (2 bay $\times 2$ bay floor system from building $\mathrm{A}$ )

\subsection{DETAILED MODELING APPROACH}

Figure 4-3 shows a detailed model of the floor system in Figure 4-1, which is based on the model previously developed by Sadek et al. (2008). Only one quarter of the floor system is modeled, with appropriate boundary conditions on the planes of symmetry. The columns extend one story above and 
below the floor slab, and the upper and lower ends of the columns are modeled as pinned. As shown in Figure 4-4(a), concrete in the floor slab is represented using solid elements, while the welded wire reinforcement is represented using beam elements sharing common nodes with the solid elements. Bond slip of the reinforcement is not considered. The profiled steel deck and the wide flange beam and column sections are represented using shell elements. Shear studs embedded in the concrete slab and connecting the steel deck to the floor beams are represented using beam elements sharing common nodes with the solid and shell elements of the concrete slab, steel deck, and wide flange beams. The typical edge length of the solid, shell, and beam elements in the model is about $38 \mathrm{~mm}$ (1.5 in). Sliding contact with a frictional coefficient of 0.3 was defined among the various components of the model to prevent interpenetration and to allow for the possibility of bearing (e.g., of the floor slab and/or beam flanges against the columns).

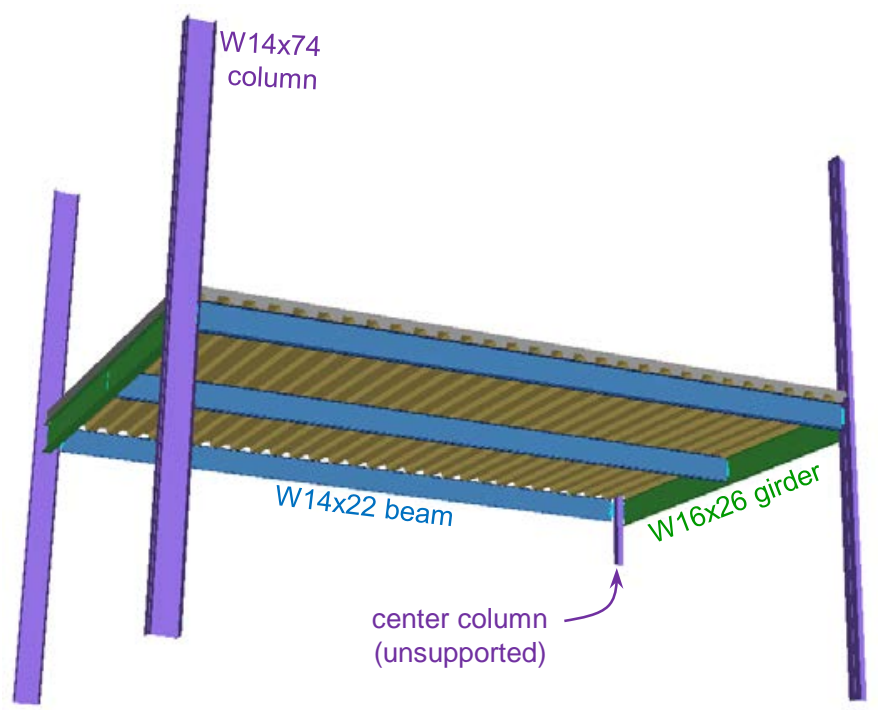

Figure 4-3 Detailed model of composite floor system.
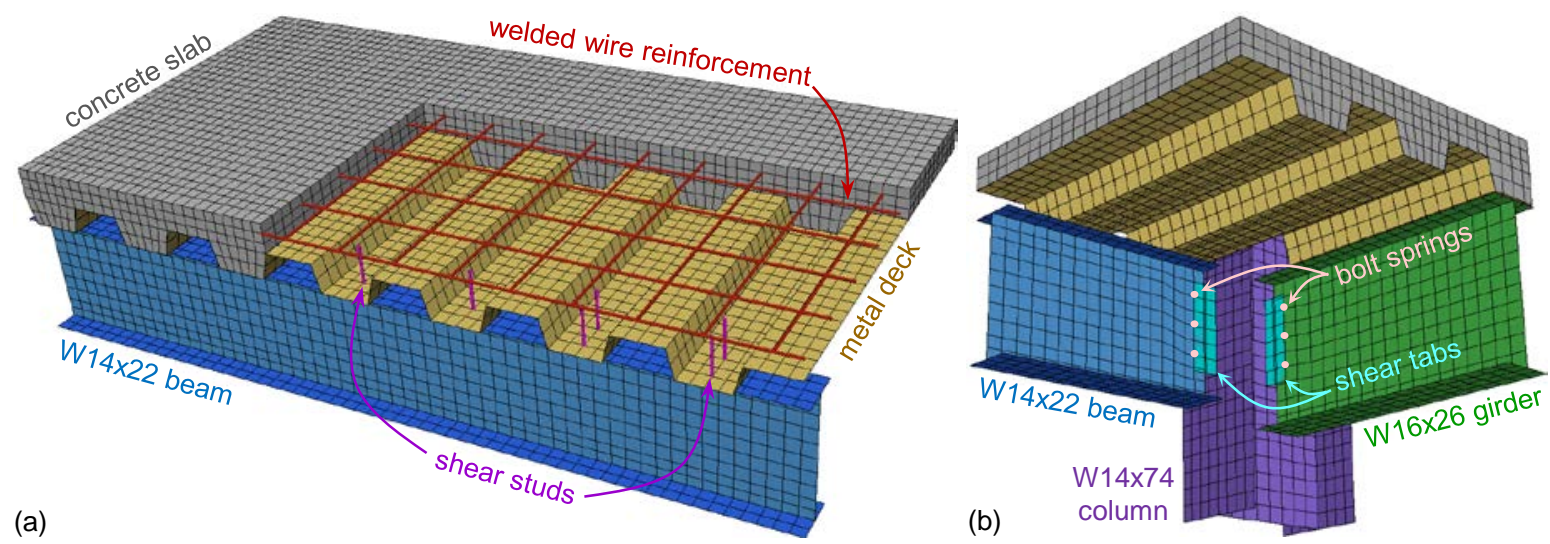

Figure 4-4 Finite element mesh used in detailed model: (a) composite floor slab; (b) beam-to-column connections.

\subsubsection{Connection Modeling}

While Sadek et al. (2008) and Alashker et al. (2010) used specially calibrated shell elements to model the nonlinear behavior and failure of the shear tab connections, in this study the shear tab connections are represented using the nonlinear springs described previously in Section 3.2.1. As illustrated in Figure 4- 
4(b), these spring elements interconnect nodes of shell elements on the beam webs with nodes of shell elements representing the shear tabs. These bolt spring elements are used in both the detailed model of the floor system and in the reduced model described subsequently in Section 4.3, in order to ensure consistency in modeling of the shear connections under the two approaches.

Two rows of shell elements represent each shear tab, as shown in Figure 4-4(b). Since bearing-induced deformations and failure are incorporated in the nonlinear bolt spring elements, shell elements in the row connected to the nonlinear spring elements are assigned an elastic material model to preclude local plastic deformations. Shell elements in the row connected to the column are assigned a piecewise linear plasticity material model, as described in the following section, to allow for yielding of the connections when subjected to torsion and transverse shear loading due to membrane action of the floor slab. Using this approach, load-displacement curves obtained for transverse shear and torque-rotation curves obtained for torsion were found to be reasonably consistent with corresponding curves obtained using high-fidelity solid-element models of the connections, described subsequently in Section 4.3.2.

\subsubsection{Material Modeling}

The various steel components in the model are represented using piecewise linear plasticity models: material type 3 in LS-DYNA for the beam elements representing shear studs and welded wire reinforcement, and material type 24 for the shell elements representing the steel deck, shear tabs, and wide flange sections. Stress-strain curves used in the models were calibrated to match the values of yield strength, tensile strength, and percent elongation listed in Table 2-1 for the various components. Fracture was modeled using element erosion, in which elements were deleted at a value of plastic strain corresponding to the specified elongation.

Figure 4-5 shows engineering stress-strain curves used for the wire reinforcement, shear studs, and steel deck. Because ASTM standard A82 (ASTM 2007a) does not specify a minimum elongation for welded wire reinforcement, a value of $5 \%$ was used for the fracture elongation, based on tensile test data reported by Gilbert and Sakka (2007), which indicated an elongation between $4 \%$ and $6 \%$ at fracture. Note that this is substantially less than the fracture elongation of $25 \%$ used for the wire reinforcement by Sadek et al. (2008) and Alashker et al. (2010). The stress-strain curve shown in Figure 4-5 was used for the portion of the shear stud embedded in concrete, while the portion of the shear stud connecting the beam flange to the steel deck was modeled using a spot weld model (material type 100 in LS-DYNA), with a shear failure criterion based on the nominal shear strength from the AISC Specification (AISC 2010, Section I8.2a). The steel deck is modeled as continuous, under the assumption that connections between adjacent panels (e.g., shear studs welded to the floor beams through deck panels) are able to develop the full capacity of the deck. Computed force levels in the steel deck can be used to assess the required strength of such connecting elements to develop membrane action. 


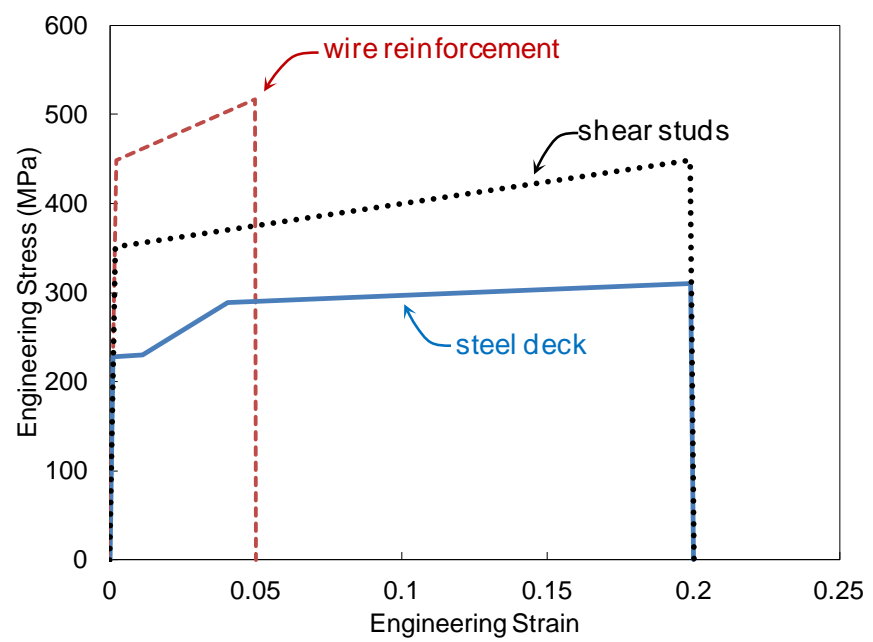

Figure 4-5 Engineering stress-strain curves used to represent wire reinforcement, shear studs, and steel deck.

Two material models are considered for the concrete floor slab. The first is a three-invariant concrete damage model (material type 72R3 in LS-DYNA) used by Sadek et al. (2008) and Alashker et al. (2010) in their analyses of composite floor systems. The second is a continuous surface cap model (material type 159 in LS-DYNA) used by Lew et al. (2011) in their analyses of reinforced concrete beam-column assemblies under a column removal scenario, which yielded good agreement with full-scale data. Material model parameters for both material types were generated automatically based on the specified minimum compressive strength of $20.7 \mathrm{MPa}$ (3000 psi). Solid elements with reduced integration are used for both material types, so hourglass control is required to suppress spurious zero-energy modes of deformation, and an assumed strain co-rotational stiffness form of hourglass control was selected (hourglass control type 6 in LS-DYNA).

Figure 4-6 shows a comparison of load-displacement curves obtained using the two concrete models under concentrated loading of the center column. For each model, curves are presented for different values of the hourglass control coefficient QM, and increases in the peak load with increasing QM are evident. Material type 72R3 generally yielded lower values of the peak load than material type 159 and exhibited somewhat greater sensitivity to the hourglass control coefficient QM. In this study, material type 159 is selected to represent the concrete slab, and a value of $\mathrm{QM}=0.03$ was deemed adequate for hourglass control, since further increases in QM produced only slight changes in the computed response. Using material type 159 with QM $=0.03$, the hourglass energy at the peak vertical load, with a center column displacement of about $500 \mathrm{~mm}$ (20 in), was approximately $2.6 \%$ of the external work done by the concentrated load. The combined effect of the concrete material type and the hourglass control coefficient illustrated in Figure 4-6 is the primary reason that the capacities obtained using the detailed model in this study, based on material type 159 with $\mathrm{QM}=0.03$, are larger than those reported previously by Sadek et al. (2008), based on material type 72R3 with QM $=0.003$. Results of the detailed model are presented subsequently in Section 4.4, for comparison with results obtained using the reduced modeling approach described in the following section. 



Figure 4-6 Influence of hourglass control coefficient QM on load-displacement curves for detailed models with different concrete material types: (a) Material type 72R3; (b) material type 159. (2 bay $\times 2$ bay floor system from building A; concentrated load)

\subsection{REDUCED MODELING APPROACH}

Figure 4-7 shows a reduced model of the 2 bay $\times 2$ bay floor system of Figure $4-1$. As in the detailed model discussed previously, the columns extend one story above and below the floor slab, and the tops and bottoms of the columns are modeled as pinned. The wide flange beams and columns are represented using beam elements, while the floor slab is represented using shell elements. The finite element mesh in Figure 4-7 was generated with a target element size of $610 \mathrm{~mm}$ (24 in). The mesh is constructed in such a way that nodes along the beams are aligned directly below nodes of the shell elements representing the floor slab, so that these nodes can be interconnected by discrete elements representing shear studs. Details of the reduced modeling approach for the composite floor system and the beam-to-column connections are illustrated in Figure 4-8 and are discussed in the following sections.

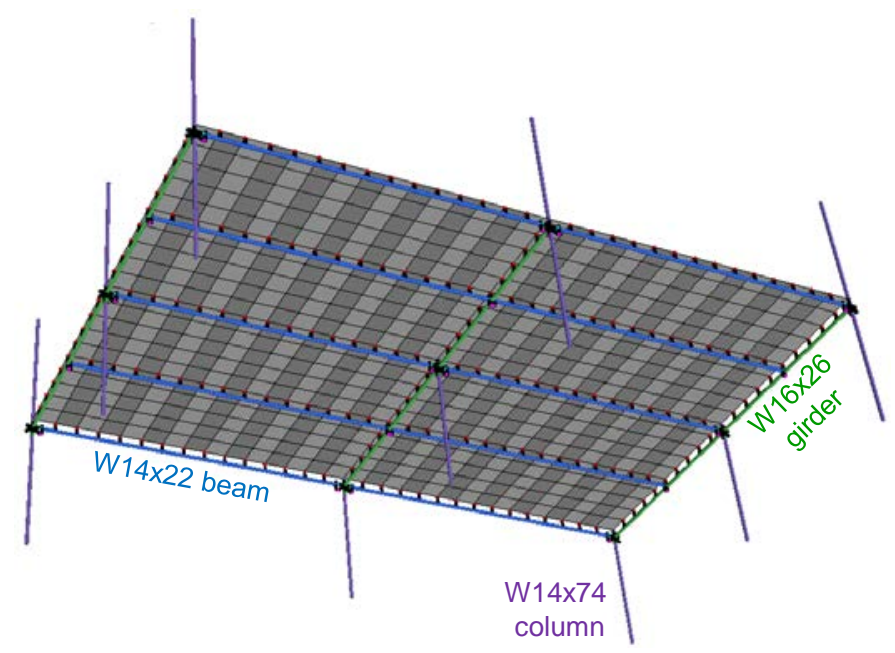

Figure 4-7 Reduced model of composite floor system. 

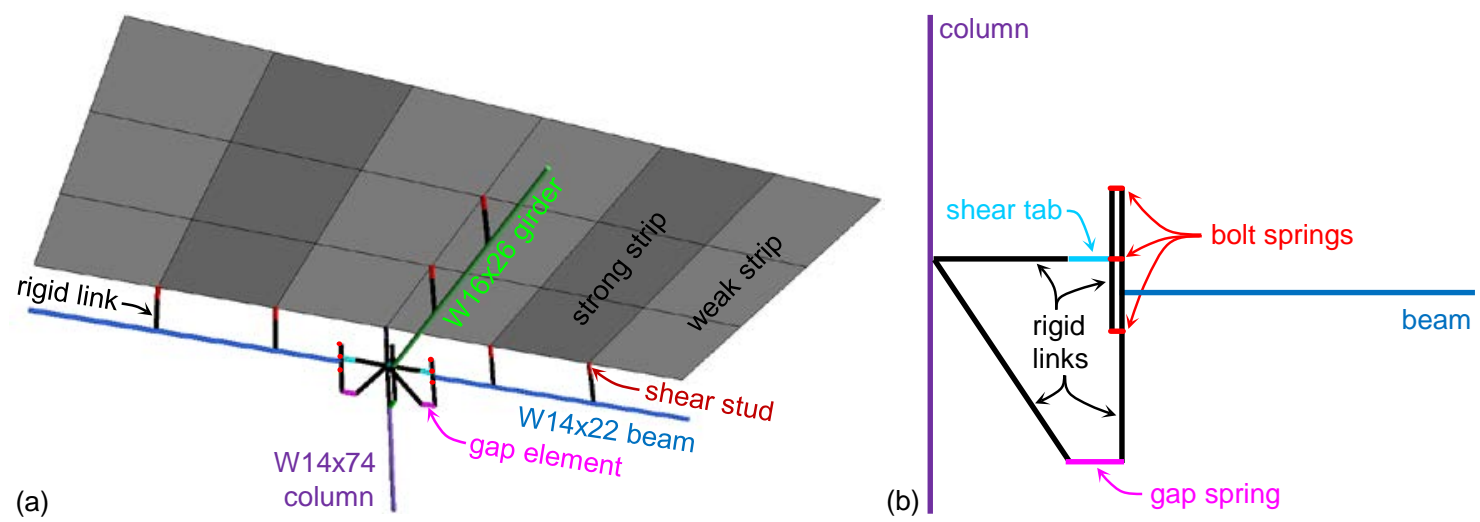

Figure 4-8 Finite element mesh used in reduced model: (a) composite floor system; (b) beam-to-column connection.

\subsubsection{Composite Floor Slab Modeling}

As illustrated in Figure 4-8(a), the concrete slab on steel deck is represented in the reduced model using alternating strips of shell elements denoted "strong" and "weak" strips, which are oriented parallel to the ribs in the steel deck. As illustrated in Figure 4-9, the weak strips include only the concrete above the top of the steel deck, while the strong strips include the full depth of concrete. No contribution from the steel deck is included in the weak strips, in order to represent the anisotropic behavior of the steel deck, which has much greater stiffness and strength along the ribs than across the ribs. Six integration points are used through the thickness of each shell element, with four integration points representing the concrete, a fifth integration point representing the welded wire, and a sixth integration point representing either the steel deck (for the strong strips) or a "dummy material” with negligible stiffness and strength (for the weak strips, to represent the absence of material below the top of the steel deck). The area of the steel deck represented in the strong strips corresponds only to the bottom surface of each rib, with a width of $132 \mathrm{~mm}$ (5.2 in) for each $152 \mathrm{~mm}$ (6 in) rib. This is consistent with the observation based on detailed modeling by Alashker and El-Tawil (2011) that since the steel deck is attached to the steel beams by shear studs, only a portion of the steel deck effectively yields at peak load.



Figure 4-9 Reduced modeling of composite floor slab: (a) actual profile; (b) alternating strong and weak strips.

Alashker et al. (2011) proposed a different approach for reduced modeling of the composite floor slab, in which lines of beam elements parallel to the ribs were used to represent the steel deck. Kwasniewski (2010) used alternating strips of shell elements to represent a composite floor slab with steel deck. However, Kwasniewski (2010) incorporated integration points representing the steel deck in both types of 
alternating strips, while the proposed approach includes the steel deck only in the strong strips, as just discussed, to represent the anisotropic behavior of the steel deck. In addition, the strips of shell elements proposed by Kwasniewki (2010) were of the same width as the ribs of the steel deck, while results presented in the following show that strips much wider than the rib width can be used in order to enhance computational efficiency, without significant loss in accuracy. Figure 4-10 shows three different shell element mesh sizes considered for the floor slab, where the strips of shell elements in Figure 4-10(c) are about twice as wide as the ribs, the strips in Figure 4-10(b) are about four times as wide as the ribs, and the strips in Figure 4-10(a) are about seven times as wide as the ribs. Two possible arrangements for the alternating strips are also considered, as illustrated in Figure 4-11, in which either (a) the weak strips or (b) the strong strips are located along the girders.

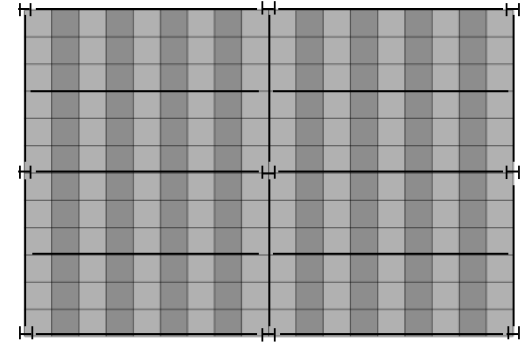

(a)

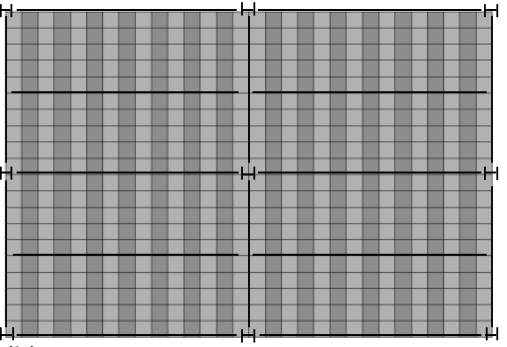

(b)

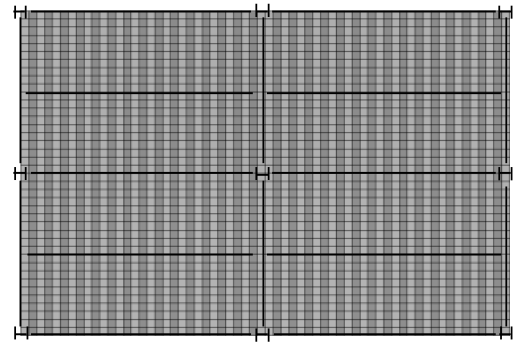

(c)

Figure 4-10 Shell element meshes of floor slab with element sizes of (a) 1016 mm, (b) 610 mm, and (c) 295 mm.

(a)



(b)



Figure 4-11 Alternative arrangements for strips of shell elements in reduced models: (a) weak strips along girders; (b) strong strips along girders.

Figure 4-12 shows the influence of mesh refinement on load-displacement curves obtained for the alternative strip arrangements shown in Figure 4-11, under concentrated loading of the center column. Figure 4-12(a) shows that placing the weak strips along the girders, as in Figure 4-11(a), yields results that are quite insensitive to the mesh size. As shown subsequently in Section 4.4, these results are also in good agreement with results of the detailed model. In contrast, Figure 4-12(b) shows that placing the strong strips along the girders, as in Figure 4-11(b), substantially overestimates the peak loads for the largest mesh size and yields results that change noticeably with mesh refinement, converging slowly towards the results in Figure 4-12(a). This comparison shows that placing the weak strips along the floor beams is preferable, enabling the use of larger shell elements in the floor slab without sacrificing accuracy. Consequently, the mesh arrangement illustrated in Figure 4-11(a) is used in the reduced models throughout the remainder of this report. The intermediate mesh size of $610 \mathrm{~mm}$ (24 in) is used for subsequent analyses, as it yields results that are consistent with the smaller mesh size, but with a significantly reduced computation time, while yielding better spatial resolution in the computed slab forces than the larger mesh size. 

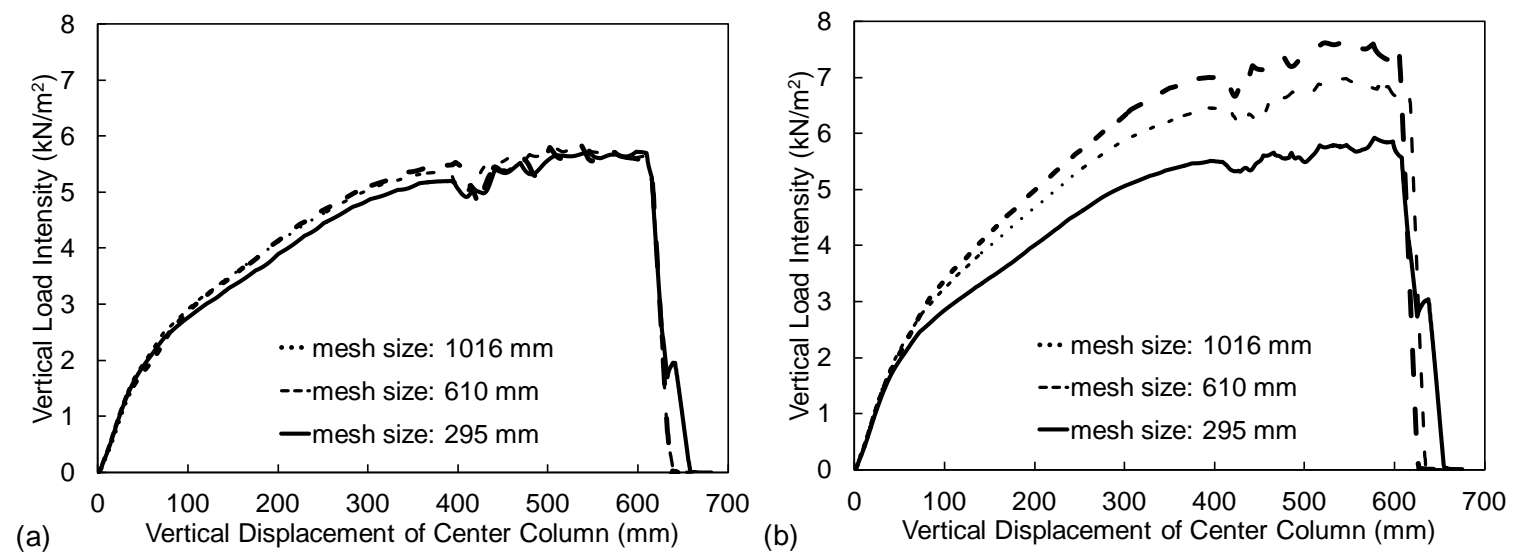

Figure 4-12 Influence of mesh refinement on load-displacement curves for reduced models: (a) weak strips along girders; (b) strong strips along girders. (2 bay $\times 2$ bay floor system from building A; concentrated load)

\subsubsection{Shear Connection Modeling}

The reduced modeling approach used for the shear tab connections is illustrated in Figure 4-8(b). The primary components of the connection model are the bolt springs, previously discussed in Section 3.2, which are interconnected with rigid links to maintain the proper connection geometry. A "gap spring" is added at the level of the bottom flange of the beam, to allow bearing forces to be transmitted if the initial gap between the beam flange and the column closes. As shown in Figure 2-3, the initial gap is $25.4 \mathrm{~mm}$ ( 1 in) for the connections considered in this study. Concrete contact springs could also be included to represent bearing of the concrete slab against the columns, using properties defined in Sadek et al. (2008). However, these concrete contact springs were found to have a negligible effect for column removal scenarios considered in this study and therefore were not included in the analyses.

Because of the three-dimensional nature of the composite floor system considered here, an additional discrete beam element (labeled "shear tab" in Figure 4-8(b)) is used to represent the torsional and transverse shear behavior of the shear tab connection. When membrane forces develop in the floor slab, transverse forces are transmitted to the top flanges of the floor beams through the shear studs, subjecting the connections to a combination of torsion and transverse shear.

The torsional and tranverse shear behavior of the connections was analyzed using detailed models of the shear connections subjected to torsional rotation about the center of the bolt group, as illustrated in Figure 4-13(b), and transverse displacement, as illustrated in Figure 4-13(c). Figure 4-14 shows (a) the torque vs. torsional rotation and (b) the transverse shear force vs. transverse displacement curves obtained from detailed models of the 3-bolt and 4-bolt connections shown in Figure 2-3, along with simplified piecewise-linear representations of these curves used in the reduced models. The ultimate failure modes of the connections were rupture of the shear tab near the welded edge for torsion and tearout of the bolts through the beam web for transverse shear.

A discrete beam element formulation (beam element type 6 in LS-DYNA) is used for the "shear tab" beam, with material type 119 , which allows arbitrary load-deformation and moment-rotation curves to be defined along orthogonal coordinate axes (Hallquist 2007). The reduced model curves shown in Figure 414 are specified for the torsional and transverse shear behavior of the "shear tab" beam element, while the axial, vertical shear, and bending behavior are modeled using the elastic stiffness of the shear tab. In this manner, the torsional and transverse shear behavior of the connection is represented by the "shear tab" beam element, while the in-plane axial, shear, and bending behavior is represented by the bolt springs. To ensure that the bolt springs contribute only to the in-plane behavior, a large stiffness is specified for these elements in the out-of-plane direction. 


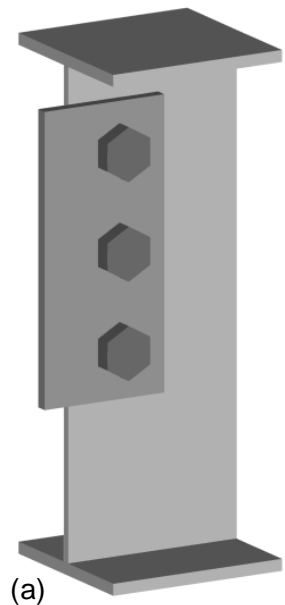

(a)



Figure 4-13. (a) Detailed model of 3-bolt shear tab connection subjected to (b) torsion and (c) transverse shear.


Figure 4-14. Comparison of detailed and reduced models for (a) torsional and (b) transverse shear behavior of shear tab connections

\subsubsection{Material Modeling}

As discussed previously in Section 4.3.1, distinct integration points through the thickness of the floor slab are used for the concrete, welded wire reinforcement, and steel deck. The concrete in the floor slab is modeled using material type 172 in LS-DYNA, which includes concrete cracking in tension and crushing in compression, based on material data and equations from Eurocode 2, part 1.2. The minimum specified compressive strength of $20.7 \mathrm{MPa}$ (3000 psi) is used in the model, with a tensile strength of $2.07 \mathrm{MPa}$ (300 psi).

The welded wire reinforcement and steel deck are represented using a piecewise linear plasticity model (material type 24 in LS-DYNA) with stress-strain curves calibrated to match those shown in Figure 4-5. The welded wire reinforcement and the steel deck are modeled as continuous, under the assumption that splices and connections between adjacent panels are able to develop the full capacity of the material. For the strong strips of shell elements (see Figure 4-9), element erosion is specified at an engineering strain of $20 \%$, corresponding to fracture of the steel deck. For the weak strips, element erosion is specified at a larger engineering strain of $38 \%$, corresponding to the strain at which the steel deck would be completely flat, after unfolding of the ribs. The wide flange beam and column sections are also modeled using material type 24 in LS-DYNA, with stress-strain curves calibrated to match the yield stress, ultimate stress, and elongation values listed in Table 2-1 for ASTM A992 steel. 


\subsubsection{Shear Stud Modeling}

As illustrated in Figure 4-8(a), rigid links extend vertically from the centerline of the beams and girders to the top-of-steel elevation, and discrete beam elements representing shear studs connect these rigid links to nodes of the shell elements representing the floor slab. Using a discrete beam formulation (beam element type 6 in LS-DYNA with material type 119), the force vs. slip curve labeled "reduced model” in Figure 4-15 is used to represent the shear behavior of the shear studs.

The initial portion of the piecewise-linear "reduced model” curve in Figure 4-15 approximates the empirical load-slip relationship proposed by Ollgaard et al. (1971) based on pushout testing of shear studs without steel deck. The empirical curve is also plotted in Figure 4-15, and while the curve is plotted up to a slip of $25 \mathrm{~mm}$ ( $1 \mathrm{in}$ ), it is noted that the equation is only intended to represent the initial load-slip behavior, up to slip of about $5 \mathrm{~mm}$ (0.2 in), for which the empirical relationship yields a normalized shear force value of 0.99. While Ollgaard et al. (1971) considered the initial load-slip behavior of shear studs without steel deck, Rambo-Roddenberry (2002) described the behavior at larger slip values of shear studs welded through steel deck, and the plateau region of the reduced model curve in Figure 4-15 is based on the behavior observed by Rambo-Roddenberry. For $19 \mathrm{~mm} \mathrm{(} 3 / 4$ in) diameter shear studs, RamboRoddenberry (2002, p. 114) measured an average slip of $5.8 \mathrm{~mm}(0.23 \mathrm{in})$ at the ultimate load. RamboRoddenberry (2002, p. 71) also noted that for shear studs in the weak position (i.e., with less concrete on the compression side of the shear stud than on the tension side), the load remained constant for values of slip between $5 \mathrm{~mm}$ and $15 \mathrm{~mm}$ (0.2 in and $0.6 \mathrm{in}$ ) or more, after which the load either fell steadily or in some cases increased further. Based on these observations, the shear force in the reduced model curve remains constant at the ultimate load between $5 \mathrm{~mm}$ and $15 \mathrm{~mm}$ (0.2 in and $0.6 \mathrm{in})$, after which it drops linearly to zero at a displacement of $25 \mathrm{~mm}$ ( 1 in). The ultimate shear strength of a $19 \mathrm{~mm}(3 / 4 \mathrm{in})$ diameter shear stud was calculated as $Q_{u}=76.1 \mathrm{kN}$ (17.1 kip) based on the AISC Specification (AISC 2010, Section I8.2a).

The number of shear studs along each beam in the model depends on the mesh size, but is generally less than the number specified in the design, and the shear force values are scaled up accordingly. Elastic rotational stiffness is also specified for the shear stud elements to provide torsional restraint along the top flange of the floor beams.



Figure 4-15 Shear force versus slip relationship for shear studs used in reduced models. 


\subsection{COMPARISON OF MODEL PREDICTIONS}

Figure 4-16 shows a comparison of load-displacement curves obtained using the detailed and reduced models of the 2 bay $\times 2$ bay floor system in Figure 4-1 under (a) concentrated loading of the center column and (b) uniform loading of the entire slab. Good general agreement is observed between the detailed and reduced models, providing verification of the reduced modeling approach. Under uniform loading, the reduced model is quite consistent with the detailed model up to the initial peak load at a displacement of about $600 \mathrm{~mm}$ (24 in), prior to failure of the connections to the center column. After failure of these connections, the detailed model predicts load values that are slightly greater than those from the reduced model. The slightly larger strength predicted by the detailed model is partly a consequence of the resistance of the steel deck to extension in the across-rib direction. This resistance is neglected in the reduced model by using weak strips with no contribution from the steel deck (see Figure 4-9). However, the differences between the detailed and reduced model remain fairly small, and the predictions of the reduced model are conservative, so the reduced modeling approach is considered acceptable for assessing the collapse resistance of composite floor systems. Throughout the remainder of this report, results are presented using the reduced modeling approach.
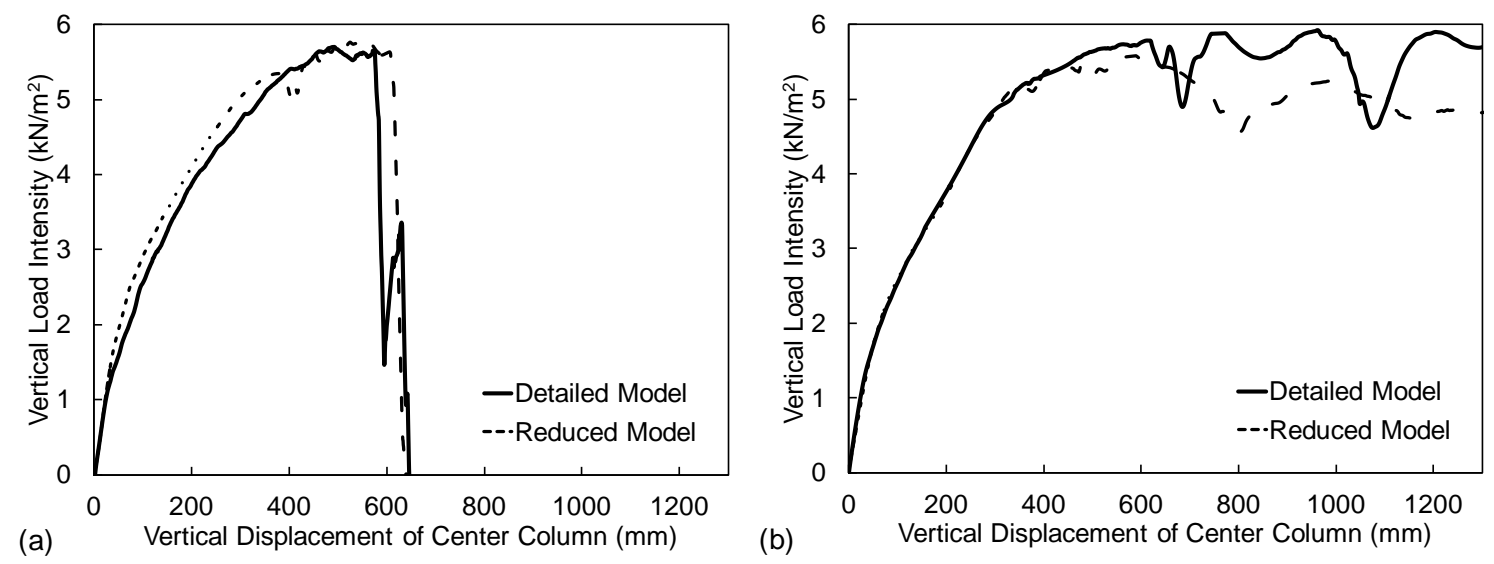

Figure 4-16 Comparison of load-displacement curves from detailed and reduced models: (a) concentrated load; (b) uniform load. ( 2 bay $\times 2$ bay floor system from building $\mathrm{A}$ ) 


\section{Chapter 5 \\ ASSESSMENT OF COLLAPSE RESISTANCE}

Assessing the collapse resistance of steel gravity frame systems involves comparing the capacity of the structure with the demands imposed, in the form of gravity loads. While Section 4.1 presented procedures for the analysis of quasi-static column loss, the demands imposed under sudden column loss are higher than those under static loading. Gudmundsson and Izzuddin (2010) discuss the "sudden column loss" idealization and note that it provides a useful event-independent design scenario for disproportionate collapse assessment. For these reasons, sudden column loss, in addition to quasi-static column loss, is considered for assessing the collapse resistance of steel gravity frame systems in this chapter.

Section 5.1 presents two approaches for assessing structural capacity under sudden column loss. The first approach involves direct dynamic analysis of the structural response to instantaneous loss of the column's vertical support. The second approach involves a simplified approximate procedure proposed by Izzuddin et al. (2008) based on the balance between internal energy and external work at the peak dynamic displacement. In Section 5.2, the gravity loads used for analysis of the floor system are considered, including both an "extraordinary event" load combination used in ASCE 7-10 (ASCE 2010) and UFC 4023-03 (DOD 2009) and a lower level of loading corresponding to the expected gravity loading. In Section 5.3, the collapse resistance of the prototype floor systems is assessed by comparing the capacities under both quasi-static and sudden column loss to the imposed gravity loading. In some cases the capacity is found to be inadequate to sustain even the lower level of expected gravity loading. Section 5.4 presents an assessment of current structural integrity requirements, including the requirements incorporated for high-rise buildings in the 2010 version of the International Building Code (ICC 2010) and the tie force requirements in UFC 4-023-03 (DOD 2009). The 2010 IBC requirements are found to be inadequate to prevent collapse in a column loss scenario, even under the expected gravity loading. The UFC 4-023-03 requirements, on the other hand, are found sufficient to prevent collapse of the prototype floor systems under the "extraordinary event" gravity load combination. Section 5.5 investigates the tie forces required to prevent collapse by considering the capacity of floor systems with varying levels of slab reinforcement.

\subsection{SUDDEN COLUMN LOSS}

\subsubsection{Direct Dynamic Analysis}

The procedure used for direct dynamic analysis of sudden column loss is similar to that presented by Alashker et al. (2010). The procedure is illustrated here for the 2 bay $\times 2$ bay floor system from building A shown in Figure 4-1. Uniform gravity loading of $w=4.36 \mathrm{kN} / \mathrm{m}^{2}\left(91.1 \mathrm{lbf} / \mathrm{ft}^{2}\right)$ is first applied gradually over a period of $1 \mathrm{~s}$ using a smooth ramp function and is held constant for $0.25 \mathrm{~s}$ to avoid introduction of spurious dynamic effects. This gravity initialization phase is indicated in the plot of the vertical reaction at the base of the center column in Figure 5-1(a), where a slight dip in the column reaction between $t=1.0 \mathrm{~s}$ and $t=1.25 \mathrm{~s}$ is due to dynamic effects associated with the gravity initialization. The vertical deflections of the floor system at the end of the gravity initialization phase are shown in Figure 5-2(a). At $t=1.25 \mathrm{~s}$, the vertical support of the center column is suddenly removed. (This is accomplished in LS-DYNA by using a *BOUNDARY_PRESCRIBED_MOTION card to impose a zero displacement constraint that is removed at the specified time.) As shown in Figure 5-1(b), the column drops vertically to a peak dynamic displacement of $595 \mathrm{~mm}$ (23.4 in) at $t=1.9 \mathrm{~s}$ before 
rebounding and oscillating about a new equilibrium position. The computed vertical deflections of the floor system at the instant of peak displacement are shown in Figure 5-2(b). In this case the floor system is able to sustain the applied loading under sudden column loss without collapse.

By repeating this analysis procedure for different levels of the uniform load intensity $w_{k}$, and calculating in each case the peak dynamic deflection $\Delta_{k}$, discrete points on a load-displacement curve for sudden column loss can be generated, as illustrated in Figure 5-3. Different values of the load intensity $w_{k}$ are achieved in the computational model by adding distributed mass to the floor slab in addition to the selfweight. Gravity loading is applied by imposing body forces due to gravitational acceleration in the model (using the LOAD_BODY_Z card in LS-DYNA). In this manner, both the gravity loading and the inertia of the structure are correctly represented. The resulting curve in Figure 5-3 represents the dependence of the peak dynamic displacement under sudden column loss on the intensity of the uniform gravity load acting on the floor slab.

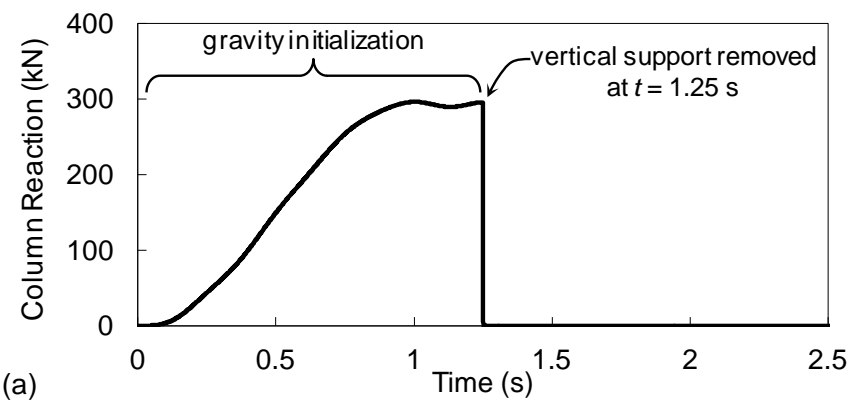

(a)



Figure 5-1. (a) Vertical reaction at center column base and (b) vertical displacement of center column in 2 bay $\times$ 2 bay floor system from building A under sudden column loss 


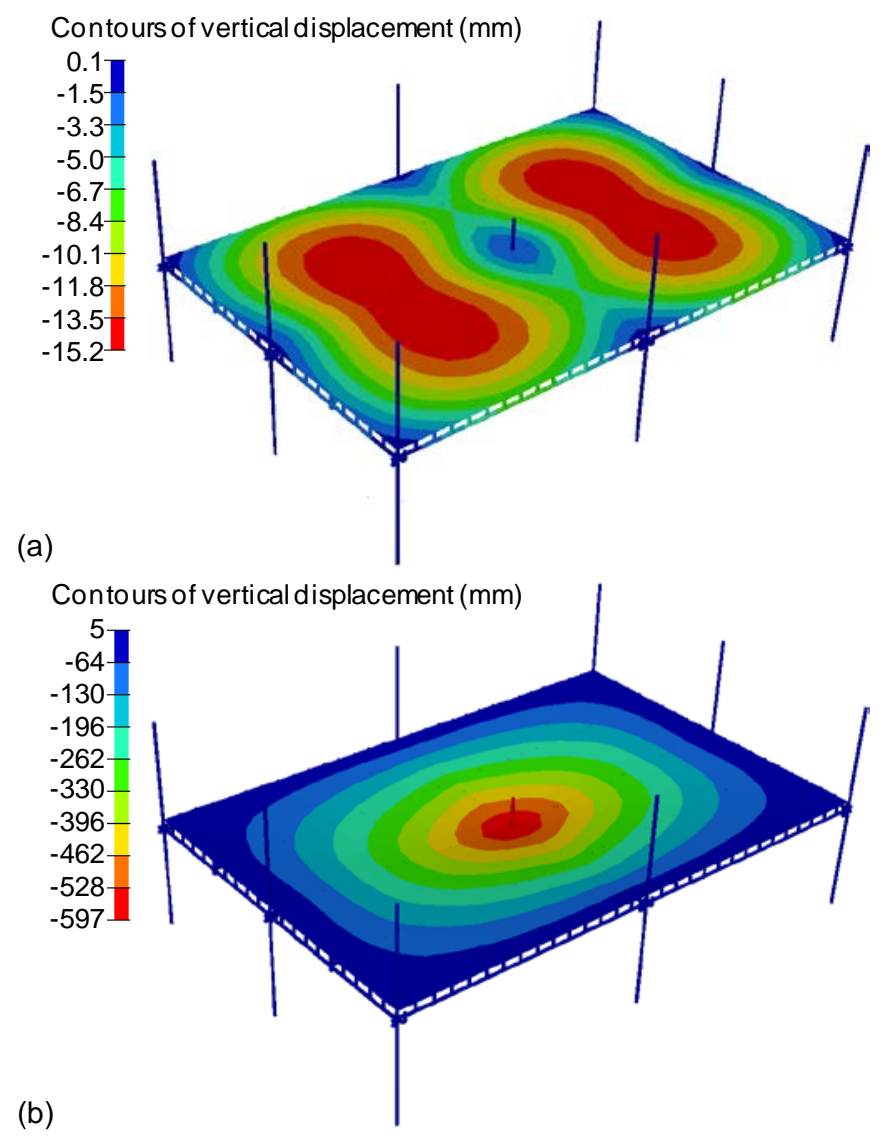

Figure 5-2. Deflections of 2 bay $\times 2$ bay floor system from building A: (a) at equilibrium prior to column loss; (b) at peak displacement after column loss

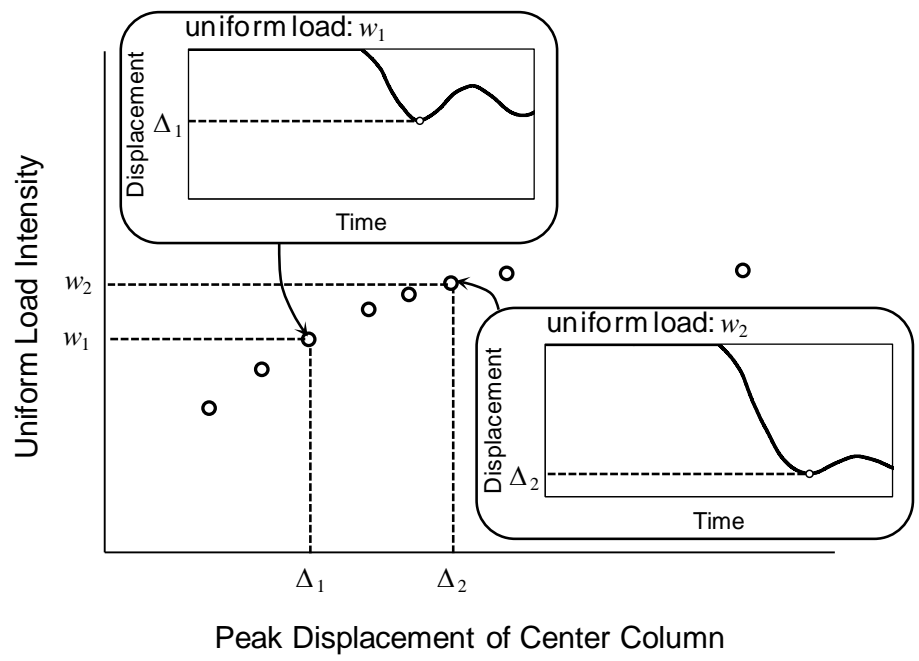

Figure 5-3. Direct analysis procedure for generating a load-displacement curve for sudden column loss 


\subsubsection{Approximate Analysis Based on Energy Balance}

While the procedure described in the previous section requires a separate dynamic analysis to be performed for each point on the resulting load-displacement curve (corresponding to various load intensities), a load displacement curve for sudden column loss can be generated more efficiently using the “simplified dynamic assessment” procedure proposed by Izzuddin et al. (2008). This procedure, which is summarized here in a slightly different form, is based on the assumption that the structure responds in a single mode of deformation, whereby it can be analyzed as a single-degree-of-freedom system. It then follows that at the instant of peak displacement after sudden column removal, the kinetic energy must be zero, and the internal work done by the structure $\left(W_{\text {int }}\right)$ must equal the external work done by the applied loads $\left(W_{\text {ext }}\right)$.

In a sudden column loss scenario, the external work done by the applied loads in reaching the peak dynamic displacement $\Delta_{o}$ can be expressed as

$$
W_{\text {ext }}=\alpha w_{S C L} \Delta_{o}
$$

where $w_{S C L}$ is the unknown value of the uniform load that produces a peak dynamic displacement of $\Delta_{o}$ after sudden column loss, and $\alpha$ is a constant (also unknown, with units of area) that depends on the shape of the deformation mode. Assuming the same deformation mode under static loading, the internal energy at displacement $\Delta_{o}$ can be expressed as

$$
W_{\text {int }}=\alpha \int_{0}^{\Delta_{o}} W_{\text {static }}(\Delta) d \Delta
$$

where the function $w=w_{\text {static }}(\Delta)$, illustrated in Figure 5-4, represents a load-displacement curve obtained from a quasi-static pushdown analysis under uniform load, as described in Section 4.1. Equating internal and external work allows the unknown constant $\alpha$ to be eliminated, yielding the following equation:

$$
w_{S C L} \Delta_{o}=\int_{0}^{\Delta_{o}} w_{\text {static }}(\Delta) d \Delta
$$

The right-hand side of Eq. (5.3) represents the shaded area in Figure 5-4, while the left-hand side represents the hatched area. Eq. (5.3) then yields the following expression for the load intensity $w_{S C L}$ that yields a peak dynamic displacement of $\Delta_{o}$ after sudden column loss:

$$
w_{S C L}=\frac{1}{\Delta_{o}} \int_{0}^{\Delta_{o}} w_{\text {static }}(\Delta) d \Delta
$$

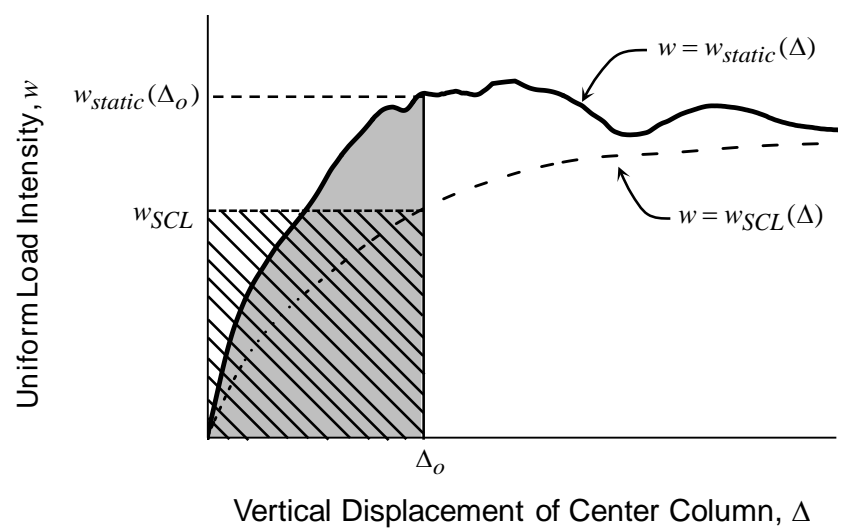

Figure 5-4. Approximate procedure for generating a load-displacement curve for sudden column loss 
By evaluating Eq. (5.4) with varying $\Delta_{o}$, the function $w=w_{S C L}(\Delta)$ can be obtained, which represents the load-displacement curve for sudden column loss, shown by the dashed curve in Figure 5-4. In this manner, the dynamic enhancement associated with sudden column loss can be included using only the results from a static pushdown analysis. The Dynamic Increase Factor (DIF) at a given displacement, denoted $\Omega(\Delta)$, can be defined as follows:

$$
\Omega(\Delta)=\frac{w_{\text {static }}(\Delta)}{w_{S C L}(\Delta)}
$$

\subsubsection{Comparison of Direct and Approximate Analysis Results}

Figure 5-5 shows a comparison of load-displacement results for sudden column loss obtained using the direct and approximate analysis procedures just described. These results correspond to the 2 bay $\times 2$ bay floor system shown in Figure 4-1 under loss of the center column. Three different load-displacement relationships are presented in Figure 5-5. The first relationship, presented as a solid curve, was obtained from quasi-static uniform loading of the floor system under force control, as described previously in Chapter 4. This curve is the same as that previously presented in Figure 4-16(b) for the reduced model. The second relationship, presented using open circles, corresponds to direct dynamic analysis of sudden column loss. These values were generated using the procedure illustrated in Figure 5-3. The third relationship, presented as a dashed curve, also corresponds to sudden column loss but was generated based on the solid curve using the approximate procedure illustrated in Figure 5-4. Fairly good agreement is observed in Figure 5-5 between the results for sudden column loss using the direct and approximate analysis procedures, with differences in the calculated load intensity for a given peak displacement being less than $10 \%$. Figure 5-5 also presents the estimated ultimate capacity under sudden column loss, denoted $w_{S C L, u}$, which is discussed in the following section.

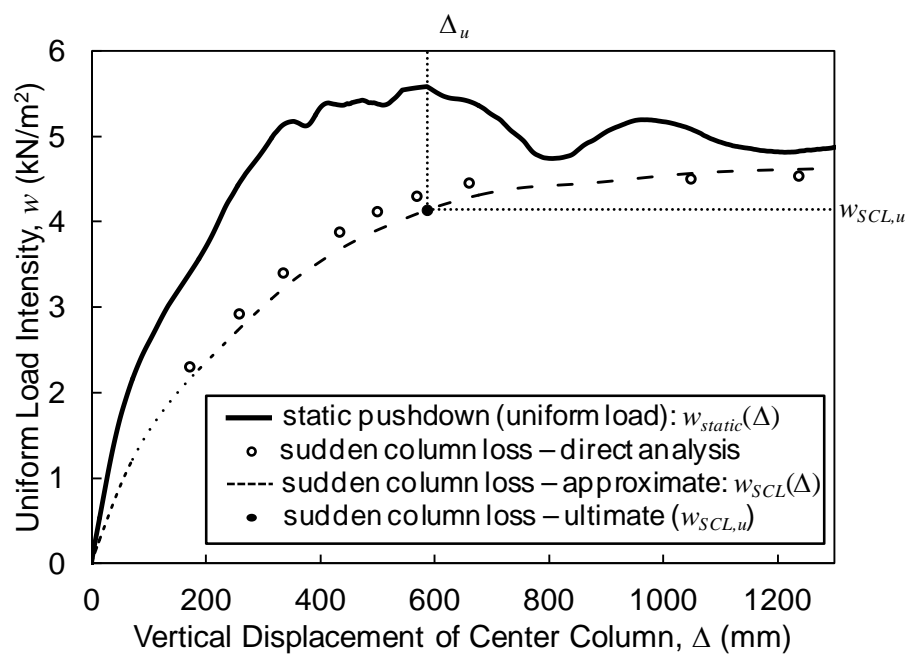

Figure 5-5. Comparison of load-displacement results from direct and approximate analyses of sudden column loss ( 2 bay $\times 2$ bay floor system from building $A$ )

\subsubsection{Determination of Ultimate Capacity under Sudden Column Loss}

While Izzuddin et al. (2008) used a limit state of first connection failure in assessing structural capacity, the analysis procedure described in Section 4.1, with uniform loading under force control, allows the quasi-static load-displacement curve $w=w_{\text {static }}(\Delta)$ to be evaluated beyond the initial failure of connections to the ultimate static capacity of a structural system. Let $\Delta_{u}$ denote the vertical column displacement 
corresponding the ultimate static capacity, as illustrated in Figure 5-5. Even for displacements exceeding $\Delta_{u}$, Figure 5-5 shows good agreement between the direct and approximate analysis results for sudden column loss, confirming that the approximate procedure illustrated in Figure 5-4 remains applicable even after connection failures have occurred.

It is evident in Figure 5-5 that the function $w=w_{S C L}(\Delta)$ can continue to increase for displacements exceeding $\Delta_{u}$, due to residual, post-ultimate resistance of the structural system. Provided that $w_{\text {static }}(\Delta)>w_{S C L}(\Delta)$, the analysis predicts that collapse will not occur. However, uncertainties in model predictions increase significantly in the post-ultimate response, particularly given the force-controlled nature of the uniform loading protocol, which produces accelerations and increasing dynamic effects after the ultimate capacity of the system is exceeded. The assumption of an unchanging mode of deformation, inherent in Eq. (5.4), may also become less appropriate after the ultimate load has been exceeded and displacements become very large. For this reason, and for the sake of conservatism, the ultimate capacity under sudden column loss, denoted $w_{S C L, u}$, is evaluated at the displacement $\Delta_{u}$ corresponding to the ultimate static load (see Figure 5-5):

$$
w_{S C L, u}=w_{S C L}\left(\Delta_{u}\right)
$$

A maximum permissible displacement $\Delta_{\max }$ can also be introduced, so that if the uniform load $w_{\text {static }}(\Delta)$ is still increasing at $\Delta_{\max }$, the ultimate static load is limited to its value at this displacement. In other words, the ultimate static load is evaluated over an interval between 0 and $\Delta_{\max }$ in the vertical displacement $\Delta$ :

$$
w_{\text {static }}\left(\Delta_{u}\right)=\max _{0<\Delta \leq \Delta_{\max }}\left[w_{\text {static }}(\Delta)\right]
$$

In this study, $\Delta_{\max }=1300 \mathrm{~mm}$ (51.2 in) is selected as the maximum permissible displacement for evaluation of ultimate capacities. This corresponds to the approximate displacement at which erosion of shell elements representing the floor slab is first observed for the analysis results illustrated in Figure 5-5. Element erosion represents fracture of the steel deck and is observed at a value of strain corresponding to complete unfolding of the steel deck in the across-rib direction (see Section 4.3.3). While shell element erosion occurs at somewhat larger displacements in other analyses presented subsequently, the selected value of $\Delta_{\max }$ is sufficiently large that in almost all cases, the ultimate static load occurs prior to $\Delta_{\max }$.

\section{$5.2 \quad$ GRAVITY LOADS}

\subsubsection{Load Combination for Extraordinary Events}

ASCE 7-10 (ASCE 2010, Section 2.5.2.2) specifies the following load combination for assessing residual capacity of structural systems following the notional removal of load-bearing elements:

$$
(0.9 \text { or } 1.2) D+0.5 L+0.2\left(L_{r} \text { or } S \text { or } R\right)
$$

where $D$ is dead load, $L$ is live load, $L_{r}$ is roof live load, $S$ is snow load, and $R$ is rain load. For the floor systems considered in this study, this load combination can be simplified as follows:

$$
1.2 D+0.5 L
$$

in which the factor 1.2 is selected for the dead load, rather than 0.9 , because gravity loads do not stabilize the structural system. Roof live loads, snow loads, and rain loads are omitted because a typical intermediate floor of the structure is considered. For a typical floor in the prototype buildings (see 
Chapter 2), the total dead load $D$ is $3.64 \mathrm{kN} / \mathrm{m}^{2}$ (76 lbf/ $\left./ \mathrm{ft}^{2}\right)$, which includes the floor self-weight of $2.2 \mathrm{kN} / \mathrm{m}^{2}\left(46 \mathrm{lbf} / \mathrm{ft}^{2}\right)$ and a superimposed dead load of $1.44 \mathrm{kN} / \mathrm{m}^{2}\left(30 \mathrm{lbf} / \mathrm{ft}^{2}\right)$.

The live load $L$ in this combination is reduced based on Eq. (4.7-1) in ASCE 7-10, which can be written as:

$$
L=L_{o}\left(0.25+\frac{\lambda_{o}}{\sqrt{K_{L L} A_{T}}}\right) \geq \begin{cases}0.5 L_{o} & \text { (if supporting one floor) } \\ 0.4 L_{o} & \text { (if supporting multiple floors) }\end{cases}
$$

where $\lambda_{o}=4.57 \mathrm{~m}(15 \mathrm{ft}), A_{T}$ is tributary area, and $K_{L L}$ is the live load element factor given in Table 4-2 of ASCE 7-10 (ASCE 2010).

Minimum specified values of the live load $L_{o}$ for different occupancies in an office building are listed in Table 5-1, from Table 4-1 of ASCE 7-10 (ASCE 2010). In the structural design of the prototype buildings (see Chapter 2), the largest of these live load values, $L_{o}=4.79 \mathrm{kN} / \mathrm{m}^{2}\left(100 \mathrm{lbf} / \mathrm{ft}^{2}\right)$, was conservatively applied to the entire area of each typical floor, with reduction according to Eq. (5.10). This value of live load applies to lobbies and first-floor corridors, and is thus considered too conservative for assessment of residual capacity of an upper floor, as considered here. A value of $L_{o}=2.40 \mathrm{kN} / \mathrm{m}^{2}$ (50 lbf/ $\left./ \mathrm{ft}^{2}\right)$, applicable to offices, is used instead.

The live load is reduced according to Eq. (5.10), based on the influence area $K_{L L} A_{T}$ of a typical floor beam, for which $K_{L L}=2$. Influence areas for typical floor beams in buildings A and B (see Figure 2-1) are listed in Table 5-2, along with the corresponding live load reduction factors calculated from Eq. (5.10) and the resulting values of the reduced live load $L_{\text {office. }}$. Using this level of live loading in the load combination of Eq. (5.8) yields the values of uniform floor load listed in Table 5-2.

Table 5-1. Minimum specified live loads for different occupancies in an office building

\begin{tabular}{lc}
\hline Occupancy & $\begin{array}{c}\text { Uniform Live Load, } L_{o} \\
\mathrm{kN} / \mathrm{m}^{2}\left(\mathrm{lbf} / \mathrm{ft}^{2}\right)\end{array}$ \\
\hline Offices & $2.40(50)$ \\
Corridors above first floor & $3.83(80)$ \\
Lobbies and first-floor corridors & $4.79(100)$ \\
\hline
\end{tabular}

Table 5-2. Gravity loads used for assessing collapse resistance

\begin{tabular}{lcc}
\hline Quantity & Building A & Building B \\
\hline Influence area of typical floor beam, $K_{L L} A_{T}, \mathrm{~m}^{2}\left(\mathrm{ft}^{2}\right)$ & $55.7(600)$ & $61.9(667)$ \\
Live load reduction factor, $L / L_{o}$ & 0.862 & 0.831 \\
Reduced live load for offices, $L_{\text {office }}, \mathrm{kN} / \mathrm{m}^{2}\left(\mathrm{lbf} / \mathrm{ft}^{2}\right)$ & $2.06(43.1)$ & $1.99(41.6)$ \\
Combined floor load, $1.2 D+0.5 L_{\text {office }}, \mathrm{kN} / \mathrm{m}^{2}\left(\mathrm{lbf} / \mathrm{ft}^{2}\right)$ & $5.40(113)$ & $5.36(112)$ \\
\hline
\end{tabular}




\subsubsection{Expected Gravity Loading}

In some of the analyses presented subsequently, the floor systems are unable to sustain the combined loading from Eq. (5.9), given in Table 5-2. In such cases, it is of interest to compare the capacity of the floor systems with the expected (or "point-in-time") value of the gravity loading. This lower level of gravity loading is given as follows:

$$
1.05 D+L_{\text {survey }}
$$

where $L_{\text {survey }}=0.52 \mathrm{kN} / \mathrm{m}^{2}\left(10.9 \mathrm{lbf} / \mathrm{ft}^{2}\right)$ denotes the mean live load for offices based on survey data, from Table C4-2 of ASCE 7-10 (ASCE 2010). Note that the live load contribution to the combined floor load in Table 5-2, given by $0.5 L_{\text {office, }}$, equals $1.03 \mathrm{kN} / \mathrm{m}^{2}\left(21.6 \mathrm{lbf} / \mathrm{ft}^{2}\right)$ for building A and $0.99 \mathrm{kN} / \mathrm{m}^{2}$ $\left(20.8 \mathrm{lbf} / \mathrm{ft}^{2}\right)$ for building B. These values are about twice as large as the mean live load based on survey data.

The dead load factor in Eq. (5.11) is taken as 1.05 in order to more accurately represent the expected dead load. As noted by Ellingwood et al. (2007, p. 22), the dead load factor of 1.2 in the load combination of Eq. (5.8) might appropriately be taken as 1.0, but it is conservatively kept as 1.2 because the mean dead load in modern construction typically exceeds the nominally specified value by $5 \%$ to $10 \%$. The total gravity loading given by Eq. (5.11) equals $4.34 \mathrm{kN} / \mathrm{m}^{2}\left(90.7 \mathrm{lbf} / \mathrm{ft}^{2}\right)$ for both buildings $\mathrm{A}$ and $\mathrm{B}$. The values of $1.2 D+0.5 L_{\text {office }}$ listed in Table $5-2$ thus exceed the expected floor loading by about $24 \%$.

\subsection{ANALYSIS OF PROTOTYPE FLOOR SYSTEMS}

\subsubsection{Prototype Building A: $6.10 \mathrm{~m}$ by $9.14 \mathrm{~m}$ ( $20 \mathrm{ft}$ by $30 \mathrm{ft})$ Bay Spacing}

Figure 5-6 shows a comparison of the two levels of gravity loading with load-displacement curves for (a) 2 bay $\times 2$ bay and (b) 4 bay $\times 4$ bay floor systems from building $A$ under column loss scenarios. The three load-displacement relationships in Figure 5-6(a) are the same as those presented previously in Figure 5-5 for the 2 bay $\times 2$ bay floor system shown in Figure 4-1, while Figure 5-6(b) presents corresponding curves for the 4 bay $\times 4$ bay gravity framing system shown in Figure 5-7. Loss of the center column is considered in both cases. Since the focus of this study is on the collapse resistance of gravity frame systems, no moment frames are considered in the 4 bay $\times 4$ bay framing system shown in Figure $5-7$. The slab in the 4 bay $\times 4$ bay system is assumed to be connected to the beams and girders (including those along the perimeter) by shear studs designed for fully composite action (see Table 2-2), as was assumed for the 2 bay $\times 2$ bay system. Values of the approximate ultimate capacity under sudden column loss, $w_{S C L, u}$ from Eq. (5.6), are indicated with solid circles in Figure 5-6, and it is noted that $w_{S C L, u}$ in Figure 56(b) corresponds to the maximum permissible displacement of $\Delta_{\max }=1300 \mathrm{~mm}$ (47.2 in). 

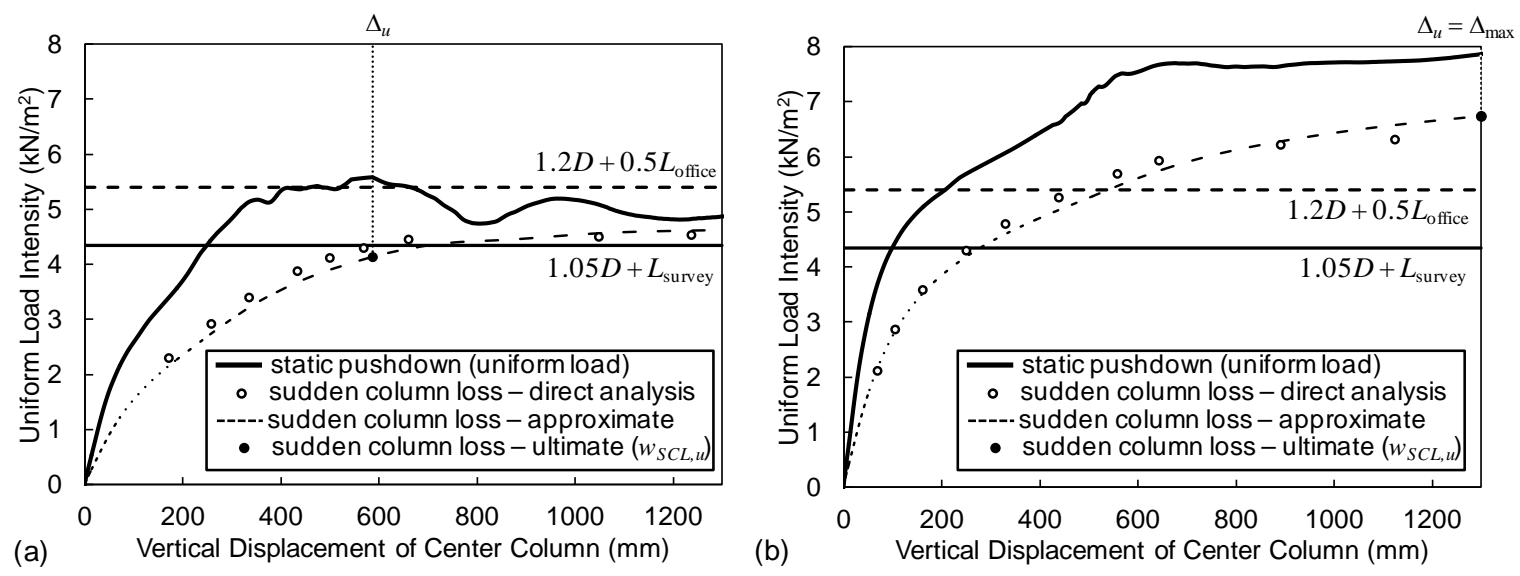

Figure 5-6. Load-displacement curves under central column loss for floor systems from building A with gradual softening in post-ultimate response of connections: (a) 2 bay $\times 2$ bay; (b) 4 bay $\times 4$ bay

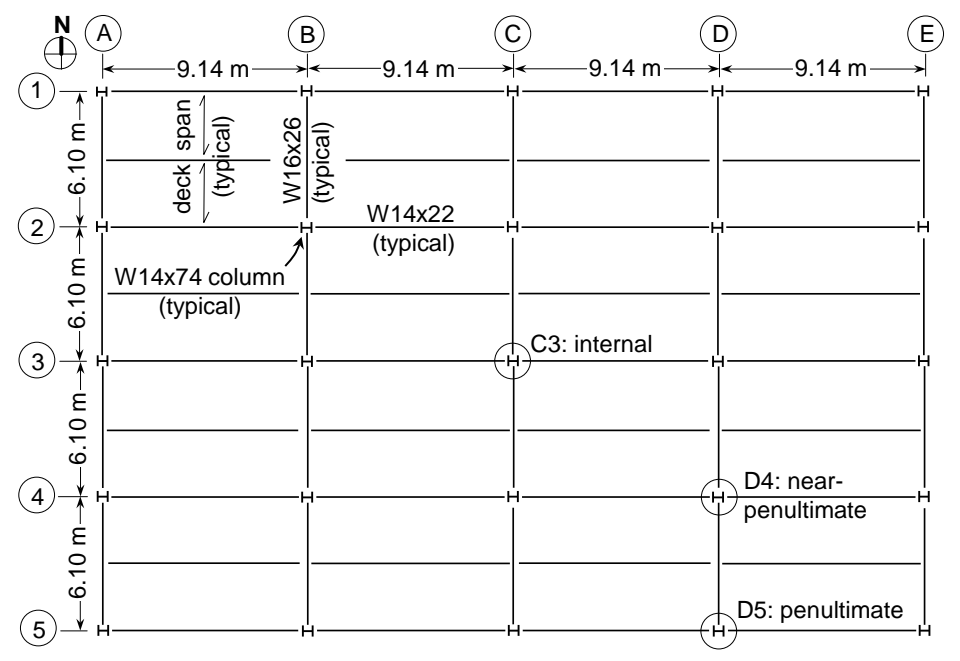

Figure 5-7. 4 bay $\times 4$ bay gravity framing system from prototype building $A$

Figure 5-6(a) shows that the capacity of the 2 bay $\times 2$ bay floor system from building A under sudden column loss is close to the expected gravity loading from Eq. (5.11). The direct analysis procedure predicts that collapse would not occur under the expected gravity loading, with a peak dynamic displacement of about $600 \mathrm{~mm}$ (24 in), which is comparable to the displacement $\Delta_{u}$ at the ultimate static load of the system. The approximate ultimate capacity under sudden column loss, $w_{S C L, u}$, conservatively evaluated at a displacement of $\Delta_{u}$ according to Eq. (5.7), is slightly less than the expected gravity loading. The 2 bay $\times 2$ bay floor system is clearly unable to sustain the larger level of gravity loading, $1.2 D+0.5 L_{\text {office }}$, under sudden column loss.

Figure 5-6(b) shows that the 4 bay $\times 4$ bay floor system from building $A$ is able to sustain both the expected gravity loading and the larger level of gravity loading, $1.2 D+0.5 L_{\text {office, }}$, under sudden loss of the center column, with peak dynamic displacements of about $250 \mathrm{~mm}$ (10 in) and $500 \mathrm{~mm}$ (20 in), respectively, under the two levels of loading. The continuity provided by the adjoining bays in the 4 bay $x$ 4 bay floor system is found to increase its capacity under quasi-static loading by $41 \%\left(7.87 \mathrm{kN} / \mathrm{m}^{2}\right.$ / $\left.5.58 \mathrm{kN} / \mathrm{m}^{2}=1.41\right)$ and under sudden column loss by $63 \%\left(6.74 \mathrm{kN} / \mathrm{m}^{2} / 4.14 \mathrm{kN} / \mathrm{m}^{2}=1.63\right)$ relative to the 2 bay $\times 2$ bay floor system. As observed previously for the 2 bay $\times 2$ bay floor system in Figure 5-5, Figure 5-6(b) shows fairly good agreement for 4 bay $\times 4$ bay system between the direct and approximate 
analysis results for sudden column loss. Differences in the calculated load intensity for a given peak displacement are generally less than $10 \%$. Because of this good agreement and because of the much greater efficiency of the approximate analysis procedure, subsequent results use only the approximate procedure for analysis of sudden column loss.

Figure 5-8 shows plots comparable to those in Figure 5-6, but while the results in Figure 5-6 were based on an assumption of gradual softening in the post-ultimate behavior of the connections [see Figure 313(a)], the results in Figure 5-8 are based on an assumption of sudden fracture [see Figure 3-13(b)]. Comparing Figure 5-8(a) with Figure 5-6(a) shows that sudden connection fracture reduces the static capacity of the 2 bay $\times 2$ bay system by $13 \%\left(4.84 \mathrm{kN} / \mathrm{m}^{2} / 5.58 \mathrm{kN} / \mathrm{m}^{2}=0.87\right)$ and reduces the corresponding capacity under sudden column loss $\left(w_{S C L, u}\right)$ by $17 \%\left(3.45 \mathrm{kN} / \mathrm{m}^{2} / 4.14 \mathrm{kN} / \mathrm{m}^{2}=0.83\right)$. Reductions for the 4 bay $\times 4$ bay system are somewhat smaller, with a reduction of $9 \%$ in the static capacity $\left(7.15 \mathrm{kN} / \mathrm{m}^{2} / 7.87 \mathrm{kN} / \mathrm{m}^{2}=0.91\right)$ and a reduction of $13 \%$ in the capacity under sudden column loss $\left(5.90 \mathrm{kN} / \mathrm{m}^{2} / 6.74 \mathrm{kN} / \mathrm{m}^{2}=0.87\right)$. While these reductions are significant, it is noted that reductions by as much as $23 \%$ in peak vertical capacity were observed for two-span beam assemblies without floor slab for sudden fracture vs. gradual softening (see Section 3.5.3). The contribution of the floor slab is thus found to make the composite framing systems somewhat less sensitive to the effect of sudden connection failure than the bare steel framing system. Because of the significant reductions in capacity that result from sudden connection fracture, and because sudden fractures have been observed experimentally (Thompson 2009, Weigand et al. 2012), all subsequent analyses in this report use connection models that represent sudden fracture in the post-ultimate response.
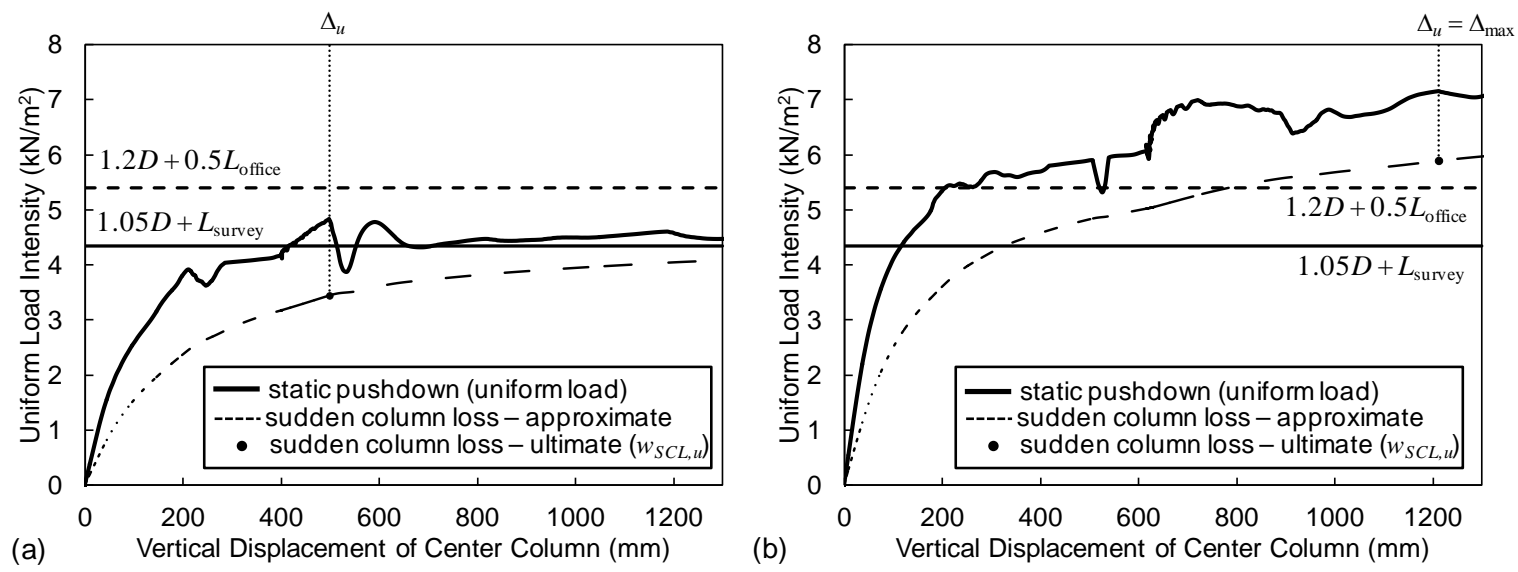

Figure 5-8. Load-displacement curves under central column loss for floor systems from building A with sudden fracture in post-ultimate response of connections: (a) 2 bay $\times 2$ bay; (b) 4 bay $\times 4$ bay

Figure 5-8 shows that the capacity of the 4 bay $\times 4$ bay floor system under sudden loss of the central column is $71 \%$ larger than that of the 2 bay $\times 2$ bay system $\left(5.90 \mathrm{kN} / \mathrm{m}^{2} / 3.44 \mathrm{kN} / \mathrm{m}^{2}=1.71\right)$. Insight into the greater capacity of the 4 bay $\times 4$ bay floor system relative to the 2 bay $\times 2$ bay system is afforded by considering the forces in the beams and the floor slab, as shown in Figure 5-9 and Figure 5-10 for the 2 bay $\times 2$ bay and the 4 bay $\times 4$ bay systems, respectively. These figures correspond to the results in Figure 5-8 for the case of central column loss under quasi-static loading, and in both cases, forces are shown along the edges of the bay immediately to the northwest of the missing column. For clarity, alphanumeric column designations are indicated at each corner of the isolated bay, corresponding to the grid systems shown in Figure 4-1 and Figure 5-7. Axial forces at the beam ends are shown using arrows, and numerical values of axial force are indicated, with positive values denoting tension. Tensile forces normal to the slab edges are shown using filled areas along the slab edges, and peak values of force per length are indicated. While these forces were obtained under quasi-static loading, they correspond closely to the forces at the same level of displacement under sudden column loss. This correspondence occurs 
because the deformation mode matches closely under the two types of loading, as evidenced by the good agreement between the approximate and direct analysis results for sudden column loss in Figure 5-6.

The values of force per length shown along the west and east edges in Figure 5-9 and Figure 5-10 correspond only to the tension in the welded wire reinforcement, while the values along the north and south edges were obtained by adding the values of force per length for the welded wire reinforcement and the steel deck. In-plane forces in the concrete were not included in evaluating these forces. Since tensile forces are of primary interest, compressive forces were set to zero in computing these forces. In some cases, flexure of the slab caused the steel deck to be in compression while the welded wire reinforcement was in tension, or vice versa. Setting the compressive component to zero in such cases prevents cancellation of forces that would obscure the true magnitude of tension sustained by one component or the other. Tensile forces along the slab edge were calculated as the larger of the values from each pair of elements on either side of the edge.
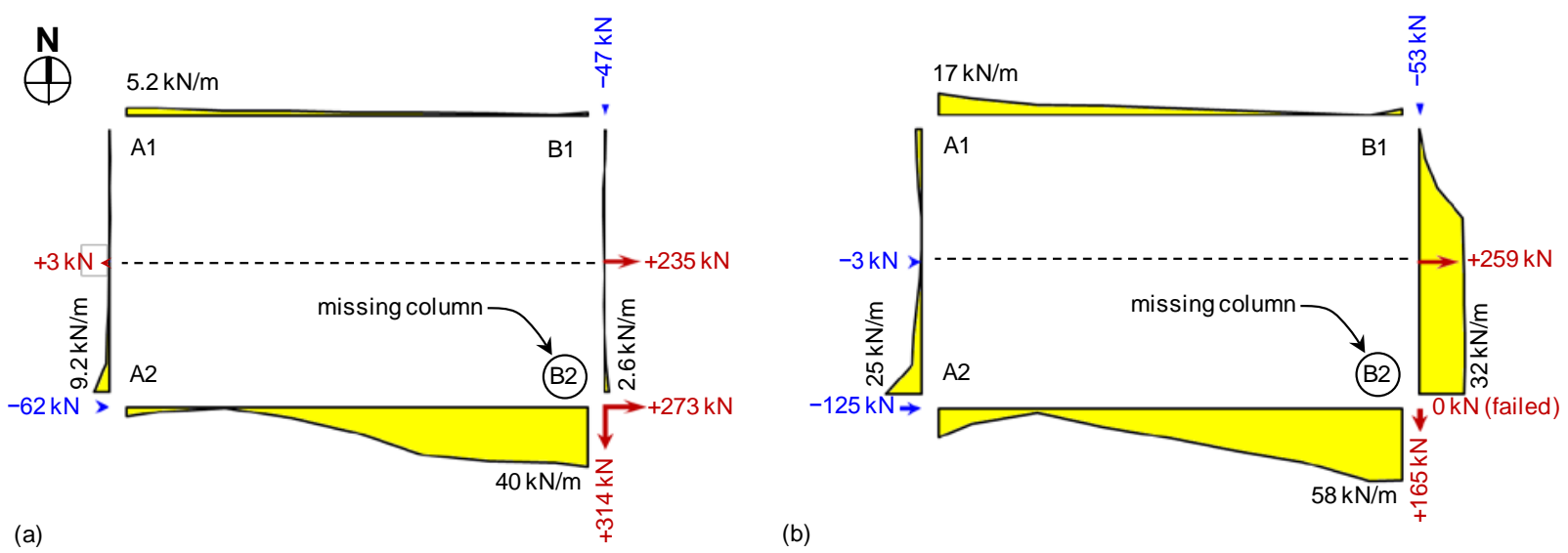

(b)

Figure 5-9. Axial forces at beam ends (arrows) and tensile force per length normal to slab edges (filled areas) for 2 bay $\times 2$ bay floor system from building A under central column displacements of (a) $206 \mathrm{~mm}$ (initial connection failure) and (b) $474 \mathrm{~mm}$ (ultimate static capacity)

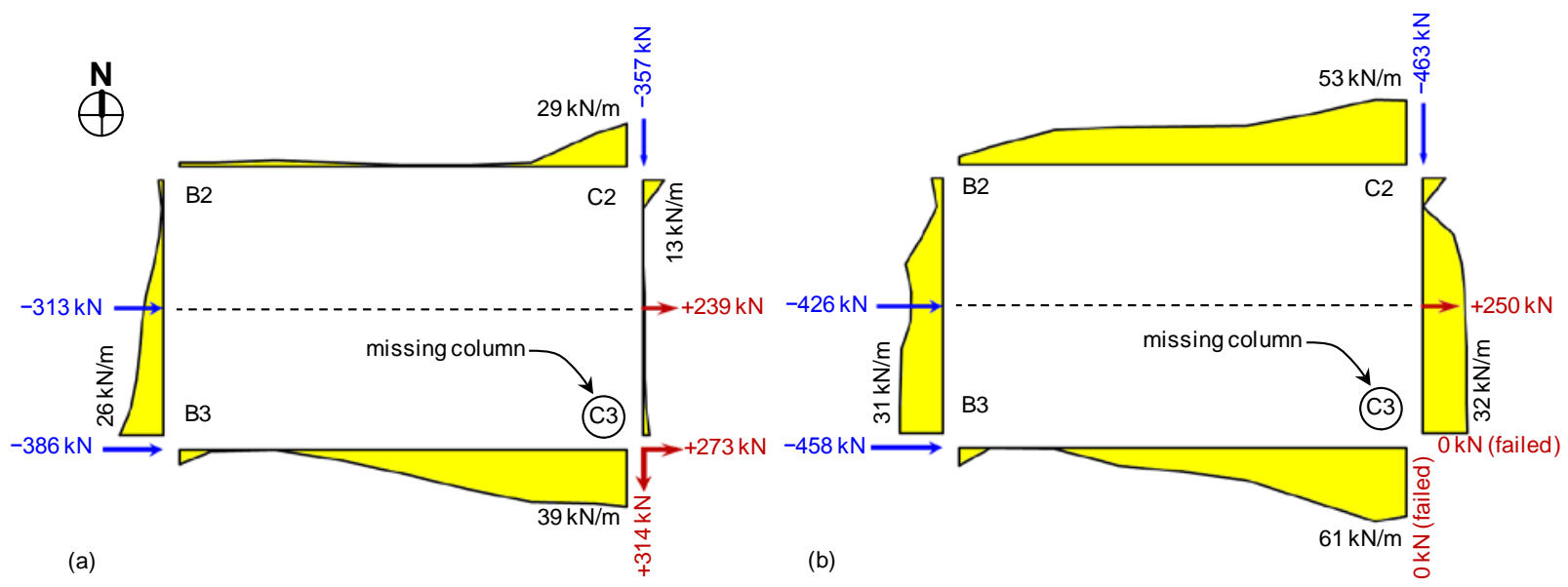

Figure 5-10. Axial forces at beam ends (arrows) and tensile force per length normal to slab edges (filled areas) for 4 bay $\times 4$ bay floor system from building A under central column displacements of (a) $206 \mathrm{~mm}$ (initial connection failure) and (b) $497 \mathrm{~mm}$ 
Figure 5-9(a) and Figure 5-10(a) show forces immediately prior to the initial failure of the east-west connections to the central column, while Figure 5-9(b) shows forces corresponding to the ultimate static load of the 2 bay $\times 2$ bay system, and Figure 5-10(b) shows forces at a central column displacement comparable to that in Figure 5-9(b). Comparing force levels before and after connection failure [i.e., comparing Figure 5-9(b) with Figure 5-9(a) and comparing Figure 5-10(b) with Figure 5-10(a)] shows a significant increase in the tensile forces in the welded wire reinforcement along the east edge of the isolated bay, as the floor slab bridges over the failed connections in the direction normal to the ribs of the steel deck. Comparing force levels for the 2 bay $\times 2$ bay and 4 bay $\times 4$ bay systems shows comparable forces along the south and east edges of the isolated bay, but significantly larger tensile forces along the north and west edges for the 4 bay $\times 4$ bay system, where continuity of the floor slab is not provided in the 2 bay $\times 2$ bay system. The larger tensile forces in the slab along the north and west edges are associated with much larger values of axial compression at the beam ends, indicating the development of a negative bending moment through composite action of the beams and slab. Such flexural resistance, which is developed at the beam ends opposite the missing column, is much more pronounced in Figure 510 than in Figure 5-9 and contributes to the enhanced capacity of the 4 bay $\times 4$ bay system relative to the 2 bay $\times 2$ bay system.

While Figure 5-8(b) showed results for loss of the center column (column C3 in Figure 5-7), the 4 bay $\times$ 4 bay floor system is actually more susceptible to collapse due to the loss of other columns, where slab continuity is not provided along all edges of the affected bays. Figure 5-11 shows load-displacement curves for loss of (a) near-penultimate column D4 and (b) penultimate column D5 (see Figure 5-7), which were found to be the most critical for the 4 bay $\times 4$ bay floor system. Note that the column descriptions in Figure 5-7 (“internal," "near-penultimate," and "penultimate”) are from Figure C-2 of UFC 4-023-03 (DOD 2009). Note also that corner column loss is not considered in this study, because each corner column in the prototype buildings is part of a moment-resisting frame (see Figure 2-1), where previous studies (Main et al. 2011, Alashker et al. 2011) have shown the moment frames to be adequate to sustain the loss of a corner column without collapse. The ultimate capacities under sudden column loss are comparable for the two scenarios in Figure 5-11, in both cases being about $19 \%$ less than the capacity under sudden loss of the center column. In both cases the capacity is adequate to sustain the expected gravity loading under sudden column loss, but not the higher level of gravity loading, $1.2 D+0.5 L_{\text {office. }}$


Figure 5-11. Load-displacement curves for 4 bay $\times 4$ bay floor system from building A: (a) loss of near-penultimate column (D4); (b) loss of penultimate column (D5) 


\subsubsection{Prototype Building B: $10.16 \mathrm{~m}$ by $9.14 \mathrm{~m}$ (33 ft by $30 \mathrm{ft}$ ) Bay Spacing}

Figure $5-12$ shows similar plots to those in Figure $5-11$ but for a 3 bay $\times 4$ bay gravity framing system from building B, shown in Figure $5-13$. As in the 4 bay $\times 4$ bay system, the slab is assumed to be connected to the beams and girders (including those along the perimeter) by shear studs designed for fully composite action (see Table 2-2). Load-displacement curves are shown for loss of (a) near-penultimate column D3 and (b) penultimate column E3 (see Figure 5-13), which were found to be the most critical for the 3 bay $\times 4$ bay floor system. As noted for the 4 bay $\times 4$ bay system from building A, corner column loss is not considered in this study, because each corner column in the prototype buildings is part of a moment-resisting frame (see Figure 2-1). Actually, for building B it is not necessary to consider penultimate column loss either, because of the placement of the perimeter moment frames [see Figure 21(a)]. However, the penultimate column loss scenario is still considered to enable comparison with the corresponding scenario for the 4 bay $\times 4$ bay system from building A. Note that for both building $A$ and building $\mathrm{B}$, the critical penultimate column loss scenario requires the floor slab to develop membrane forces in its weak direction, normal to the ribs.

Figure 5-12 shows that in both column loss scenarios, the 3 bay $\times 4$ bay system from building $B$ is unable to sustain even the expected gravity loading under sudden column loss. The maximum capacity under sudden loss of the penultimate in Figure 5-12(b) is only $84 \%$ of the expected gravity loading. Note that building A (see Figure 5-7) has spans of $6.10 \mathrm{~m} \mathrm{(20} \mathrm{ft)} \mathrm{in} \mathrm{the} \mathrm{N-S} \mathrm{direction,} \mathrm{while} \mathrm{building} \mathrm{B} \mathrm{(see} \mathrm{Figure}$ 5-13) has longer spans of $10.16 \mathrm{~m}\left(33^{1 / 3} \mathrm{ft}\right)$ with correspondingly larger tributary areas for the columns. Comparing Figure 5-12 with Figure 5-11 shows that the floor system with longer spans (larger tributary areas) is more susceptible to collapse than the floor system with shorter spans (smaller tributary areas). The system with shorter spans can sustain the expected gravity loading under sudden column loss, while the system with longer spans collapses.
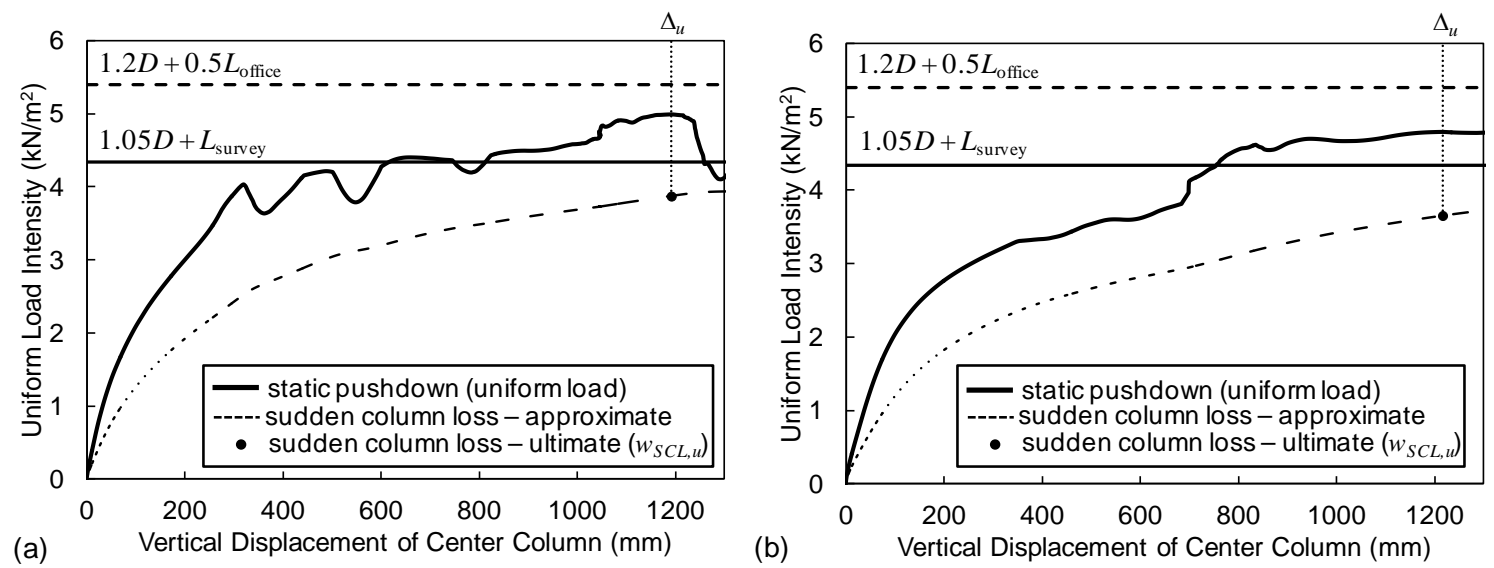

Figure 5-12. Load-displacement curves for 3 bay $\times 4$ bay floor system from building B: (a) loss of near-penultimate column (D3); (b) loss of penultimate column (E3) 




Figure 5-13. 3 bay $\times 4$ bay gravity framing system from prototype building $B$

\subsubsection{Rotational Capacities}

For the results in Figure 5-8, Figure 5-11, and Figure 5-12, initial connection failures occur for center column displacements between approximately $200 \mathrm{~mm}$ and $300 \mathrm{~mm}$ and are reflected by dips in the quasi-static load-displacement curves. Table 5-3 presents beam chord rotations corresponding to the initial connection failures observed in Figure 5-11(a) and Figure 5-12(a), for near-penultimate column loss in the 4 bay $\times 4$ bay system from building $A$ and the 3 bay $\times 4$ bay system from building $B$, respectively. For consistency with the rotational capacities presented previously in Section 3.6 for initial connection failure, the beam chord rotations in Table 5-3 correspond to the column displacement at which the axial force in the bottom bolt row reaches its peak value.

Also presented in Table 5-3 are rotational capacities from Eq. (3.3), based on FEMA 355D (FEMA 2000), which exceed the computed rotations at initial failure by as much as 4.7 times (0.148 rad / $0.0313 \mathrm{rad}=4.73$ for the N-S connection from building B), and rotational capacities from Eq. (3.25) for two-span beam assemblies with two shear connections per span, which exceed the computed rotations at failure by as much as 1.9 times ( $0.0654 \mathrm{rad} / 0.0343 \mathrm{rad}=1.91$ for the $\mathrm{N}-\mathrm{S}$ connection from building A). The significantly smaller computed rotations at failure are a consequence of composite action between the beams and the floor slab, whereby the slab carries tension and the beam-to-column connections carry compression along the perimeter of the affected bays (see Figure 5-10), with the neutral axis of the composite section being located approximately at the top surface of the beam. Rather than equal vales of connection extension occurring at both ends of the beam span, as assumed in Figure 3-30, the end connection opposite the unsupported column thus actually experiences compressive deformation, which imposes a significantly larger extension on the connection to the unsupported column.

The rotational capacity corresponding to this composite behavior can be calculated quite simply by using Eq. (3.22), for the rotational capacity of a beam span with an exterior pin support located at a distance $\bar{y}$ below the center of the bolt group, and setting $\bar{y}=-\bar{y}_{T S}$, where $\bar{y}_{T S}$ is the vertical distance from the center of the bolt group to the top surface of the steel beam. This location is chosen to represent rotation about the neutral axis of the composite section, which, as noted above, is approximately at the top surface of the beam. For the connections considered in this study (see Figure $2-3$ ), $\bar{y}_{T S}$ is given by: 


$$
\bar{y}_{T S}=s(N+1) / 2
$$

In Eq. (5.12) $N$ is the number of bolts and $s=76.2 \mathrm{~mm}$ (3 in) is the vertical spacing between bolts, which is assumed also to be the vertical distance from the top bolt to the top surface of the steel beam.

Rotational capacities from Eq. (3.22) with $\bar{y}=-\bar{y}_{T S}$ are shown in the last row of Table 5-3, and excellent agreement with the computed values is observed, with differences being $7 \%$ or less $(0.0346 \mathrm{rad} /$ $0.0372 \mathrm{rad}=0.930$ for the $\mathrm{E}-\mathrm{W}$ connection in building $\mathrm{B}$ ).

Table 5-3. Comparison of computed and predicted beam chord rotations corresponding to initial connection failure

\begin{tabular}{lcccc}
\hline & \multicolumn{3}{c}{ Beam Chord Rotation, rad } \\
\cline { 2 - 5 } Source of Value & \multicolumn{2}{c}{ Building A, 4 bay $\times 4$ bay } & \multicolumn{2}{c}{ Building B, 3 bay $\times 4$ bay } \\
\cline { 2 - 5 } & E-W & N-S & E-W & N-S \\
\hline Computed for near-penultimate column loss & 0.0319 & 0.0343 & 0.0372 & 0.0313 \\
Eq. (3.3), based on FEMA 355D & 0.148 & 0.148 & 0.138 & 0.148 \\
Eq. (3.25), two connections per span & 0.0569 & 0.0654 & 0.0630 & 0.0537 \\
Eq. (3.22), with exterior pin at top of flange & 0.0312 & 0.0343 & 0.0346 & 0.0299 \\
\hline
\end{tabular}

\subsection{ASSESSMENT OF STRUCTURAL INTEGRITY REQUIREMENTS}

\subsubsection{International Building Code}

The 2009 version of the International Building Code (IBC) (ICC 2009, Section 1614) introduced structural integrity requirements for design of high-rise buildings in occupancy categories III (buildings that represent a substantial hazard to human life in the event of a failure) and IV (essential facilities). For steel frame structures, as considered in this study, the requirement for end connections of beams and girders is as follows:

1614.3.2.2 Beams. End connections of all beams and girders shall have a minimum nominal axial tensile strength equal to the required vertical shear strength for allowable stress design (ASD) or two-thirds of the required shear strength for load and resistance factor design (LRFD) but not less than 10 kips $(45 \mathrm{kN})$. For the purpose of this section, the shear force and the axial tensile force need not be considered to act simultaneously.

The requirement can be expressed as follows, using the notation of AISC 360-10 (AISC 2010) for LRFD:

$$
T_{n} \geq \frac{2}{3} V_{u}
$$

where $T_{n}$ is the nominal tensile strength and $V_{u}$ is the required shear strength. Geschwindner and Gustafson (2010) previously showed that all properly designed single-plate shear connections (designed for shear forces) comply with this requirement. Table 5-4 confirms that the requirement is indeed satisfied for the shear connections considered in this study. The values of $V_{u}$ in Table 5-4 are from the third column of Table 2-4, while the values of $T_{n}$ were obtained by multiplying the values of $t_{u}$ from Table 3-2 by the number of bolts for each connection. The ratio $T_{n} / V_{u}$, which must not be less than $2 / 3$, is greater than 2 in all cases, indicating that the nominal tensile strength is more than three times greater than required for these connections. 
Table 5-4 Comparison of required shear strength and nominal tensile strength values for shear tab connections

\begin{tabular}{ccccc}
\hline \multirow{2}{*}{ Building } & Beam orientation & $\begin{array}{c}\text { Required shear strength, } \\
V_{u}, \mathrm{kN} \text { (kip) }\end{array}$ & $\begin{array}{c}\text { Nominal tensile strength, } \\
T_{n}, \mathrm{kN}(\mathrm{kip})\end{array}$ & $\begin{array}{c}\text { Strength ratio, } \\
T_{n} / V_{u}\end{array}$ \\
\hline \multirow{2}{*}{$\mathrm{A}$} & East-West & $153(34.3)$ & $308 \mathrm{kN}$ (69.3 kip) & 2.02 \\
& North-South & $153(34.3)$ & $335 \mathrm{kN}$ (75.3 kip) & 2.20 \\
\multirow{2}{*}{ B } & East-West & $292(65.6)$ & $598 \mathrm{kN}$ (134.4 kip) & 2.05 \\
& North-South & $166(37.4)$ & $335 \mathrm{kN}$ (75.3 kip) & 2.01 \\
\hline
\end{tabular}

Although the shear tab connections considered in this study satisfy the structural integrity requirements of the 2009 IBC (ICC 2009), it was observed in Section 5.3.2 that the 3 bay $\times 4$ bay floor system from building $\mathrm{B}$ is unable to sustain sudden column loss under the expected gravity loading. It can therefore be concluded that the structural integrity requirements of the 2009 IBC are not sufficient to prevent collapse under sudden column loss.

It is also noted that for cases in which collapse of the floor system is arrested, the connections are called upon to carry axial forces that substantially exceed the tensile strength required by the 2009 IBC. Consider the 4 bay $\times 4$ bay floor system from building A, which can sustain sudden loss of the center column under the expected gravity loading with a peak dynamic displacement of $324 \mathrm{~mm}$ (12.8 in). The connections in the North-South direction for this floor system fail at a displacement of about $210 \mathrm{~mm}$ (8.3 in), sustaining a peak tensile force of $314 \mathrm{kN}$ (70.6 kip) prior to failure, which is about $94 \%$ of the nominal tensile strength listed in Table 5-4. The required tensile strength for this connection is only $102 \mathrm{kN}$ (22.9 kip). Thus, the tensile demands on connections under column loss scenarios can substantially exceed the strength required by the 2009 IBC, in this case by a factor of 3.1.

The 2009 IBC provides an exception whereby the required axial tensile strength can be reduced by $50 \%$ if the slab and its reinforcement satisfy certain conditions. However, since the full strength requirement was found to be inadequate to prevent collapse under sudden column loss, no further consideration is given to this permitted reduction. It is noted that the area of the steel reinforcement in the prototype buildings is approximately one-third of what is required for this reduction in axial tensile strength to be permitted.

\subsubsection{Unified Facilities Criteria 4-023-03}

The tie force approach in the Unified Facilities Criteria (UFC) 4-023-03 (DOD 2009, Section 3-1), specifies that three types of horizontal ties must be provided (longitudinal, transverse, and peripheral) and provides restrictions on which structural elements can be used to carry these forces:

Unless the structural members (beams, girders, spandrels) and their connections can be shown capable of carrying the required longitudinal, transverse, or peripheral tie force magnitudes while undergoing rotations of 0.20-rad (11.3-deg), the longitudinal, transverse, and peripheral tie forces are to be carried by the floor and roof system.

Because the shear tab connections considered in this study are unable to sustain axial forces under this level of rotation (see Section 5.3.3), the tie forces for the prototype buildings must be carried by the floor system.

The required strength of transverse and longitudinal ties is given by (DOD 2009, Section 3-1.3.1.1):

$$
F_{i}=3 w_{F} L_{1}
$$


where $w_{F}=1.2 D+0.5 \mathrm{~L}$ is the uniform floor load, consistent with the load combination in Eq. (5.9), and $L_{1}$ is the distance between the centers of the columns in the direction under consideration. The required strength of peripheral ties is given by (DOD 2009, Section 3-1.3.2):

$$
F_{p}=6 w_{F} L_{1} L_{p}
$$

where $L_{p}=0.91 \mathrm{~m}$ (3 ft) (DOD 2009, Section 3-1.3.2). Calculated values of the required tie forces are listed in Table $5-5$ for buildings $A$ and $B$. These values were calculated by setting $w_{F}$ in Eqs. (5.14) and (5.15) equal to the combined floor load of $1.2 D+0.5 L_{\text {office }}$ listed in Table 5-2.

Table 5-5. Tie force requirements from UFC 4-023-03

\begin{tabular}{lcccc}
\hline \multirow{2}{*}{ Required tie force } & \multicolumn{2}{c}{ Building A } & \multicolumn{2}{c}{ Building B } \\
\cline { 2 - 5 } & East-West & North-South & East-West & North-South \\
\hline Longitudinal/transverse, $F_{i}, \mathrm{kN} / \mathrm{m}$ (kip/ft) & $148(10.1)$ & $98(6.8)$ & $147(10.0)$ & $163(11.2)$ \\
Peripheral, $F_{p}, \mathrm{kN}(\mathrm{kip})$ & $271(60.9)$ & $181(40.6)$ & $269(60.5)$ & $299(67.2)$ \\
\hline
\end{tabular}

To develop the required tie forces from Table 5-5 in the floor systems of the prototype buildings, reinforcing bars are incorporated in the floor slabs in addition to the welded wire reinforcement, as indicated in Table 5-6. The added reinforcing bars are designed to carry all of the required tie forces, and no contribution from the steel deck and welded wire reinforcement is considered. The yield capacities of the reinforcing bars listed in Table 5-6 are based on ASTM A615 grade 60 reinforcing steel with a minimum specified yield strength of 414 MPa (60 ksi). While UFC 4-023-03 (DOD 2009, Section 3-1.1) specifies the use of both a strength reduction factor and an over-strength factor in calculating the design strength of ties, both of these factors are taken as unity in calculating the yield capacities in Table 5-6, for consistency with the computational model, which uses the minimum specified yield strength of the reinforcing steel. The layout of the reinforcing bars is illustrated in Figure 5-14 for (a) the 4 bay $\times 4$ bay framing system from building $A$ and (b) the 3 bay $\times 4$ bay framing system from building $B$. Horizontal ties parallel to floor beams are not placed directly above the floor beams, in accordance with the location restrictions in UFC 4-023-03 (DOD 2009, Section 3-1.3.1.1).

Placement of the reinforcing bars poses challenges because the depth of concrete above the steel deck is only $83 \mathrm{~mm}\left(3_{1}^{1} / 4\right.$ in) (see Figure 2-2). Tranverse reinforcing bars (in the across-rib direction) could be placed above the steel deck on $19 \mathrm{~mm}\left(\frac{3}{4} \mathrm{in}\right)$ bar supports, leaving $32 \mathrm{~mm}\left(1 \frac{1}{4} \mathrm{in}\right)$ of concrete cover above the \#10 bars, the largest bar size used. Longitudinal reinforcing bars could be placed beneath the transverse bars, along the ribs, where greater concrete depth is available. The limited concrete depth would make it difficult to implement the seismic hooks described in UFC 4-023-03 for linking the longitudinal and transverse ties to the peripheral ties (DOD 2009, Section 3-1.4). As an alternative, mechanical anchorage devices could potentially be used for the longitudinal and transverse ties to provide the required continuity for these tie bars along the perimeter of the slab.

The reinforcing bars are represented in the computational model using beam elements that share common nodes with the shell elements representing the floor slab, assuming that the reinforcement remains fully bonded to the surrounding concrete. While the longitudinal bars would be placed beneath the transverse bars, as noted above, for simplicity all reinforcing bars are modeled in the same plane as the shell elements, at mid-height of the floor slab. The reinforcing steel is represented using a piecewise-linear plasticity model (material type 24 in LS-DYNA) calibrated to match the engineering stress-strain curves shown in Figure 5-15 for the different sizes of reinforcing bar. The yield strength of $F_{y}=414 \mathrm{MPa}$ (60 ksi), the tensile strength of $F_{u}=621 \mathrm{MPa}(90 \mathrm{ksi})$, and the elongation at fracture (8\% for \#7 and \#8 
bars and $7 \%$ for \#10 bars) are based on the minimum specified values from the ASTM A615 standard (ASTM 2009) for grade 60 reinforcing steel.

Table 5-6. Additional slab reinforcement used to develop required tie forces

\begin{tabular}{ccccc}
\hline Building & Type of tie & Orientation & Reinforcement type & Yield capacity of tie \\
\hline A & Longitudinal & East-West & 7 \#7 bars between columns & $184 \mathrm{kN} / \mathrm{m}$ (12.6 kip/ft) \\
& Transverse & North-South & 7 \#7 bars between columns & $123 \mathrm{kN} / \mathrm{m}$ (8.4 kip/ft) \\
& Peripheral & East-West & \#10 bar & $338 \mathrm{kN}$ (76.0 kip) \\
& Peripheral & North-South & \#8 bar & $210 \mathrm{kN}$ (47.1 kip) \\
\multirow{2}{*}{ B } & Transverse & East-West & 8 \#8 bars between columns & $165 \mathrm{kN} / \mathrm{m}$ (11.3 kip/ft) \\
& Longitudinal & North-South & 11 \#7 bars between columns & $193 \mathrm{kN} / \mathrm{m}$ (13.2 kip/ft) \\
& Peripheral & East-West & $\# 10$ bar & $338 \mathrm{kN}$ (76.0 kip) \\
& Peripheral & North-South & $\# 10$ bar & $338 \mathrm{kN}$ (76.0 kip) \\
\hline
\end{tabular}



(a)

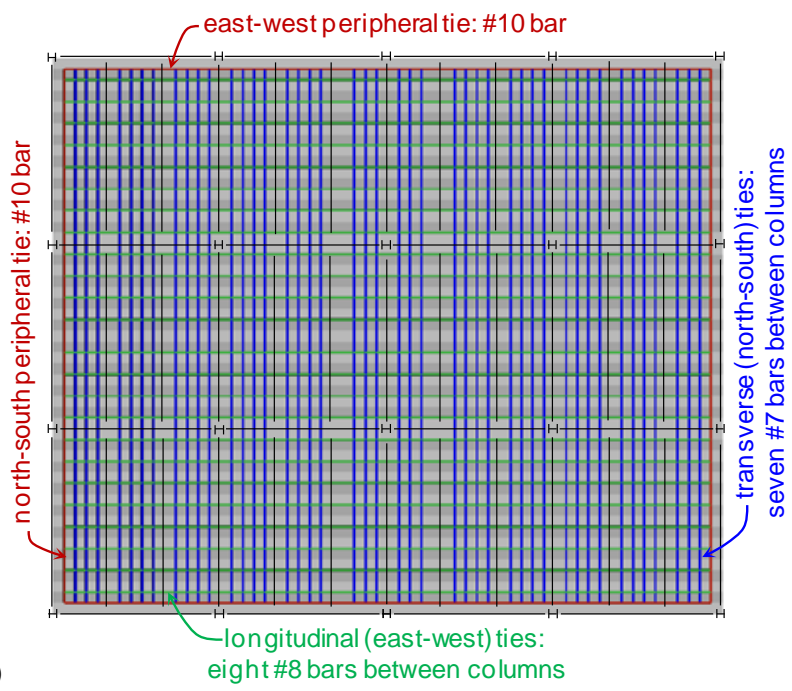

(b)

\section{Е



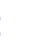
0 
Figure 5-16 shows plots corresponding to those in Figure 5-11, but for the 4 bay $\times 4$ bay floor system from building A shown in Figure 5-14(a), which incorporates additional reinforcement to satisfy the horizontal tie force requirements of UFC 4-023-03 (DOD 2009). Comparing Figure 5-16(a) with Figure 5-11(a), for near-penultimate column loss, shows that the horizontal ties more than double the capacity of the system under static loading. The capacity under sudden column loss is increased by $49 \%$, enabling the system to sustain the gravity loading of $1.2 D+0.5 L_{\text {office }}$ with a peak dynamic displacement of about 510 mm (20 in). Comparing Figure 5-16(b) with Figure 5-11(b), for penultimate column loss, shows similar increases in capacity due to the horizontal ties, enabling the system to sustain the gravity loading of $1.2 D+0.5 L_{\text {office }}$ with a peak dynamic displacement of about $580 \mathrm{~mm}$ (23 in) under sudden column loss. Since the gravity loading of $1.2 D+0.5 L_{\text {office }}$ could not be sustained without horizontal ties (see Figure 511), the results in Figure 5-16 demonstrate the effectiveness of horizontal ties specified by UFC 4-023-03 (DOD 2009).
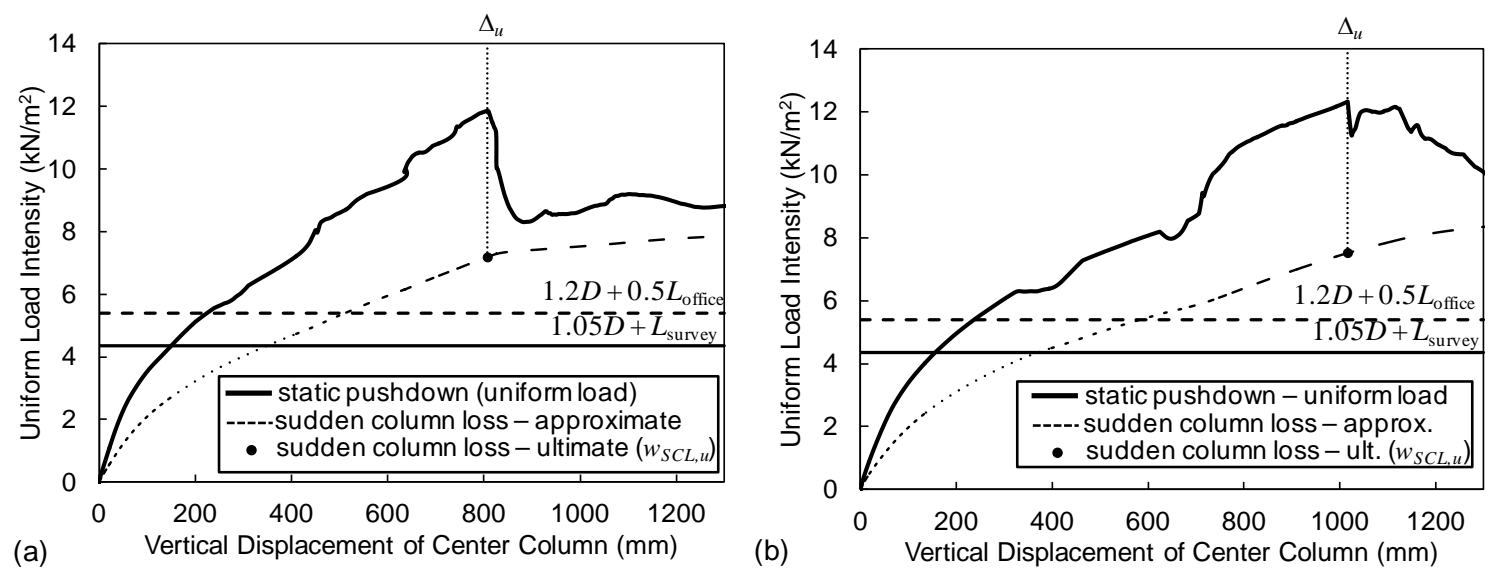

Figure 5-16. Load-displacement curves for 4 bay $\times 4$ bay floor system from building A with horizontal ties that satisfy UFC 4-023-03: (a) loss of near-penultimate column (D4); (b) loss of penultimate column (D5)

Figure 5-17 shows plots corresponding to those in Figure 5-12, but for the 3 bay $\times 4$ bay floor system from building B shown in Figure 5-14(b), which incorporates additional reinforcement to satisfy the horizontal tie force requirements of UFC 4-023-03 (DOD 2009). Comparing Figure 5-17(a) with Figure 5-12(a), for near-penultimate column loss, shows that the horizontal ties approximately double the capacity of the system under static loading. The capacity under sudden column loss is increased by $49 \%$, enabling the system to sustain the gravity loading of $1.2 D+0.5 L_{\text {office }}$ with a peak dynamic displacement of about $820 \mathrm{~mm}$ (32 in). Comparing Figure 5-17(b) with Figure 5-12(b), for penultimate column loss, shows similar increases in capacity due to the horizontal ties, enabling the system to sustain the gravity loading of $1.2 D+0.5 L_{\text {office }}$ under sudden column loss with a peak dynamic displacement of about $1030 \mathrm{~mm}$ (41 in). Since not even the expected gravity loading could be sustained under sudden column loss without horizontal ties (see Figure 5-12), the results in Figure 5-17 clearly demonstrate the effectiveness of horizontal ties specified by UFC 4-023-03 (DOD 2009). 

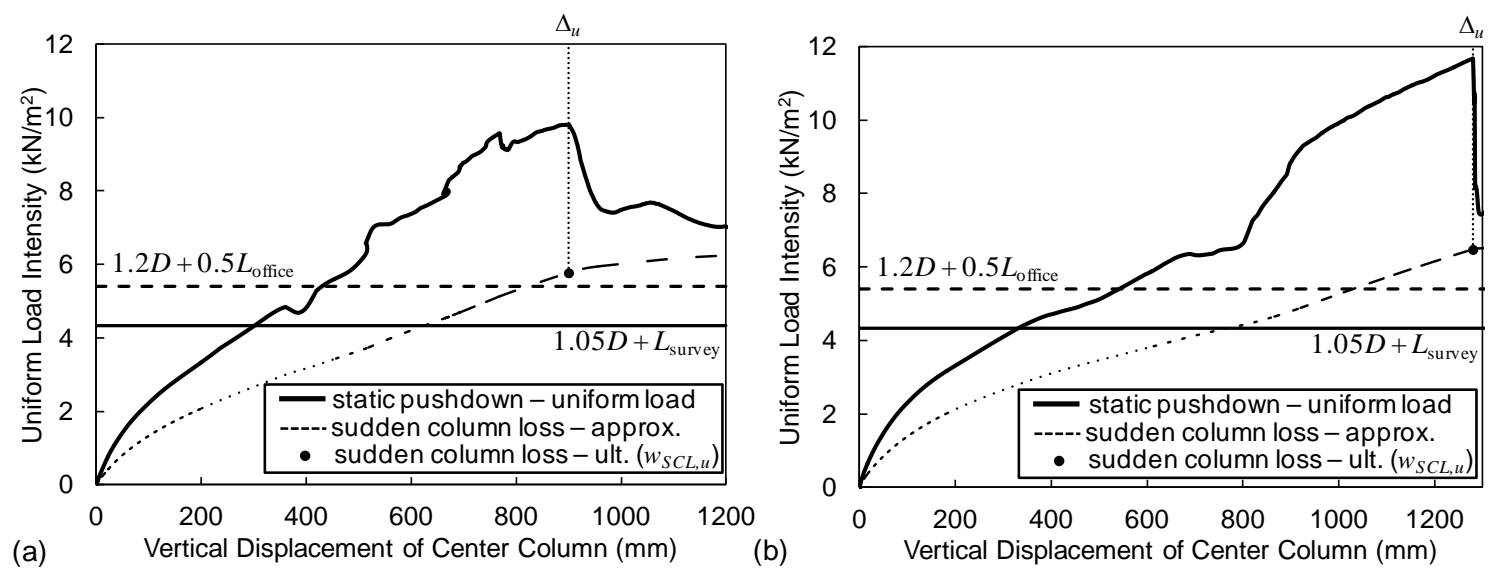

Figure 5-17. Load-displacement curves for 3 bay $\times 4$ bay floor system from building B with horizontal ties that satisfy UFC 4-023-03: (a) loss of near-penultimate column (D3); (b) loss of penultimate column (E3)

\subsection{EVALUATION OF REQUIRED TIE FORCES}

While the results of the previous section demonstrated the effectiveness of reinforcing bars in the floor slabs in preventing collapse, it is of interest to evaluate the extent to which increases in the thickness of the steel deck and the area of the welded wire reinforcement can enhance the collapse resistance of conventional composite floor slabs with only welded wire reinforcement. Alashker et al. (2010) investigated the effect of increasing both the deck thickness and the reinforcement area for a 2 bay $\times$ 2 bay floor system and found that significant increases in capacity could be achieved by increasing the deck thickness, with increases in the reinforcement area producing a much smaller effect. Of particular interest in the present study are the tie forces that must be developed in the floor slab to sustain specified levels of gravity loading.

To investigate these issues, enhanced floor slabs with increased deck thickness and reinforcement area are considered, as listed in Table 5-7. Floor slab S16-2.5 is considered for prototype building A, while floor slabs S16-5 and S16-14 are considered for building B. Since the original capacity of building B is significantly less than that of building A (compare Figure 5-11 and Figure 5-12), greater enhancement is required for building $B$. In all cases, a 16 gage steel deck is used, which is the maximum thickness listed in the American National Standards Institute/Steel Deck Institute C1.0 - 2006 Standard for Composite Steel Floor Deck (ANSI/SDI 2006). The 16 gage deck is 1.67 times thicker than the 20 gage deck used in the original design. Standard wire sizes from ASTM A82/A82M - 07 (ASTM 2007a) are considered for the welded wire reinforcement, where $A_{w}$ in Table 5-7 denotes the cross-sectional area of the wire, with a grid spacing of $152 \mathrm{~mm} \times 152 \mathrm{~mm}(6 \mathrm{in} \times 6$ in). The largest wire size of W14 in Table 5-7 represents a tenfold increase in cross-sectional area relative to the W1.4 wire used in the original design.

Table 5-7. Properties of steel deck and welded wire reinforcement for floor slabs

\begin{tabular}{lll}
\hline Slab Designation* & Steel Deck Thickness & Welded Wire Reinforcement \\
\hline S20-1.4 (original) & 20 gage: $t=0.91 \mathrm{~mm}(0.0358 \mathrm{in})$ & $6 \times 6 \mathrm{~W} 1.4 / 1.4: A_{w}=9.03 \mathrm{~mm}^{2}\left(0.014 \mathrm{in}^{2}\right)$ \\
S16-2.5 & 16 gage: $t=1.52 \mathrm{~mm}(0.0598 \mathrm{in})$ & $6 \times 6 \mathrm{~W} 2.5 / 2.5: A_{w}=16.1 \mathrm{~mm}^{2}\left(0.025 \mathrm{in}^{2}\right)$ \\
S16-5 & 16 gage: $t=1.52 \mathrm{~mm}(0.0598 \mathrm{in})$ & $6 \times 6 \mathrm{~W} 5 / 5: A_{w}=32.3 \mathrm{~mm}^{2}\left(0.05 \mathrm{in}^{2}\right)$ \\
S16-14 & 16 gage: $t=1.52 \mathrm{~mm}(0.0598 \mathrm{in})$ & $6 \times 6 \mathrm{~W} 14 / 14: A_{w}=90.3 \mathrm{~mm}^{2}\left(0.14 \mathrm{in}^{2}\right)$ \\
\hline
\end{tabular}

\footnotetext{
* This is not a standardized designation; it is simply used for convenience in this report.
} 
Figure 5-18 shows plots corresponding to those in Figure 5-11 for the 4 bay $\times 4$ bay floor system from building A, but with the properties of the enhanced floor slab S16-2.5 listed in Table 5-7. Figure 5-18 shows that the enhanced slab enables the floor system to sustain the gravity loading of $1.2 D+0.5 L_{\text {office }}$ without collapse under sudden loss of the near-penultimate and penultimate columns. Figure 5-19 and Figure 5-20 show similar plots for the 3 bay $\times 4$ bay floor system from building $B$ with the properties of enhanced floor slabs S16-5 and S16-14, respectively. Figure 5-19 shows that enhanced slab S16-5 enables the floor system to sustain the expected gravity loading, but not the higher gravity loading of $1.2 D+0.5 L_{\text {office }}$, under sudden loss of the near-penultimate and penultimate columns. Figure 5-20 shows that enhanced slab S16-14 enables the floor system to sustain the higher gravity loading of $1.2 D+0.5 L_{\text {office }}$ under these sudden column loss scenarios. In summary, Figure 5-18, Figure 5-19, and Figure 5-20 show that by increasing the steel deck thickness and the welded wire reinforcement area, the capacity of composite floor systems can be increased to sustain the required gravity loads under sudden column loss scenarios, while the required increases in reinforcement are significant for the longer spans of building B.


Figure 5-18. Load-displacement curves for 4 bay $\times 4$ bay floor system from building A with floor slab S16-2.5: (a) loss of near-penultimate column (D4); (b) loss of penultimate column (D5)


Figure 5-19. Load-displacement curves for 3 bay $\times 4$ bay floor system from building B with floor slab S16-5: (a) loss of near-penultimate column (D3); (b) loss of penultimate column (E3) 

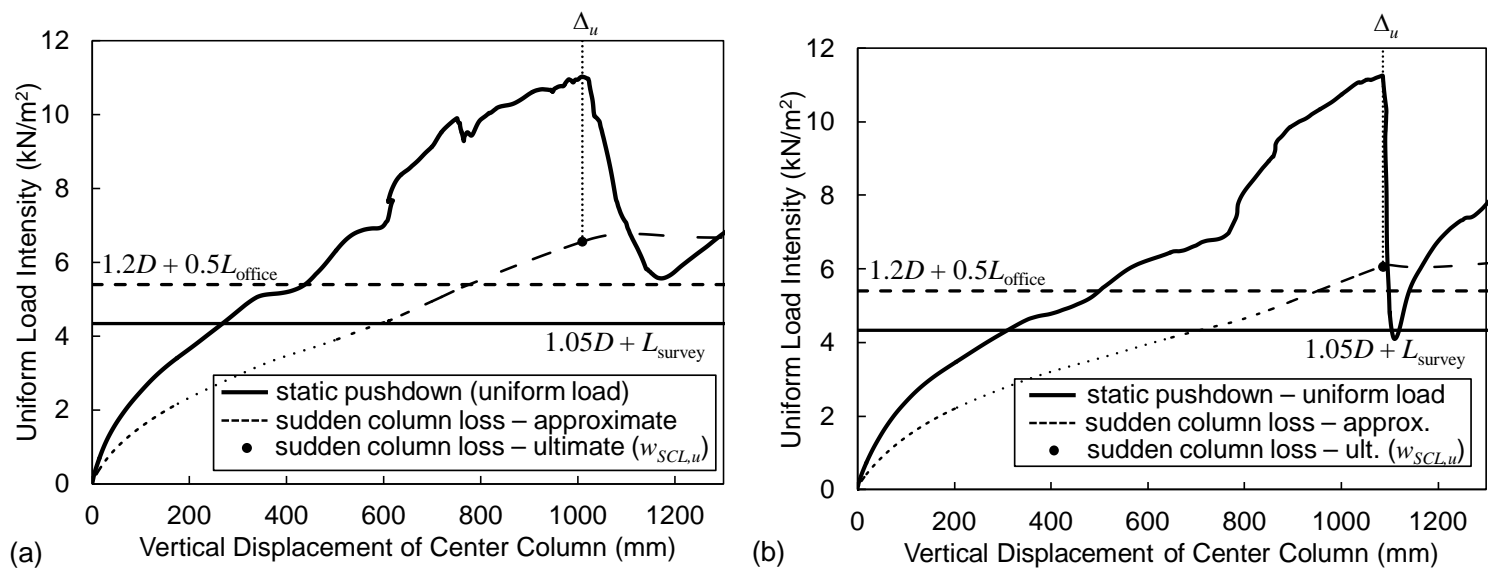

Figure 5-20. Load-displacement curves for 3 bay $\times 4$ bay floor system from building B with floor slab S16-14: (a) loss of near-penultimate column (D3); (b) loss of penultimate column (E3)

Figure 5-21 summarizes the influence of floor slab reinforcement on the capacity of the 4 bay $\times 4$ bay floor system from building A under sudden loss of the near penultimate and penultimate columns. Curves are presented for the original floor slab S20-1.4 (from Figure 5-11), the floor slab with reinforcing bars that satisfy the UFC 4-023-03 tie force requirements (from Figure 5-16), and the enhanced floor slab S16-2.5 (from Figure 5-18). Solid circles on each curve indicate the ultimate capacity under sudden column loss, $w_{S C L, u}$ from Eq. (5.6), while a gray vertical line indicates the column displacement at which initial connection failure occurs. The curves corresponding to different levels of reinforcement in Figure 5-21 differ only slightly prior to the initial connection failure, which indicates that connection failures occur before the tie forces can contribute significantly to the structural resistance. This confirms the appropriateness of the requirement in UFC 4-023-03 (DOD 2009) that tie forces should be carried by the floor slab rather than by the beams, unless the beam-to-column connections can be shown to sustain the required tie forces while undergoing significant rotations. Figure 5-21 shows that even with the highest level of reinforcement, the floor system is unable to sustain the expected gravity loading prior to connection failure. For large displacements of the center column, after connection failures have occurred and membrane action in the slab has developed, the tie forces in the slab are found to significantly increase the ultimate capacity of the floor system.

Similar results are evident in Figure 5-22, which summarizes the influence of floor slab reinforcement on the capacity of the 3 bay $\times 4$ bay floor system from building $B$ under sudden loss of the near penultimate and penultimate columns. Again, the curves corresponding to different levels of reinforcement differ only slightly prior to initial connection failure, and even with the highest level of reinforcement, the floor system is unable to sustain the expected gravity loading prior to connection failure. 



Figure 5-21. Load-displacement curves for 4 bay $\times 4$ bay floor system from building A with different levels of slab reinforcement: (a) sudden loss of near-penultimate column (D4); (b) sudden loss of penultimate column (D5)


Figure 5-22. Load-displacement curves for 3 bay $\times 4$ bay floor system from building B with different levels of slab reinforcement: (a) sudden loss of near-penultimate column (D4); (b) sudden loss of penultimate column (D5)

Figure 5-23 shows edge forces at the ultimate static load from the three analysis cases presented in Figure 5-21. These plots were generated using the same procedure described previously for Figure 5-9 and Figure 5-10, isolating the bay immediately to the northwest of the missing column. Figure 5-24 shows a similar plot for three of the four analysis cases presented in Figure 5-22, again isolating the bay immediately to the northwest of the missing column. Both figures clearly show increases in the tensile forces along the slab edges with increasing levels of slab reinforcement. In all cases, the connections to the missing column failed prior to reaching the ultimate load, as indicated by zero forces at the beam ends. Composite action is also evident in all cases, with substantial compressive forces at the beam ends along the north and west edges being accompanied by tensile forces in the floor slab, together providing negative flexural resistance along these edges. In some cases, compressive axial forces that exceed the capacity of the connection are observed; these cases are associated with binding of the beam flange against the column, as represented in the model by the "gap spring" shown in Figure 4-8(b). Failures of the welded wire reinforcement (which has relatively low ductility, as shown in Figure 4-5) are evident in some cases, such as in Figure 5-24(a), where the tension is zero along much of the south edge of the slab because the fracture strain of the welded wire has been exceeded. 



Figure 5-23. Axial forces at beam ends (arrows) and tensile force per length normal to slab edges (filled areas) at ultimate static load for 4 bay $\times 4$ bay floor system from building A under loss of near-penultimate column (D4):

(a) floor slab S20-1.4; (b) floor slab S16-2.5; (c) floor slab S20-1.4 with reinforcing bars from Table 5-6

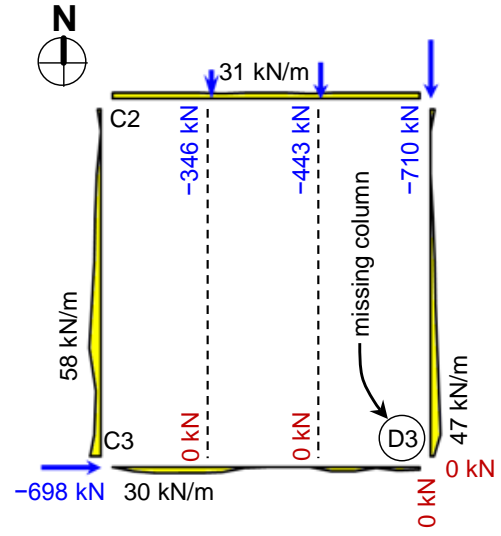

(a)

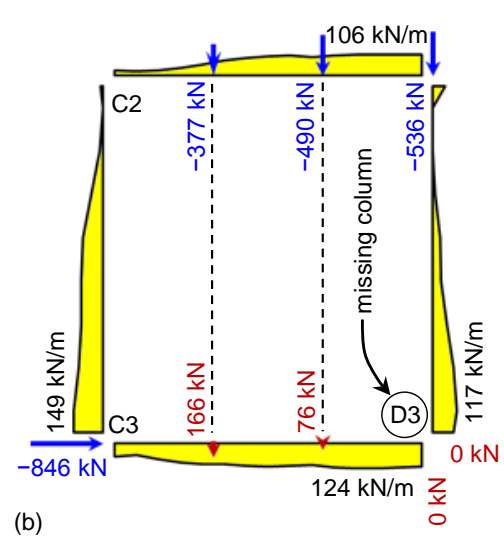

(b)

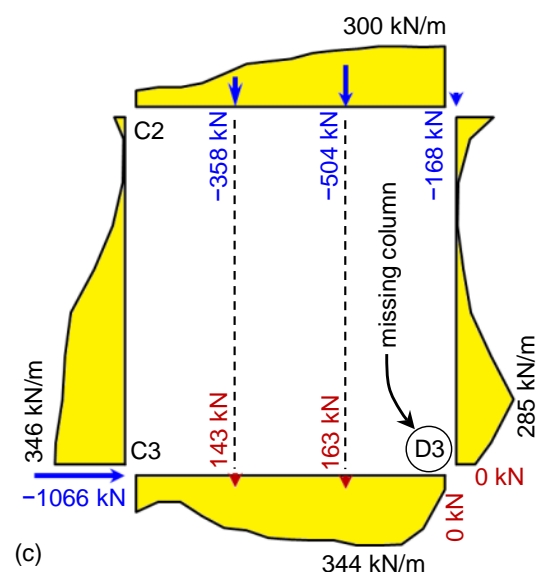

(c)

Figure 5-24. Axial forces at beam ends (arrows) and tensile force per length normal to slab edges (filled areas) at ultimate static load for 3 bay $\times 4$ bay floor system from building B under loss of near-penultimate column (D3):

(a) floor slab S20-1.4; (b) floor slab S16-5; (c) floor slab S16-14

The slab edge forces in Figure 5-23 and Figure 5-24 can be used to assess the tie forces necessary to sustain different levels of gravity loading without collapse. In making this assessment, it is useful to compare with the required strength of the transverse and longitudinal ties from UFC 4-023-03 (DOD 2009), which are given in Eq. (5.14) and can be written in the following alternative form:

$$
F_{i} / L_{1}=3 w_{F}
$$

The quantity $F_{i} / L_{1}$, obtained by dividing the tie force per length by the span length, has units of force per area and will be denoted the "normalized tie force." As shown in Table 5-8, peak values of the normalized tie force for each case in Figure 5-23 and Figure 5-24 are obtained by first identifying the peak value of $F_{i}$ (the tie force per length) in each span direction and then dividing these values by the span length $L_{1}$ in the corresponding direction. The larger of the two values of $F_{i} / L_{1}$ in either span direction (shown in boldface in Table 5-8) is the governing value of the normalized tie force sustained by the floor system. 
Table 5-8. Calculation of normalized tie forces $F_{i} / L_{1}$ from analyses of near-penultimate column loss for prototype buildings with varying floor slab reinforcement

\begin{tabular}{clcccccc}
\hline & & \multicolumn{2}{c}{$\begin{array}{c}\text { Peak Tie Force/Length } \\
F_{i}(\mathrm{kN} / \mathrm{m})\end{array}$} & \multicolumn{2}{c}{$\begin{array}{c}\text { Span Length } \\
L_{1}(\mathrm{~m})\end{array}$} & $\begin{array}{c}\text { Peak Normalized } \\
\text { Tie Force } \\
F_{i} / L_{1}\left(\mathrm{kN} / \mathrm{m}^{2}\right)\end{array}$ \\
\cline { 3 - 8 } Building & Floor Slab & E-W & N-S & E-W & N-S & E-W & N-S \\
\hline A & S20-1.4 & 32.6 & 56.1 & 9.14 & 6.10 & 3.56 & $\mathbf{9 . 2 1}$ \\
& S16-2.5 & 54.4 & 94.9 & 9.14 & 6.10 & 5.95 & $\mathbf{1 5 . 6}$ \\
& S20-1.4, with reinforcing bars* & 403 & 225 & 9.14 & 6.10 & $\mathbf{4 4 . 1}$ & 36.9 \\
\multirow{2}{*}{ B } & S20-1.4 & 58.1 & 31.3 & 9.14 & 10.16 & $\mathbf{6 . 3 6}$ & 3.08 \\
& S16-5 & 149 & 124 & 9.14 & 10.16 & $\mathbf{1 6 . 3}$ & 12.2 \\
& S16-14 & 346 & 344 & 9.14 & 10.16 & $\mathbf{3 7 . 9}$ & 33.9
\end{tabular}

* Reinforcing bars designed to satisfy tie force requirements from UFC 4-023-03; details listed in Table 5-6.

Figure 5-25(a) shows a plot of the governing values of the normalized tie forces from Table 5-8 against the ultimate capacities of the floor systems under quasi-static loading, as listed in Table 5-9. These computed values indicate the relationship between the tie forces carried by the system and the uniform load that can be sustained. The computed values for buildings A and B collapse fairly well along a single curve that can be approximated by the following equation, shown with the computed values in Figure 525(a):

$$
F_{i} / L_{1}=\left\{\begin{array}{cc}
0.32\left(w_{F}\right)^{2} & \left(w_{F} \text { in } \mathrm{kN} / \mathrm{m}^{2}\right) \\
0.0153\left(w_{F}\right)^{2} & \left(w_{F} \text { in } \mathrm{lbf} / \mathrm{ft}^{2}\right)
\end{array}\right.
$$
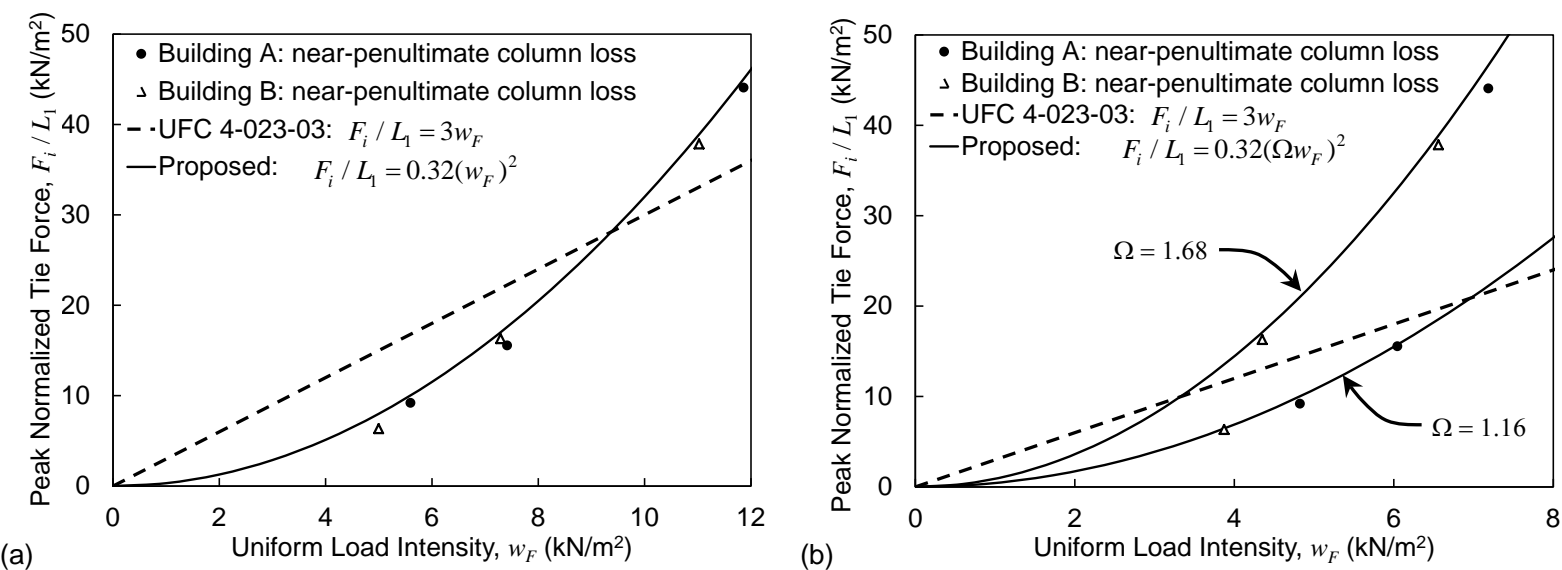

Figure 5-25. Relationships between normalized tie forces in slab and uniform floor load intensity: (a) quasi-static loading; (b) sudden column loss

Eq. (5.16) from UFC 4-023-03 (DOD 2009) is also shown in Figure 5-25(a) for comparison, as the intent of both relationships is to indicate the tie forces required to sustain a particular level of loading. The two expressions intersect at a load intensity of $w_{F}=9.38 \mathrm{kN} / \mathrm{m}^{2}\left(196 \mathrm{lbf} / \mathrm{ft}^{2}\right)$, which is about 1.73 times larger 
than the combined gravity loading of $1.2 D+0.5 L_{\text {office }}$ listed in Table $5-2$. For loads less than this value, the computed tie forces are less than required by Eq. (5.16), indicating that the UFC is conservative. For loads greater than this value, the computed tie forces exceed those required by Eq. (5.16), indicating that the UFC is not conservative.

Table 5-9. Ultimate capacities of various floor systems under both quasi-static loading and sudden column loss, with corresponding values of the Dynamic Increase Factor (missing column is near-penultimate)

\begin{tabular}{clccc}
\hline & & \multicolumn{2}{c}{ Ultimate Capacity } & $\begin{array}{c}\text { Dynamic } \\
\text { Increase } \\
\text { Building }\end{array}$ \\
\cline { 3 - 4 } & Floor Slab & $\begin{array}{c}\text { Quasi-Static Pushdown, } \\
w_{\text {staticu }}\left(\mathrm{kN} / \mathrm{m}^{2}\right)\end{array}$ & $\begin{array}{c}\text { Sudden Column Loss, } \\
w_{S C L, u}\left(\mathrm{kN} / \mathrm{m}^{2}\right)\end{array}$ & $\begin{array}{c}\text { Factor, } \\
\Omega\left(\Delta_{u}\right)\end{array}$ \\
\hline A & S20-1.4 (original) & 5.59 & 4.82 & 1.16 \\
& S16-2.5 & 7.41 & 6.04 & 1.23 \\
& S20-1.4, with reinforcing bars* & 11.9 & 7.19 & 1.65 \\
B & S20-1.4 (original) & 4.99 & 3.88 & 1.29 \\
& S16-5 & 7.29 & 4.35 & 1.68 \\
& S16-14 & 11.0 & 6.56 & 1.68 \\
\hline
\end{tabular}

* Reinforcing bars designed to satisfy tie force requirements from UFC 4-023-03; details listed in Table 5-6.

While the results in Figure 5-25(a) are for quasi-static loading, Figure 5-25(b) presents a corresponding plot for sudden column loss, in which the governing values of $F_{i} / L_{1}$ from Table 5-8 are plotted against values of $w_{S C L, u}$ listed in Table 5-9. In the case of sudden column loss, the computed values from buildings $\mathrm{A}$ and $\mathrm{B}$ no longer collapse along a single curve. This is a consequence of the variability in the Dynamic Increase Factor $\Omega\left(\Delta_{u}\right)=w_{\text {static }, u} / w_{S C L, u}$, defined in Eq. (5.5) and listed in the last column of Table 5-9. A general trend of increasing $\Omega\left(\Delta_{u}\right)$ with increasing slab reinforcement is evident in Table 59. Smaller values of $\Omega$ for lightly reinforced floor slabs are a consequence of the fact that these systems exhibit a clear plateau in the load-displacement curve (e.g., Figure 5-11), where for an elastic-plastic response, $\Omega$ decreases to approach unity at large displacements. Larger values of $\Omega$ for more heavily reinforced slabs are a consequence of the stiffer, more linear response that these systems exhibit up to the ultimate load (e.g., Figure 5-16), where a linear response corresponds to a value of $\Omega=2$.

Eq. (5.17) can be modified as follows to incorporate the Dynamic Increase Factor $\Omega$ :

$$
F_{i} / L_{1}=\left\{\begin{array}{cc}
0.32\left(\Omega w_{F}\right)^{2} & \left(w_{F} \text { in } \mathrm{kN} / \mathrm{m}^{2}\right) \\
0.0153\left(\Omega w_{F}\right)^{2} & \left(w_{F} \text { in lbf } / \mathrm{ft}^{2}\right)
\end{array}\right.
$$

Eq. (5.18) is plotted in Figure 5-25(b) for both $\Omega=1.68$ and $\Omega=1.16$, which represent the largest and smallest values of $\Omega$ in Table 5-9, and the two curves are seen to capture fairly well the upper and lower limits of the computed values for buildings A and B. Eq. (5.16) from UFC 4-023-03 (DOD 2009) is also shown in Figure 5-25(b), and the intersection points occur at load intensities of $w_{F}=3.32 \mathrm{kN} / \mathrm{m}^{2}$ (69.3 lbf $\left./ \mathrm{ft}^{2}\right)$ for $\Omega=1.68$ and $w_{F}=6.97 \mathrm{kN} / \mathrm{m}^{2}\left(146 \mathrm{lbf} / \mathrm{ft}^{2}\right)$ for $\Omega=1.16$. For particular value of $\Omega$, Eq. (5.16) is conservative for loads below the intersection point and is not conservative for loads above this point. Eq. (5.18) is proposed as a replacement for Eq. (5.16) from UFC 4-023-03 for steel frame systems 
with composite floor systems, as it more accurately captures the nonlinear behavior observed in the computations and allows dynamic effects associated with sudden column loss to be incorporated directly through the parameter $\Omega$. Different values of $\Omega$ could be used in Eq. (5.18) as deemed appropriate for different structural systems. 
This page intentionally left blank. 


\section{Chapter 6 \\ CONCLUSIONS}

This report presented a computational assessment of the performance of steel gravity framing systems with single-plate shear ("shear tab") connections and composite floor slabs under column loss scenarios. The computational assessment used a reduced modeling approach for the analyses, while comparisons with detailed model results and available experimental data were presented to establish confidence in the reduced modeling approach. The reduced modeling approach enables large multi-bay systems to be analyzed much more efficiently than the detailed modeling approach used in previous studies. Both quasistatic and sudden column loss scenarios were considered, and an energy-based approximate procedure for analysis of sudden column loss was adopted, after verification through comparisons with direct dynamic analyses, further enhancing the efficiency of the reduced modeling approach. Reduced models were used to investigate the influence of factors such bay spacing, slab continuity, and the mode of connection failure on the collapse resistance of gravity frame systems.

Based on the results of the analyses performed in this study, the following main conclusions were reached:

1. Sudden fracture of shear tab connections after reaching the ultimate load, as a result of bolt shear failure or plate rupture in tension, reduces the ultimate capacity of gravity frame systems in column loss scenarios, as compared to a gradual softening behavior associated with bolt tear-out. Reductions in the ultimate capacity under quasi-static loading were as much as $23 \%$ for bare steel framing (i.e., no slab) and as much as $13 \%$ for systems with composite floor slabs. Because of the prevalence of sudden fracture in available experimental data, it is recommended that sudden fracture should be assumed in modeling and analysis of shear tab connections.

2. Rotational capacities of shear tab connections under column loss scenarios were substantially smaller than those predicted based on seismic test data, due to the axial extension imposed on the connections in addition to rotation. Rotational capacities of connections in bare steel framing assemblies were slightly less than half of those predicted based on seismic test data, while rotational capacities of connections in composite floor systems were approximately one fourth of those same predictions. The significantly smaller rotational capacities in composite floor systems were associated with composite action, whereby axial compression developed in beam connections at the ends opposite to the missing column, imposing larger axial extensions on the connection to the missing column than if the axial extension were shared at both ends. Simple equations for the rotational capacities of the connections were derived as a function of a few parameters including the span length and the connection depth, and these equations yielded good agreement with the computational predictions.

3. The effect of slab continuity beyond the bays adjoining the missing column was found to be significant, with the ultimate capacity of a 4 bay $\times 4$ bay floor system under sudden loss of the central column being $71 \%$ larger than that of a corresponding 2 bay $\times 2$ bay system. Smaller, but still significant, increases in capacity relative to the 2 bay $\times 2$ bay system were observed for the 4 bay $\times 4$ bay system under cases of penultimate and near-penultimate column loss, for which continuity of the slab is provided along some edges but not others.

4. Longer span lengths, with correspondingly larger tributary areas for the columns, were found to result in reduced capacities under column loss scenarios, with the ultimate capacity under sudden 
loss of a near-penultimate column being $18 \%$ lower for prototype building B, with $10.16 \mathrm{~m} \times$ $9.14 \mathrm{~m}\left(33^{1} / 3 \mathrm{ft} \times 30 \mathrm{ft}\right)$ bays, than for prototype building A, with $6.10 \mathrm{~m} \times 9.14 \mathrm{~m}(20 \mathrm{ft} \times 30 \mathrm{ft})$ bays.

5. The structural integrity requirements in the 2009 IBC (ICC 2009) were found to be insufficient for preventing collapse under column loss scenarios. Although the shear tab connections considered in this study satisfied the structural integrity requirements of the 2009 IBC (ICC 2009), prototype building B was found unable to sustain even the expected gravity loading under sudden loss of penultimate and near-penultimate columns. While prototype building A was able to sustain sudden loss of these columns under the expected gravity loading without collapse, the tensile forces developed in the beam connections exceeded the 2009 IBC requirements by a factor of 3.1 .

6. The approach used in the UFC 4-023-03 (DOD 2009), to place tie forces in the slab, was found to be appropriate based on computational results that consistently indicated connection failures occurring before tie forces were able to significantly enhance the structural capacity. The tie force requirements in UFC 4-023-03 (DOD 2009) were found to be conservative under quasi-static column loss for uniform load intensities less than $9.38 \mathrm{kN} / \mathrm{m}^{2}\left(196 \mathrm{lbf} / \mathrm{ft}^{2}\right)$, while for quasi-static loads exceeding this value, computed tie forces exceeded those required by the UFC. Under sudden column loss, the computed tie forces exceeded UFC requirements at lower levels of loading. Based on the computational results presented in this study, an empirical equation was developed that relates the required tie force levels to the uniform load on the slab. This relationship, which captures well the observed nonlinearity in the computed structural responses and can account for dynamic enhancement due to sudden column loss, is proposed to replace the linear tie force equation in the current UFC for steel frame structures with composite floor systems.

While this study addressed the tie forces necessary to prevent collapse under column loss scenarios, the analyses conducted in this study assumed that the slab, its reinforcement, and the steel deck were continuous. The floor slab was assumed to be connected to the floor beams and girders (including those along the perimeter) by shear studs designed for fully composite behavior, while it is noted that partially composite beams are common in practice. Detailing requirements to ensure adequate continuity of load paths through the composite floor system need to be considered to enable the required tie forces to be developed. 


\section{REFERENCES}

Alashker, Y. and El-Tawil, S. (2011). "A design-oriented model for the collapse resistance of composite floors subjected to column loss.” Journal of Constructional Steel Research, 67, 84-92.

Alashker, Y., El-Tawil, S. and Sadek, F. (2010). "Progressive Collapse Resistance of Steel-Concrete Composite Floors.” Journal of Structural Engineering, 136(10), 1187-1196.

Alashker, Y., Li, H. and El-Tawil, S. (2011). “Approximations in progressive collapse modeling.” Journal of Structural Engineering, 137(9), 914-924.

American Concrete Institute (ACI). (2008). "Building code requirements for structural concrete.” ACI 318-08, Farmington Hills, MI.

American Society of Civil Engineers (ASCE). (2002). "Minimum design loads for buildings and other structures." SEI/ASCE 7-02, Reston, VA.

American Society of Civil Engineers (ASCE). (2010). "Minimum design loads for buildings and other structures.” ASCE/SEI 7-10, Reston, VA.

American Institute of Steel Construction (AISC). (1999). "Load and resistance factor design specifications for structural steel buildings.” Chicago, IL.

American Institute of Steel Construction (AISC). (2001). "Manual of steel construction: load and resistance factor design, third edition.” Chicago, IL.

American Institute of Steel Construction (AISC). (2002). "Seismic provisions for structural steel buildings.” ANSI/AISC 341-02, Chicago, IL.

American Institute of Steel Construction (AISC). (2010). "Specification for structural steel buildings.” ANSI/AISC 360-10, Chicago, IL.

American National Standards Institute (ANSI). (1982). "Minimum design loads for buildings and other structures.” ANSI A58, New York.

American National Standards Institute/Steel Deck Institute (ANSI/SDI). (2006). "Standard for composite steel floor deck." C1.0 - 2006. <http://www.sdi.org/ansi/C1SDIANSI.pdf> (accessed April 20, 2012)

ASTM International. (2006). "Standard specification for structural steel shapes.” ASTM A992/A992M 06a, West Conshohocken, PA.

ASTM International. (2007a). "Standard specification for steel wire, plain, for concrete reinforcement.” ASTM A82/A82M - 07, West Conshohocken, PA.

ASTM International. (2007b). "Standard specification for steel bar, carbon and alloy, cold-finished." ASTM A108 - 07, West Conshohocken, PA.

ASTM International. (2008). "Standard specification for carbon structural steel." ASTM A36/A36M - 08, West Conshohocken, PA.

ASTM International. (2009). "Standard specification for deformed and plain carbon-steel bars for concrete reinforcement.” ASTM A615/A615M - 09b, West Conshohocken, PA.

ASTM International. (2010a). "Standard specification for structural bolts, steel, heat treated, 120/105 ksi minimum tensile strength.” ASTM A325 - 10, West Conshohocken, PA.

ASTM International. (2010b). "Standard specification for structural bolts, alloy steel, heat treated, $150 \mathrm{ksi}$ minimum tensile strength.” ASTM A490 - 10a, West Conshohocken, PA.

ASTM International. (2011). "Standard specification for steel sheet, zinc-coated (galvanized) or zinc-iron alloy-coated (galvannealed) by the hot-dip process.” ASTM A653/A653M - 11, West Conshohocken, PA.

American Welding Society (AWS). (2010). “Structural welding code - steel.” AWS D1.1/D1.1M:2010, Miami, FL.

Daneshvar, H. and Driver, R.G. (2011). "Behavior of shear tab connections under column removal scenario.” Proc., 2011 Structures Congress, American Society of Civil Engineers, Reston, VA. 
DOD (2009). Design of Buildings to Resist Progressive Collapse, Unified Facilities Criteria (UFC) 4023-03, Department of Defense, 25 January 2009.

Ellingwood, B.R., Smilowitz, R., Dusenberry, D.O., Duthinh, D., Lew, H.S., and Carino, N.J. (2007). "Best practices for reducing the potential for progressive collapse in buildings.” NISTIR 7396, National Institute of Standards and Technology, Gaithersburg, MD.

Federal Emergency Management Agency (FEMA). (2000). "State of the art report on connection performance.” FEMA 355D, SAC Joint Venture and FEMA, Washington, D.C.

General Services Administration (GSA ). (2003), "Progressive Collapse Analysis Design Guidelines for New Federal Office Buildings and Major Modernization Projects,” GSA, Washington, D.C.

Geschwindner, L.F. and Gustafson, K.D. (2010). "Single-plate shear connection design to meet structural integrity requirements.” Engineering Journal, AISC, Third Quarter, 189-202.

Gilbert, R.I. and Sakka, Z.I. (2007). "Effect of reinforcement type on the ductility of suspended reinforced concrete slabs.” Journal of Structural Engineering, 133(6), 834-843.

Gudmundsson, G.V. and Izzuddin, B.A. (2010). “The 'sudden column loss' idealisation for disproportionate collapse assessment.” The Structural Engineer, 88(6), 22-26.

Hallquist, J. (2007). “LS-DYNA Keyword User’s Manual.” Livermore Software Technology Corporation, Livermore, CA.

International Code Council (ICC). (2003). International Building Code, Falls Church, VA.

International Code Council (ICC). (2009). International Building Code, Falls Church, VA.

Izzuddin, B.A., Vlassis, A.G., Elghazouli, A.Y., and Nethercot, D.A. (2008). "Progressive collapse of multi-storey buildings due to sudden column loss - Part I: Simplified assessment framework." Engineering Structures, 30, 1308-1318.

Kulak, G. L., Fisher, J. W., and Struik, J. H. A., (1986). Guide to Design Criteria for Bolts and Riveted Joints, 2nd Ed., John Wiley \& Sons, New York.

Khandelwal, K., El-Tawil, S., Kunnath, S.K., Lew, H.S. (2008). "Macromodel-based simulation of progressive collapse: steel frame structures.” Journal of Structural Engineering, 134(7), 1070-1078.

Kwasniewski, L. (2010). "Nonlinear dynamic simulations of progressive collapse for a multistory building.” Engineering Structures, 32, 1223-1235.

Lew, H.S., Bao, Y., Sadek, F., Main, J.A., Pujol, S., and Sozen, M.A. (2011). “An experimental and computational study of reinforced concrete assemblies under a column removal scenario.” NIST Technical Note 1720, National Institute of Standards and Technology, Gaithersburg, MD.

Main, J.A., Bao, Y., Sadek, F., Lew, H.S. (2011). "Experimental and computational assessment of robustness of steel and reinforced concrete framed buildings.” Applications of Statistics and Probability in Civil Engineering: Proceedings of the 11th International Conference, Held in Zürich, Switzerland, August 1-4, 2011, Taylor \& Francis Group, London, 2184-2192.

Ollgaard, J.G., Slutter, R.G., and Fisher, J.W. (1971). "Shear strength of stud connectors in lightweight and normal weight concrete.” Engineering Journal, AISC, 8(2), 55-64.

Rambo-Roddenberry, M. (2002). "Behavior and strength of welded stud shear connectors.” Ph.D. Dissertation, Virginia Polytechnic Institute and State University, Blacksburg, VA.

Research Council on Structural Connections (RCSS). (2004). Specifications for Structural Joints Using ASTM A325 or A490 Bolts, AISC, Chicago. $<$ www.boltcouncil.org/files/2004RCSCSpecification.pdf > (accessed November 23, 2011).

Rex, C.O., and Easterling, S.W. (2003). "Behavior and modeling of a bolt bearing on a single plate." Journal of Structural Engineering, 129(6), 792-800.

Richard, R.M., Gillett, P.E., Kriegh, J.D., and Lewis, B.A. (1980). “The analysis and design of single plate framing connections.” Engineering Journal, AISC, 2nd Quarter, 38-52.

Sadek, F., El-Tawil, S., and Lew, H.S. (2008). "Robustness of composite floor systems with shear connections: modeling, simulation, and evaluation.” Journal of Structural Engineering, 134(11), 1717-1725. 
Sadek, F., Main, J.A., Lew, H.S., Robert, S.D., Chiarito, V.P., El-Tawil, S. (2010). “An experimental and computational study of steel moment connections under a column removal scenario.” NIST Technical Note 1669, National Institute of Standards and Technology, Gaithersburg, MD.

Stevens, D. (2008). “Assessment and proposed approach for tie forces in framed and load-bearing wall structures.” Final Report, Prepared for Security Engineering Working Group, Protection Engineering Consultants, Dripping Springs, TX.

Thompson, S.L. (2009) “Axial, shear and moment interaction of single plate 'shear tab' connections.” Master’s Thesis, Milwaukee School of Engineering, Milwaukee, WI.

Wallaert, J.J., and Fisher, J.W. (1965). "Shear strength of high-strength bolts.” Journal of the Structural Division, ASCE, Vol. 91, ST3, 99-125.

Weigand, J.M., Meissner, J.E., Francisco, T., Berman, J.W., Fahnestock, L.A., and Liu, J. (2012).

"Overview of AISC/NSF structural integrity research and preliminary results.” Proceedings, 2012 Structures Congress, American Society of Civil Engineers, Reston, VA. 